\title{
Strong Infrared Effects in Quantum Gravity
}

\author{
N. C. Tsamis*
}

Department of Physics, University of Crete Heraklion, Crete 71409, GREECE

and

Theory Group, FO.R.T.H. Heraklion, Crete 71110, GREECE

\author{
R. P. Woodard** \\ Department of Physics, University of Florida \\ Gainesville, FL 32611, UNITED STATES
}

ABSTRACT: We explore "quantum cosmological gravity," or quantum general relativity with a nonzero cosmological constant. It is explained why and how QCG can be used reliably in the far infrared, despite the absence of renormalizability. We show that loop corrections to positive $\Lambda$ QCG mediate powerful infrared effects for two reasons: first, the theory allows massless gravitons to self-interact via a coupling of dimension three: second, the inflationary redshift of the classical background progressively increases the population of soft gravitons. One consequence is that QCG must eventually dominate the physics of inflation with respect to any phenomenologically confirmed theory, no matter how much stronger the nongravitational couplings may seem. Another consequence is that the graviton's on-shell self-energy is negative and infrared divergent at one loop, thereby inducing a negative infrared divergence in the two-loop vacuum energy. We analyze these effects in the context of an initial patch of one Hubble volume which begins inflation at finite times in one of the homogeneous and isotropic Fock states of free QCG. Up to some tedious but probably manageable tensor algebra we show that quantum infrared effects exert an ever increasing drag on the background's expansion for as long as perturbation theory remains valid. A rough estimate of the relaxation time is easily consistent with enough inflation to solve the smoothness problem. 

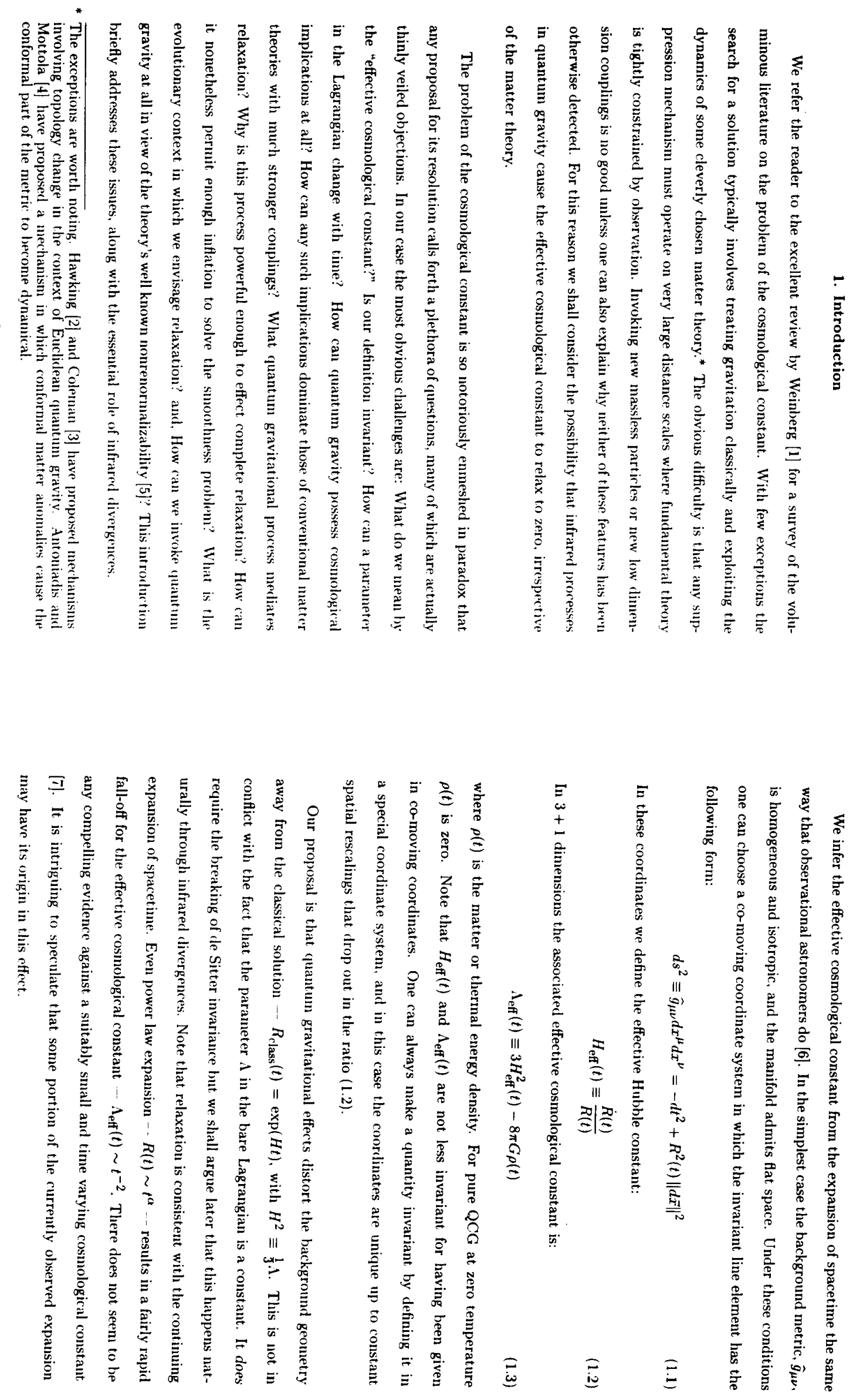

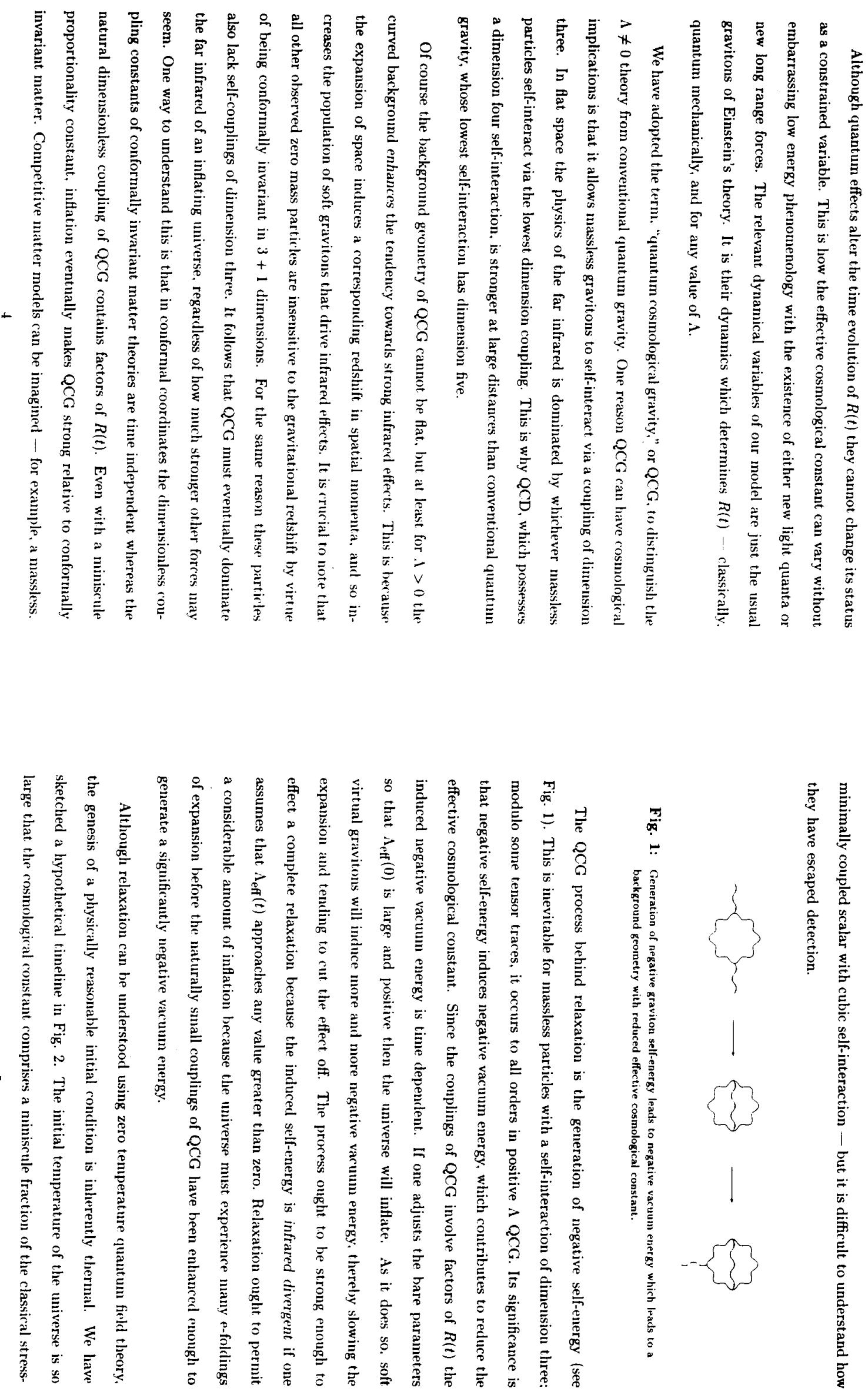


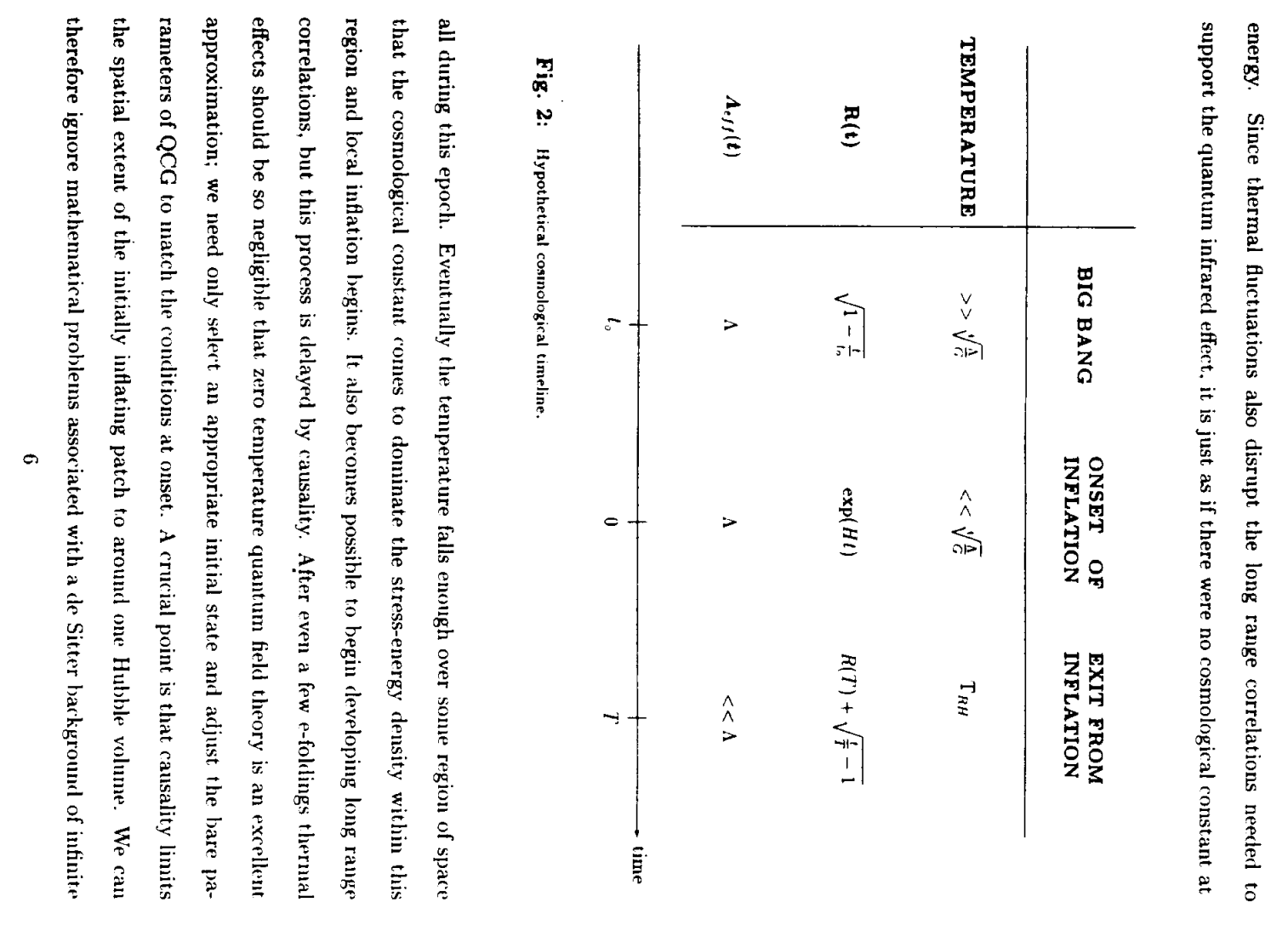

年) 

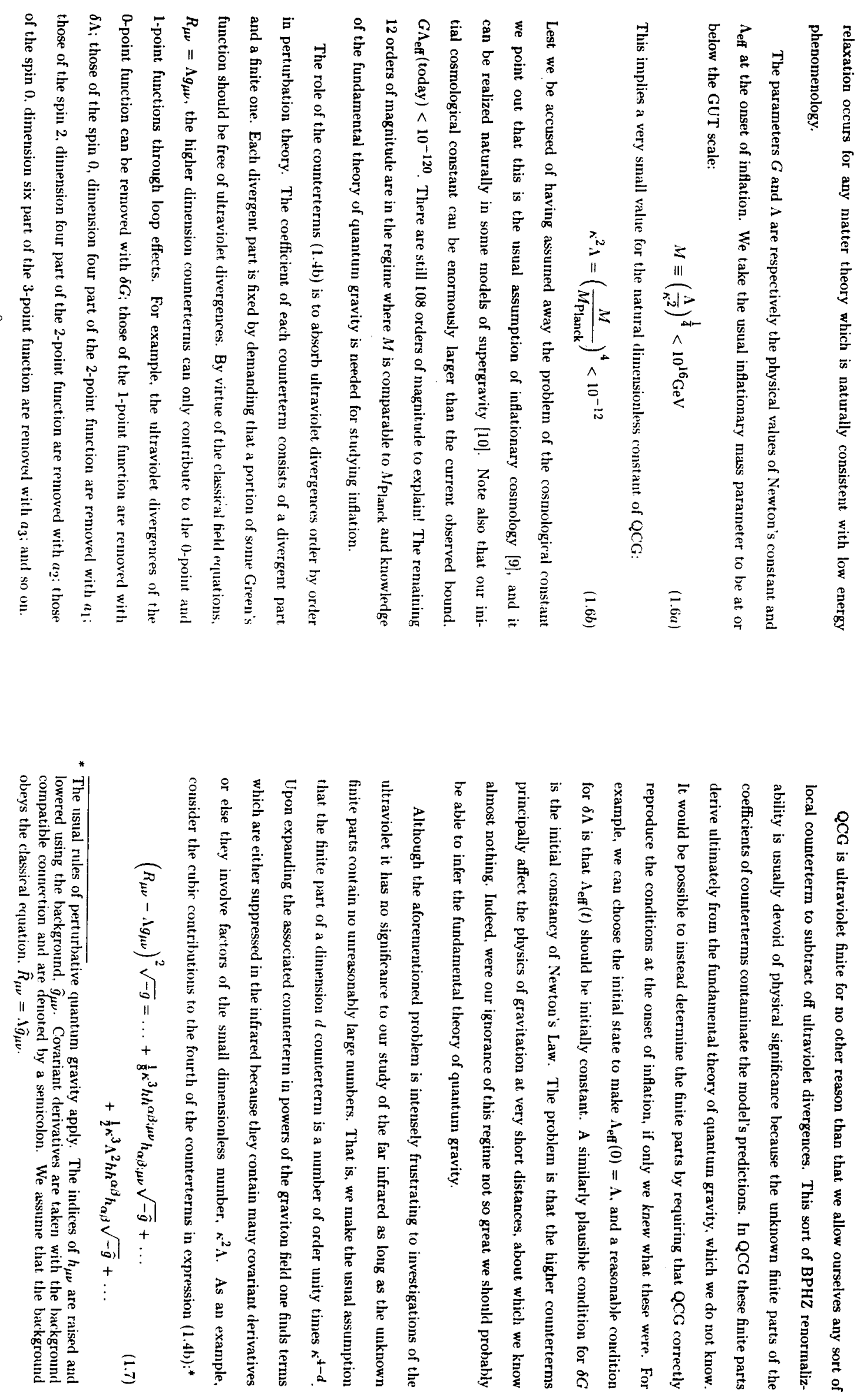

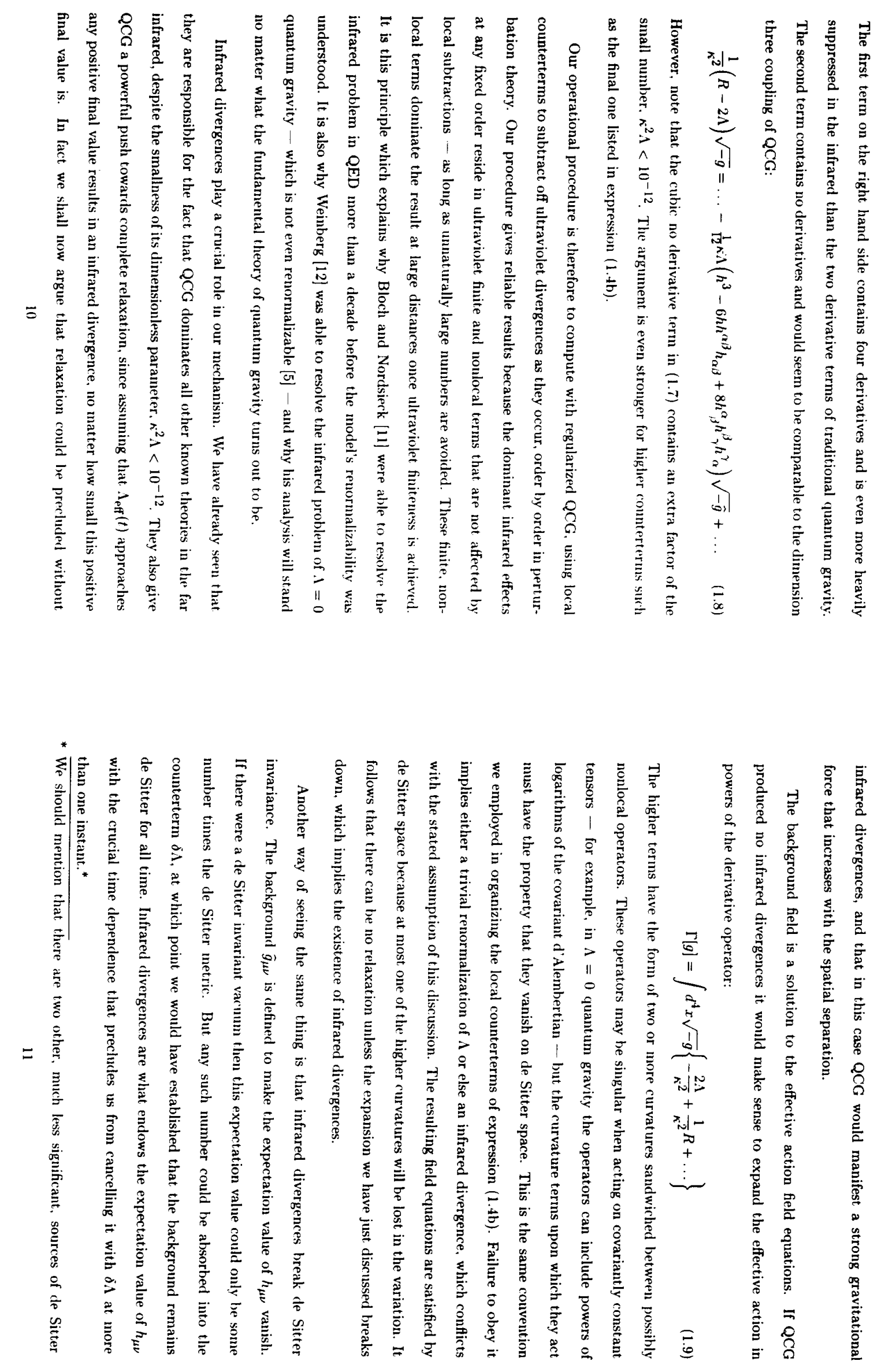
(l)

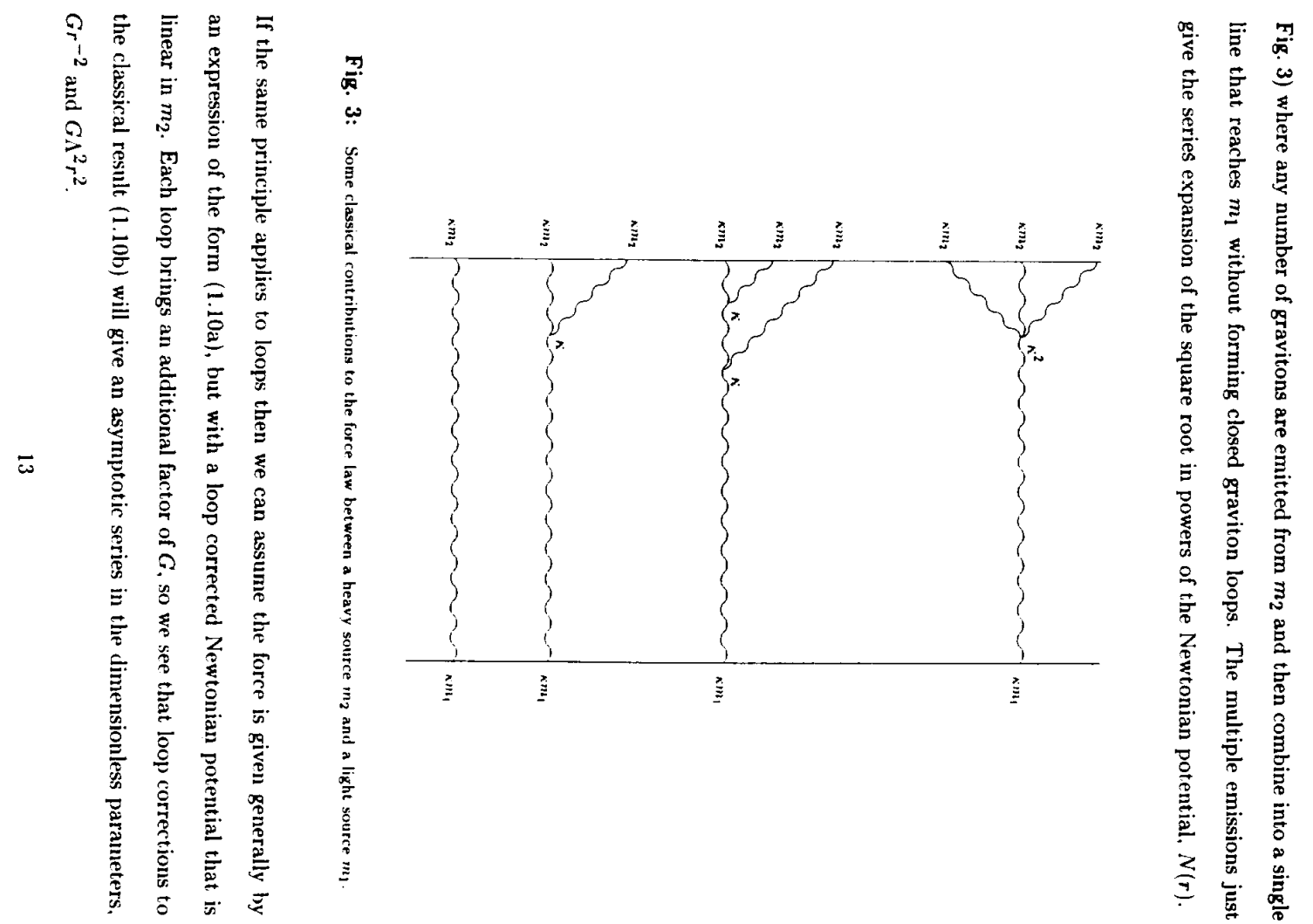



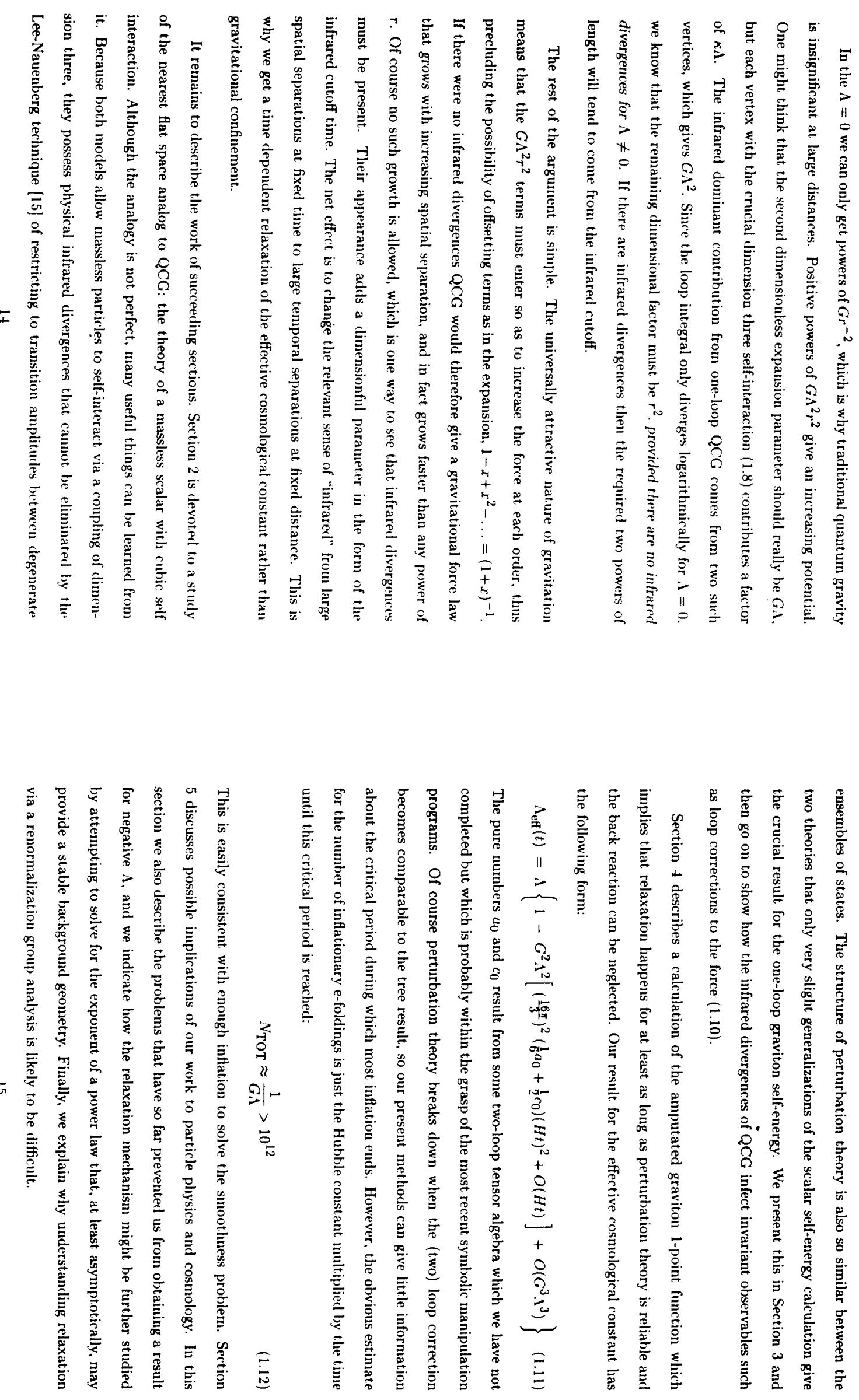


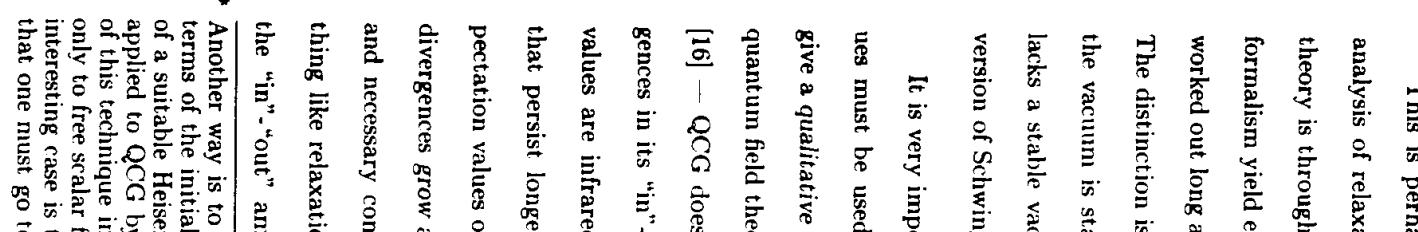

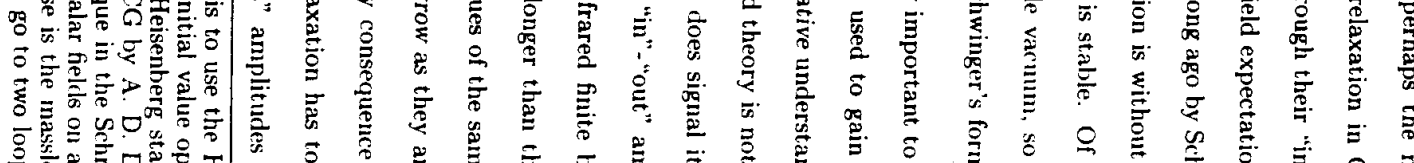
Mm mul| Whent

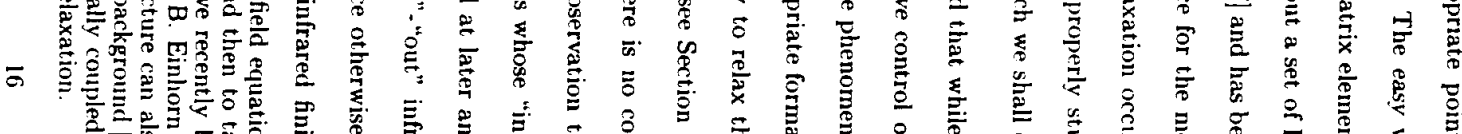
IE men |m|l|

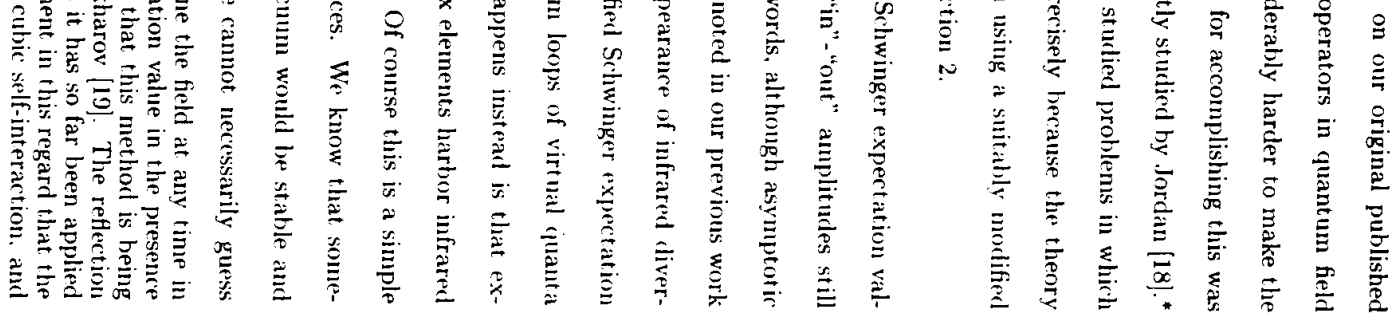

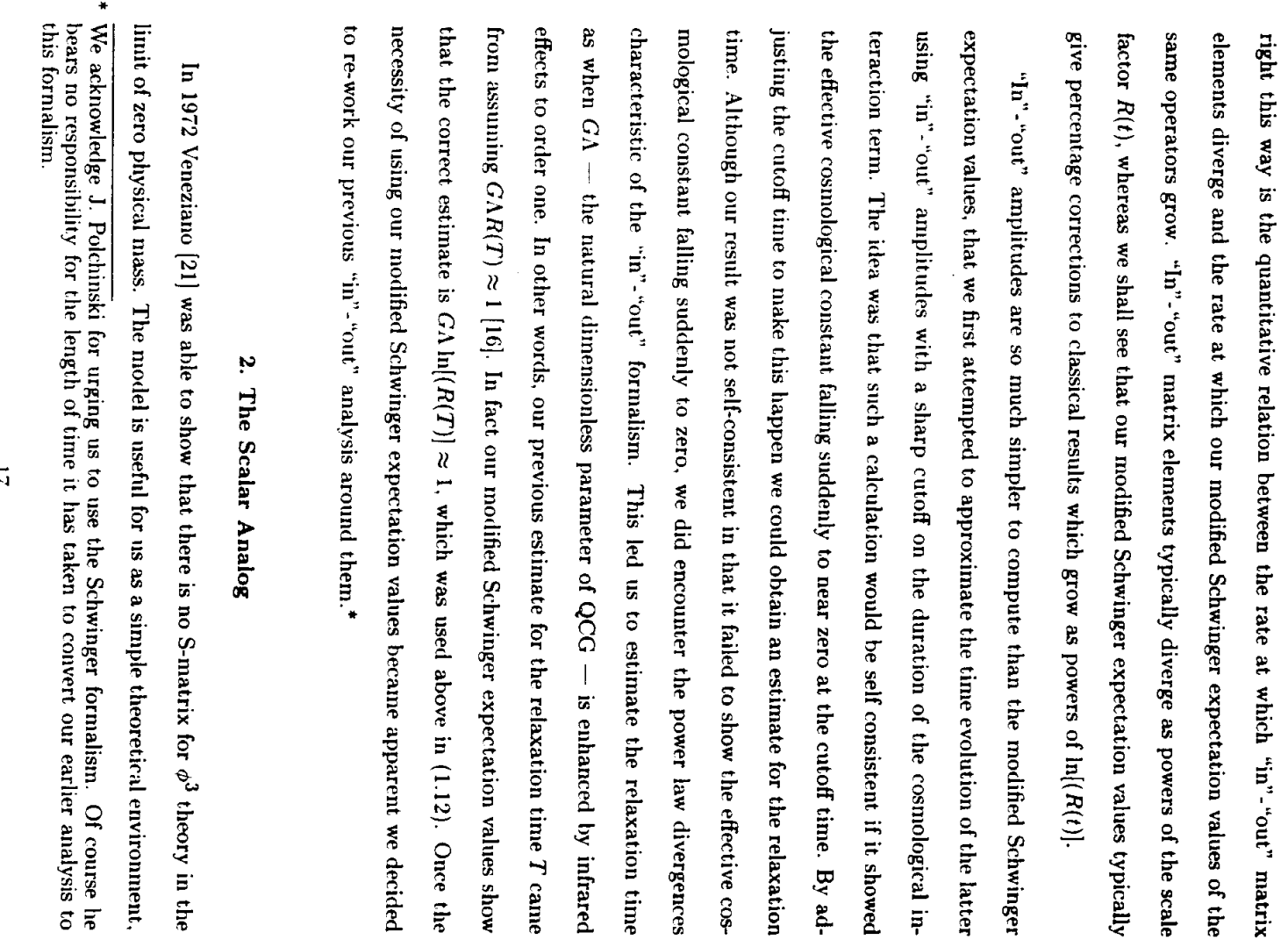




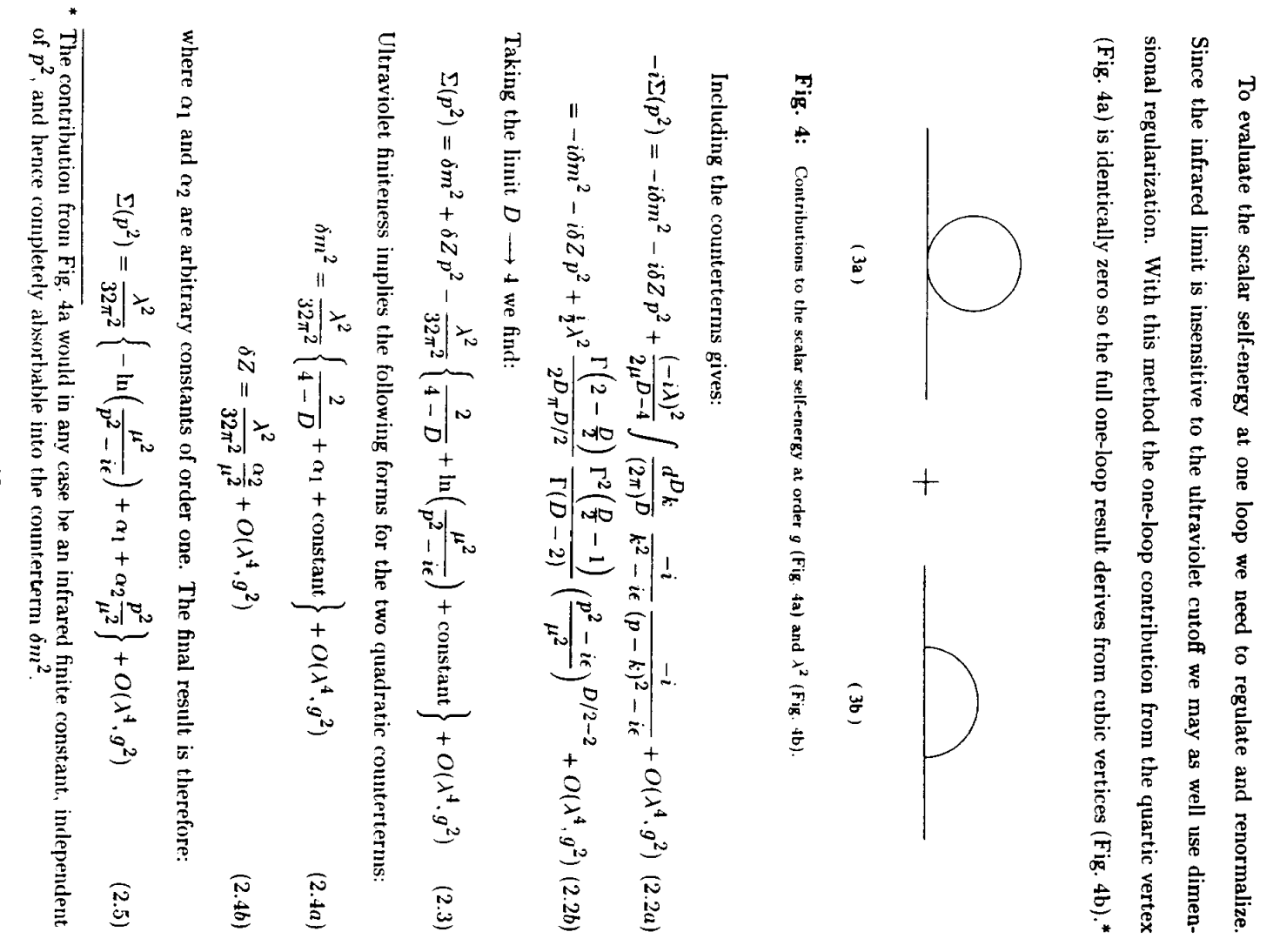



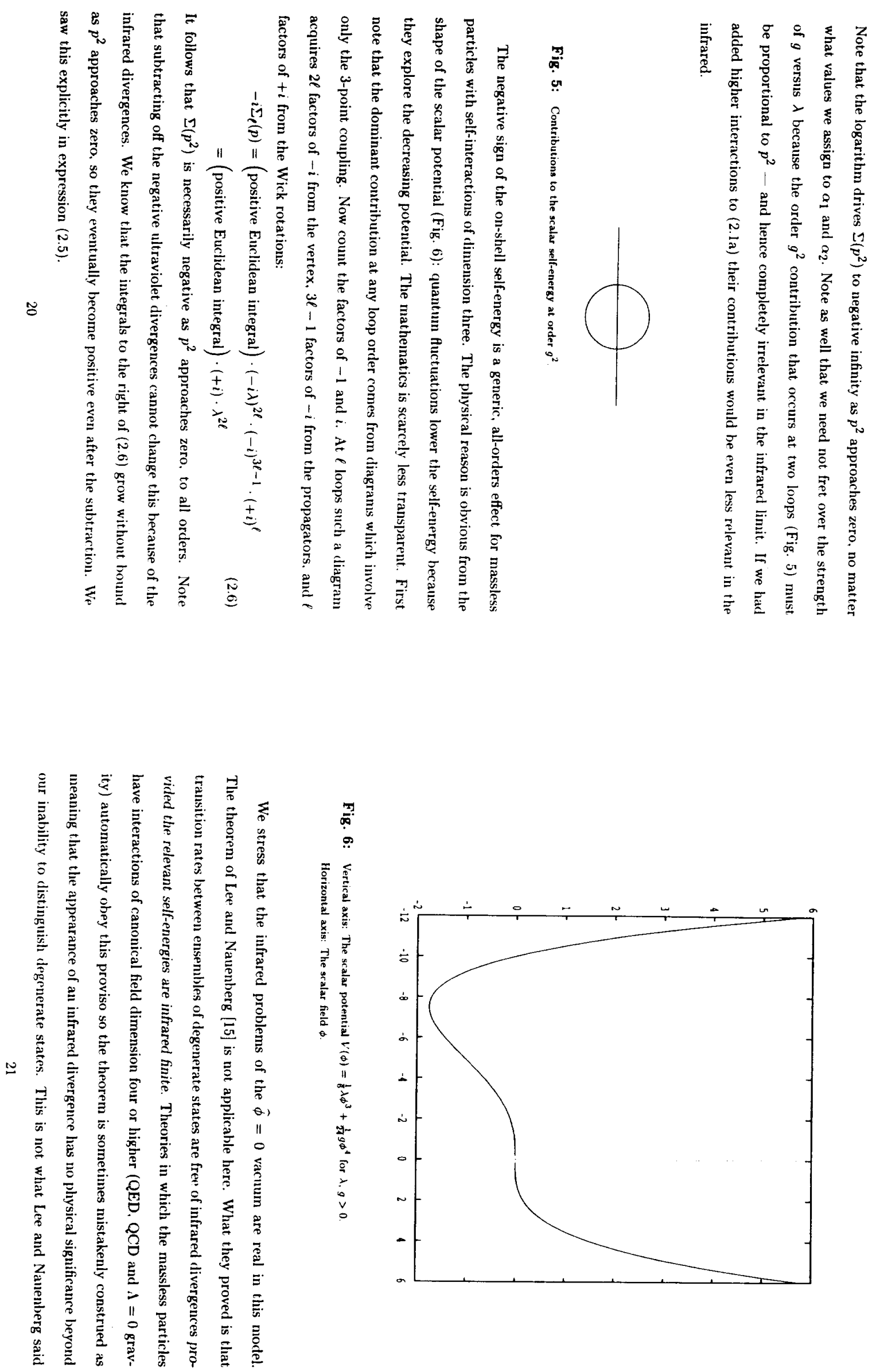

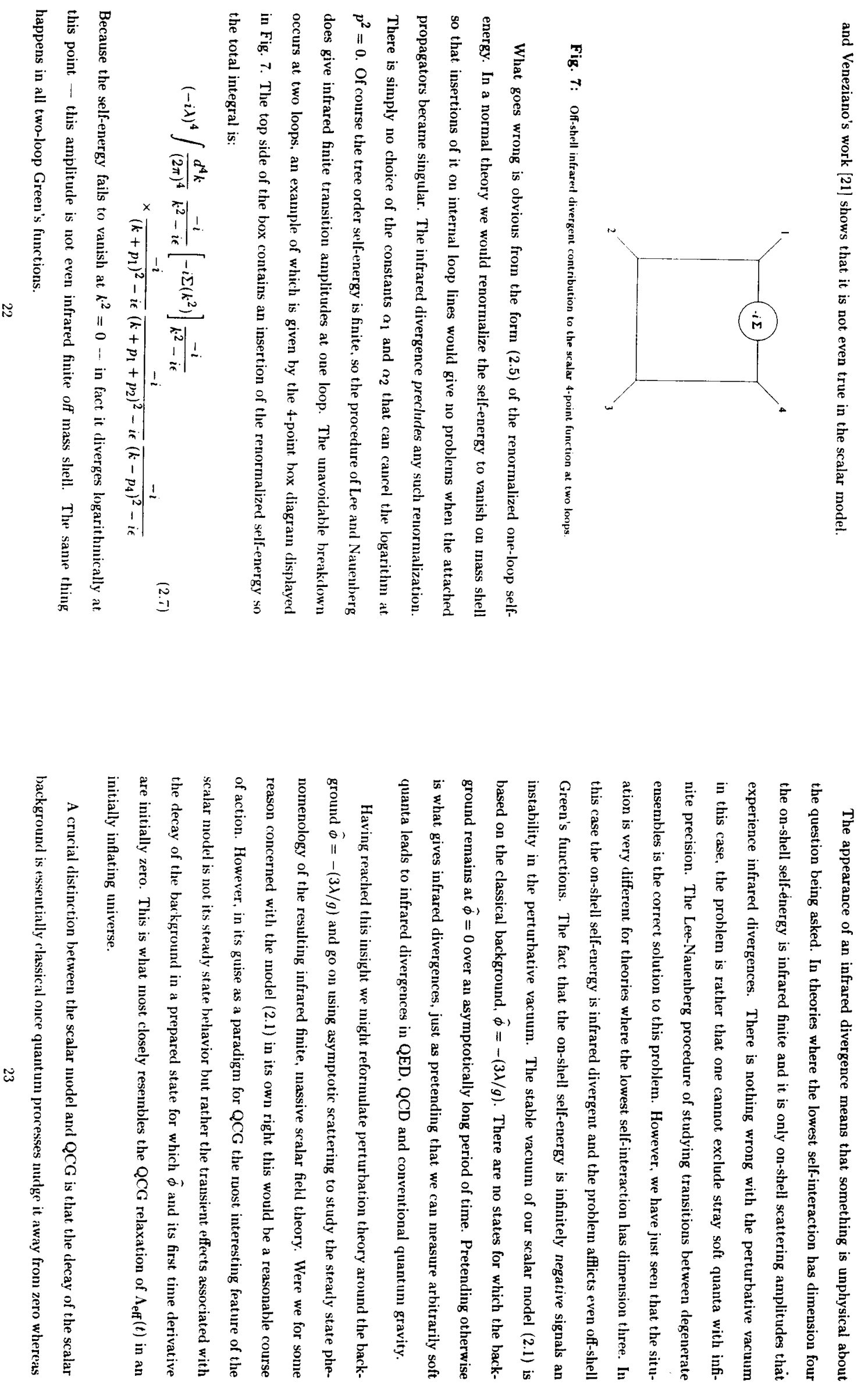

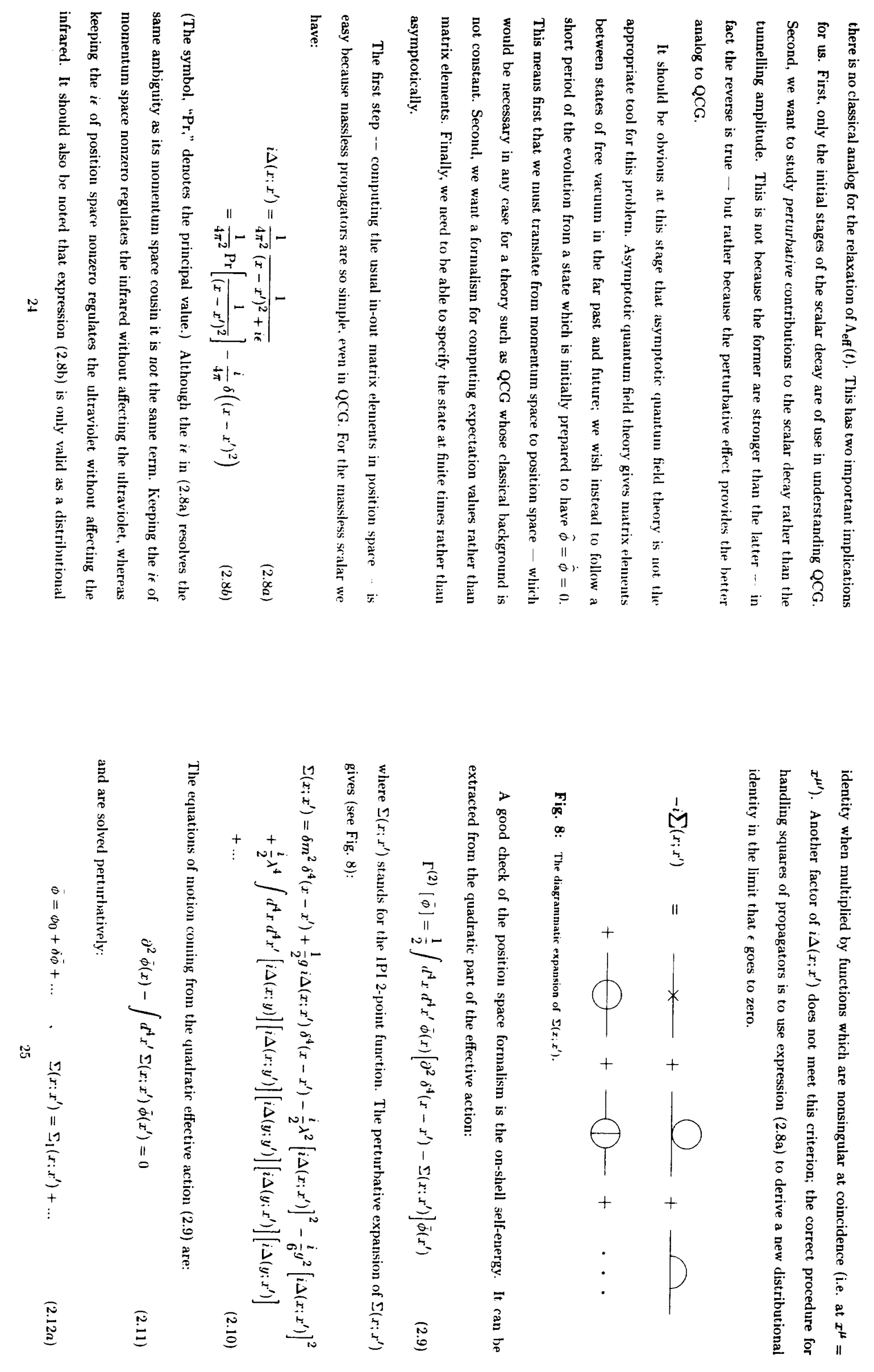


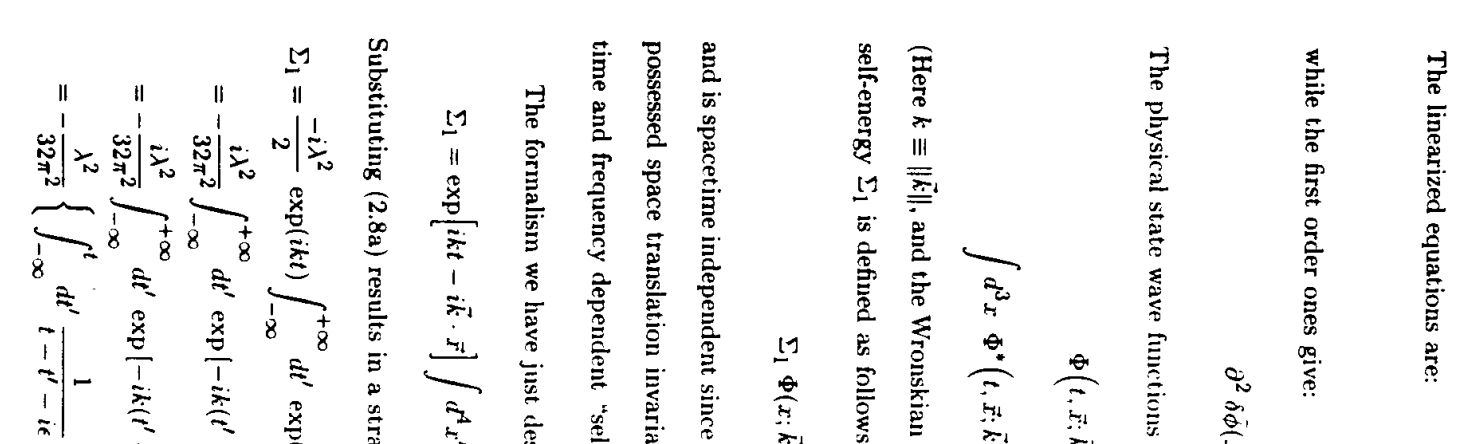
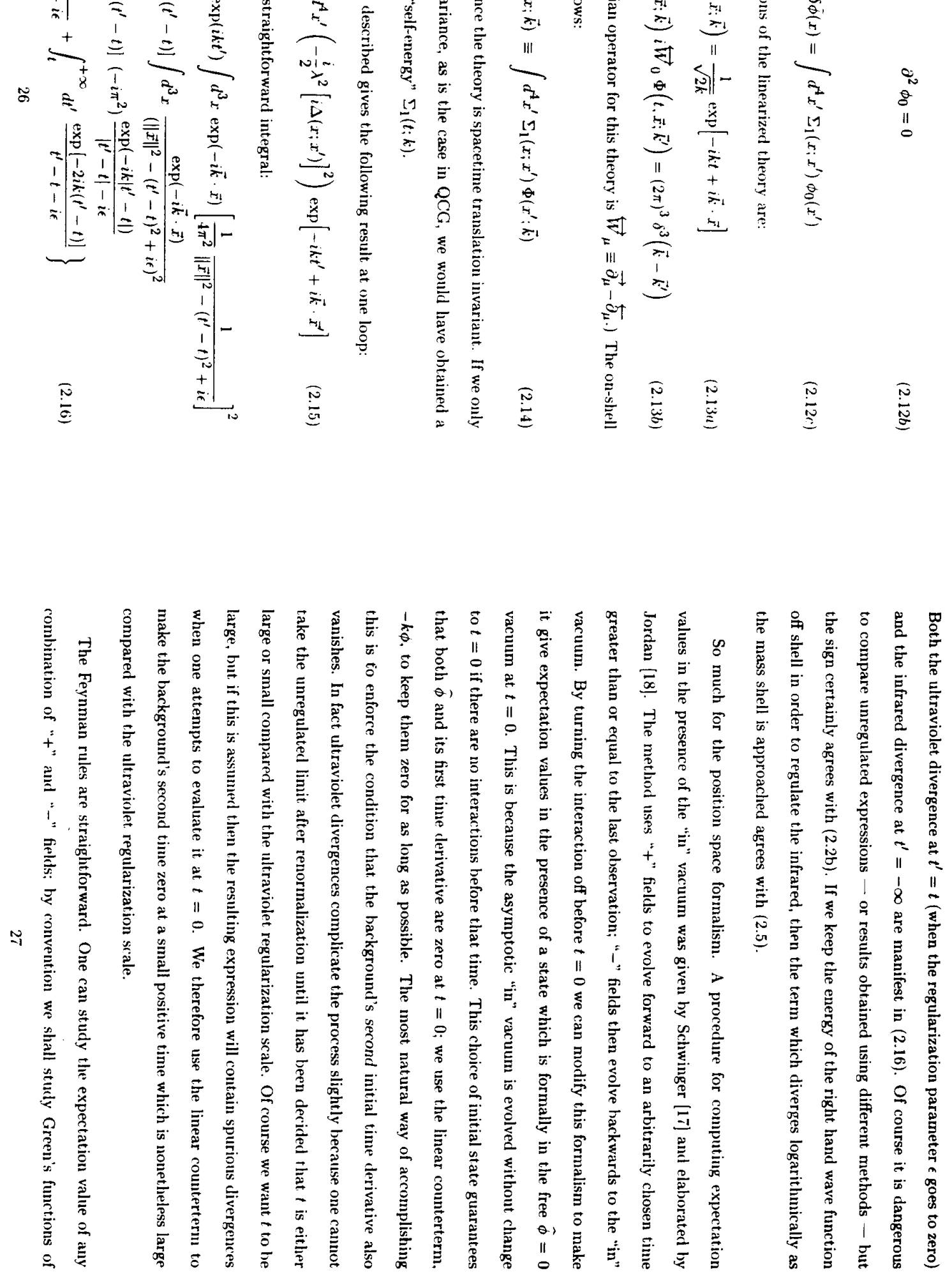

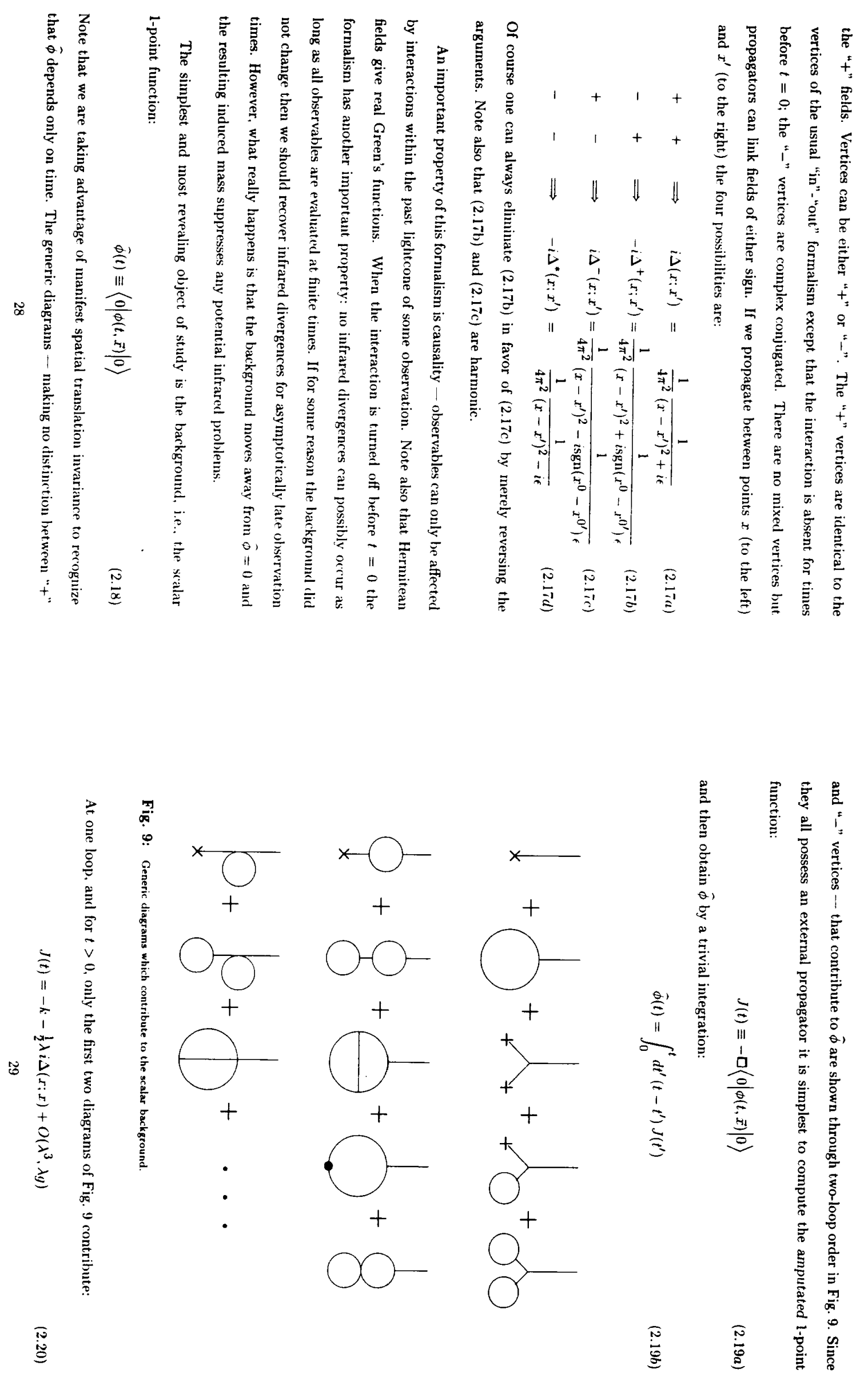

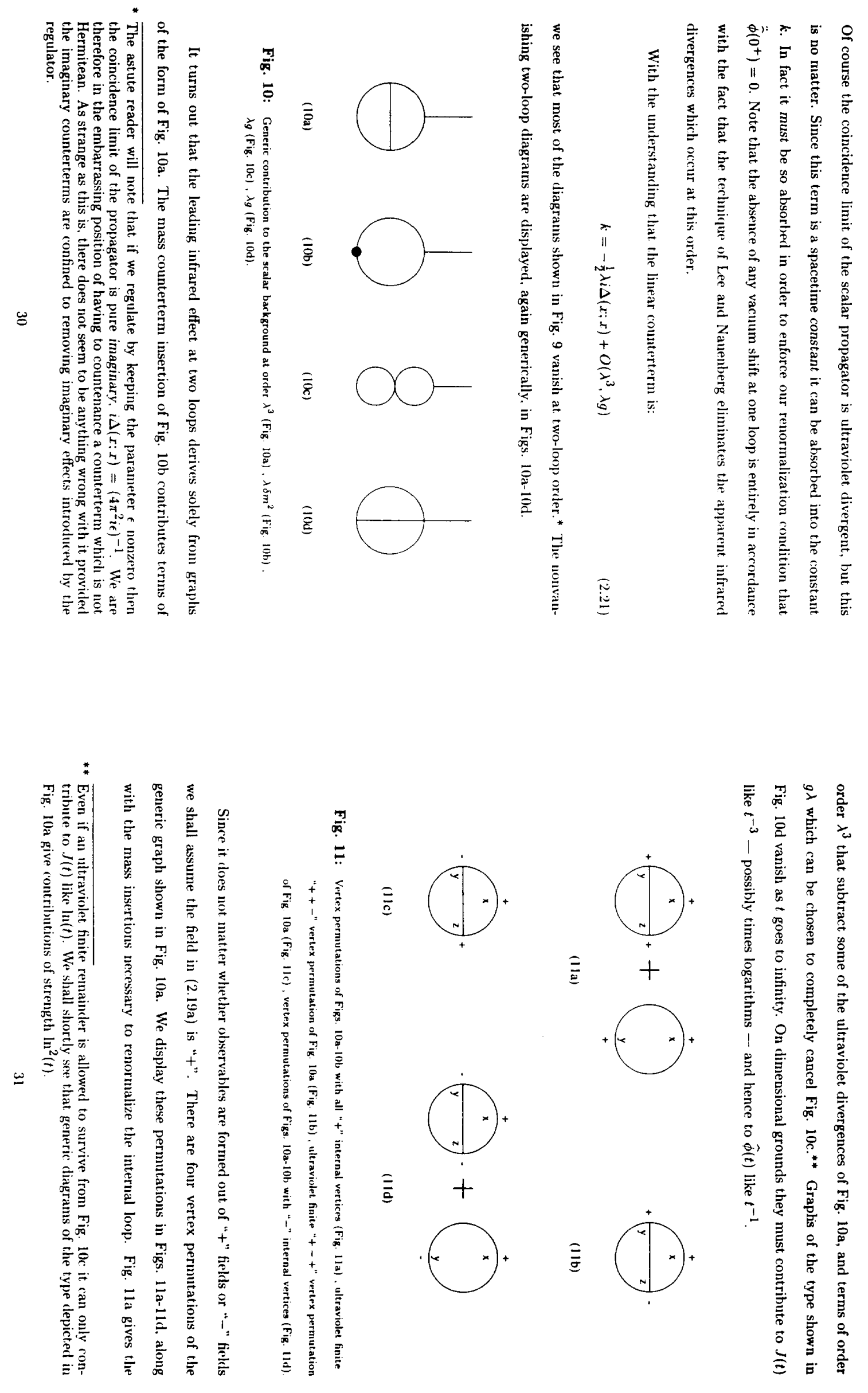

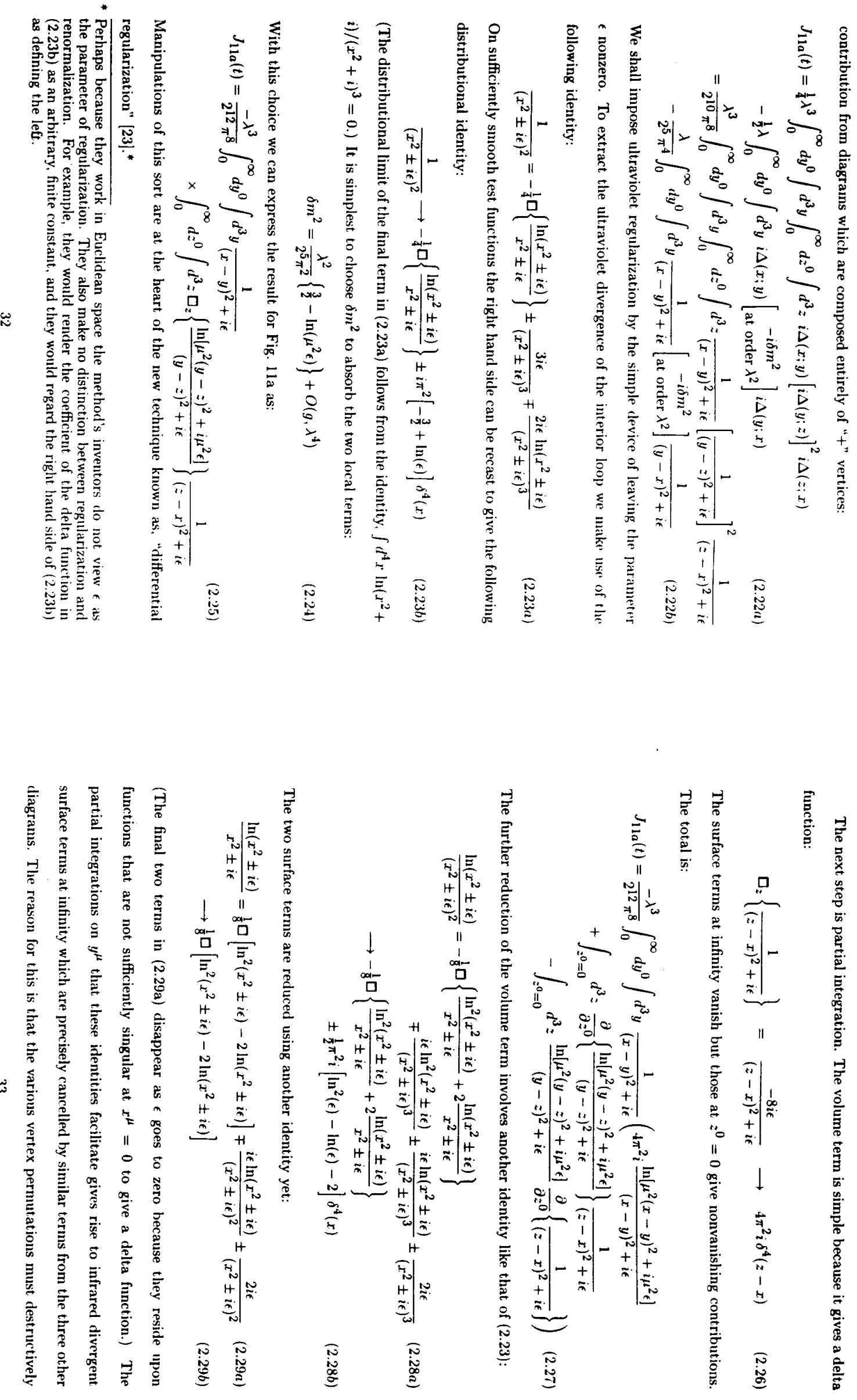

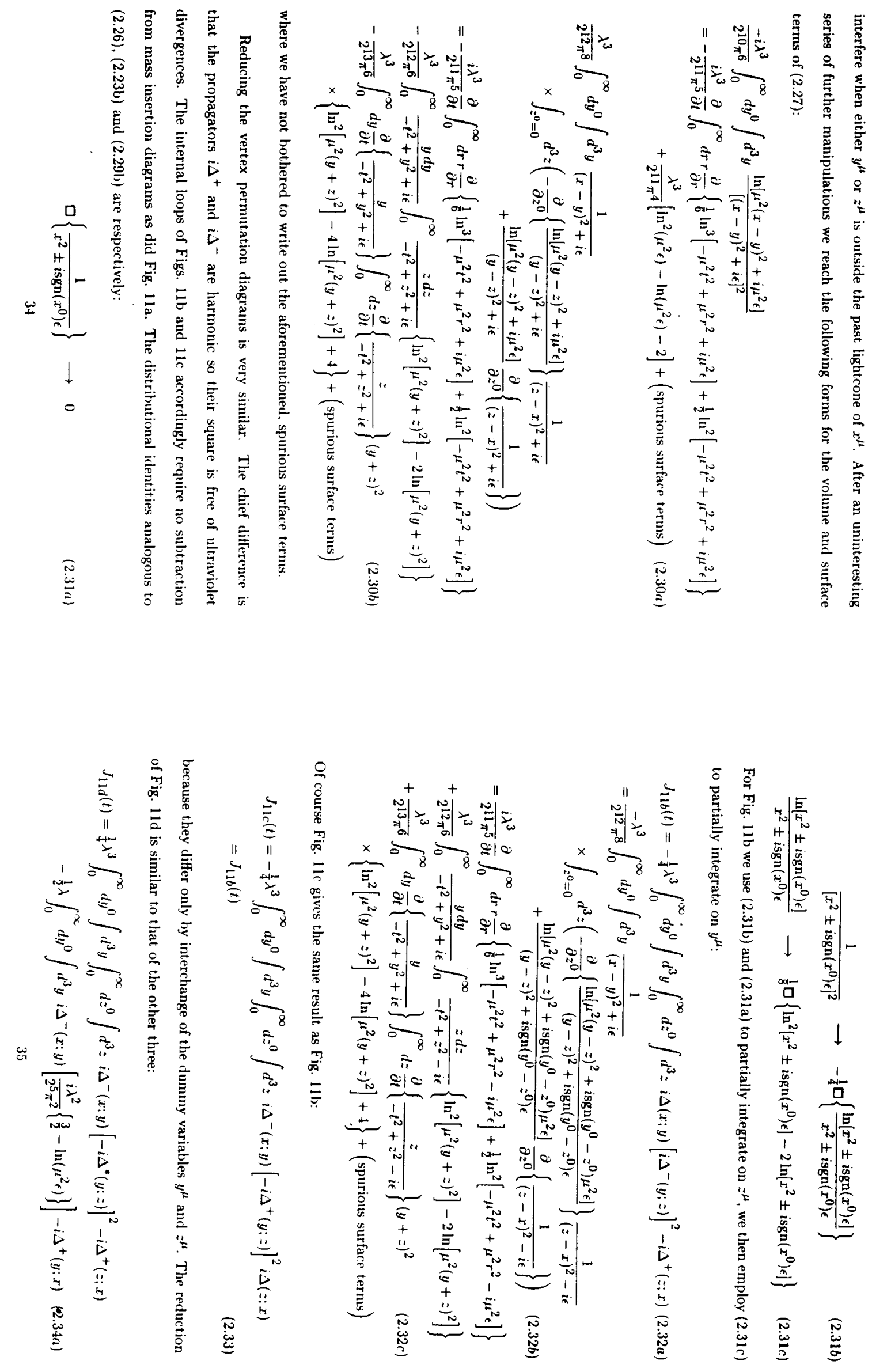

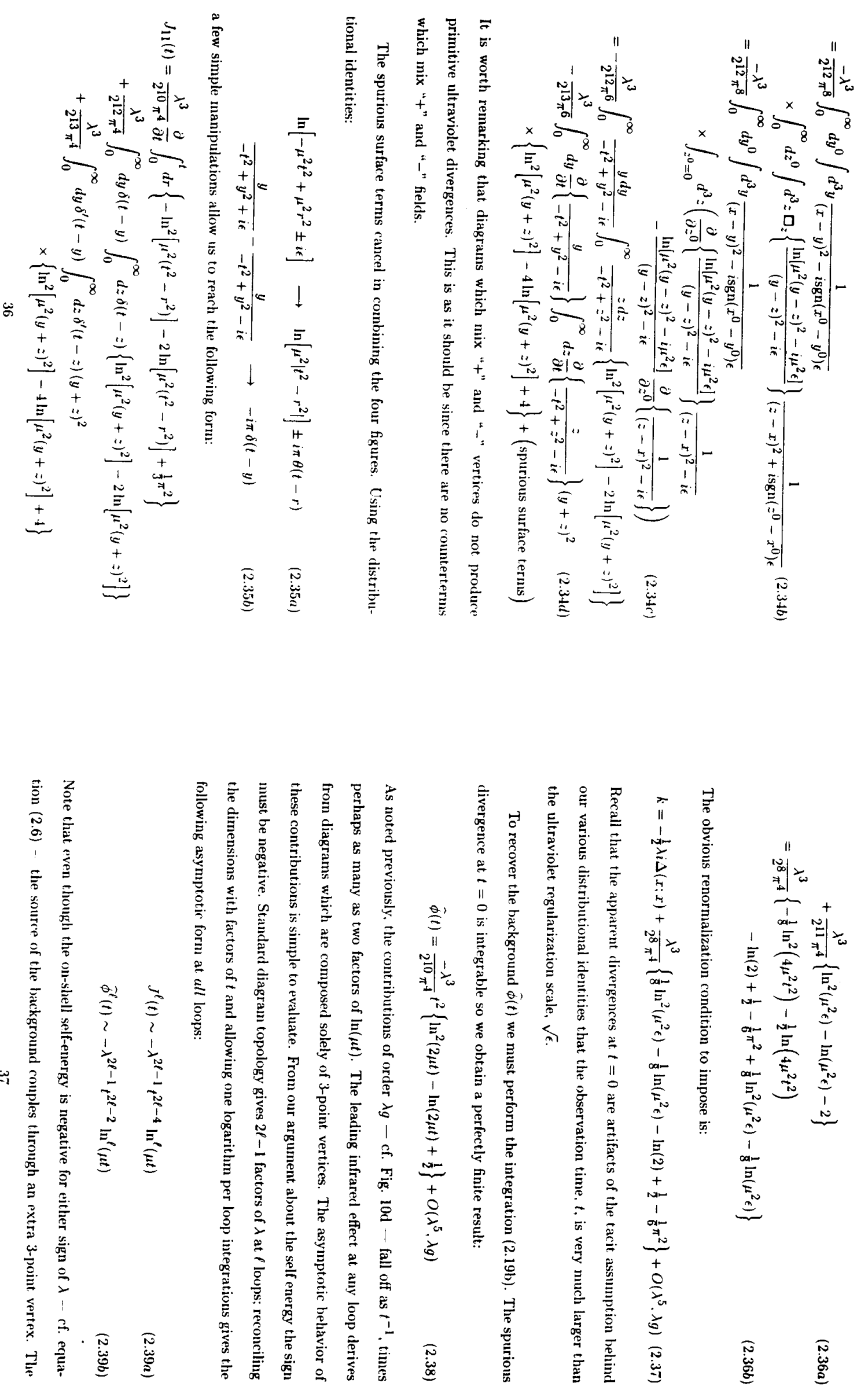

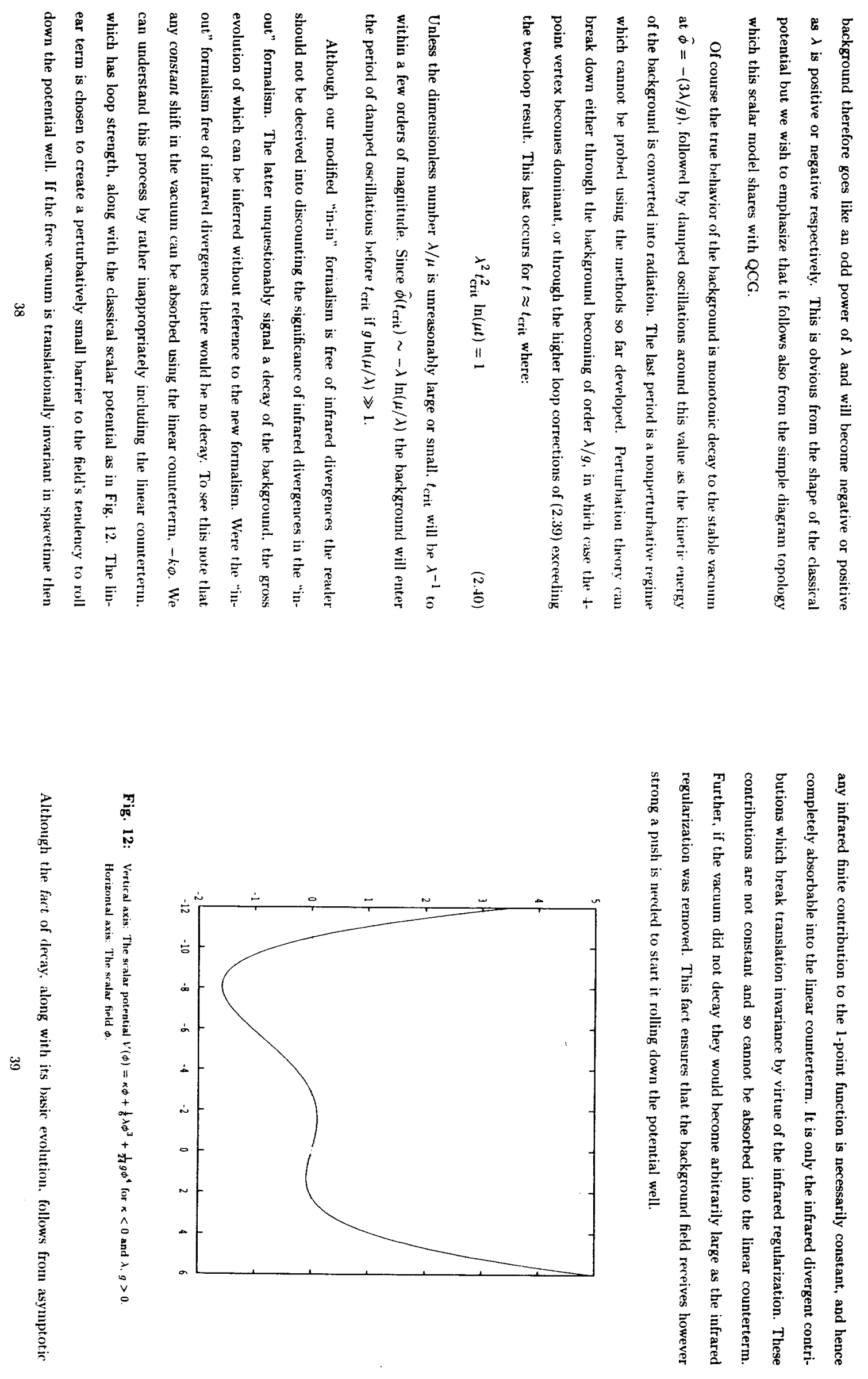

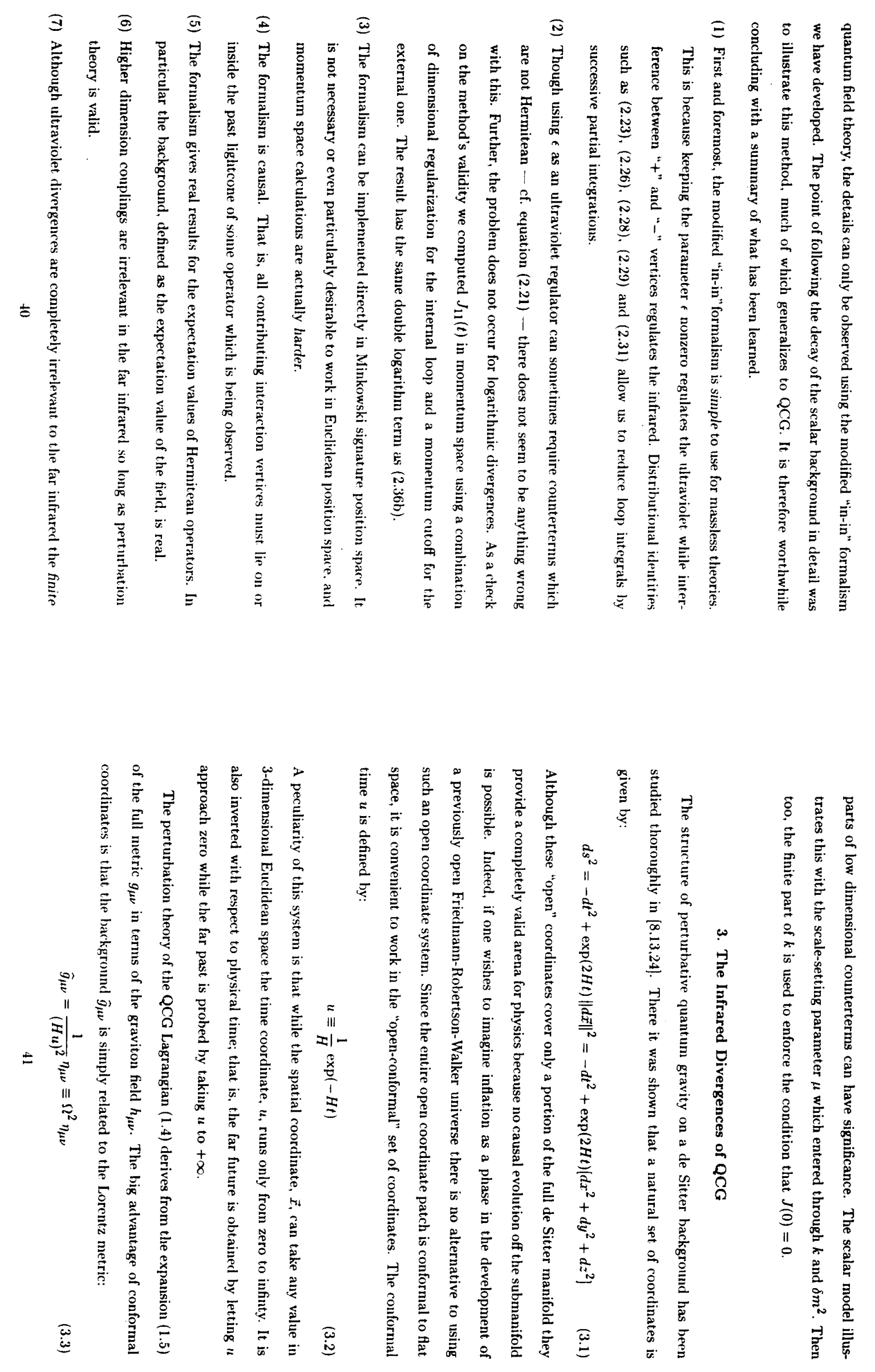

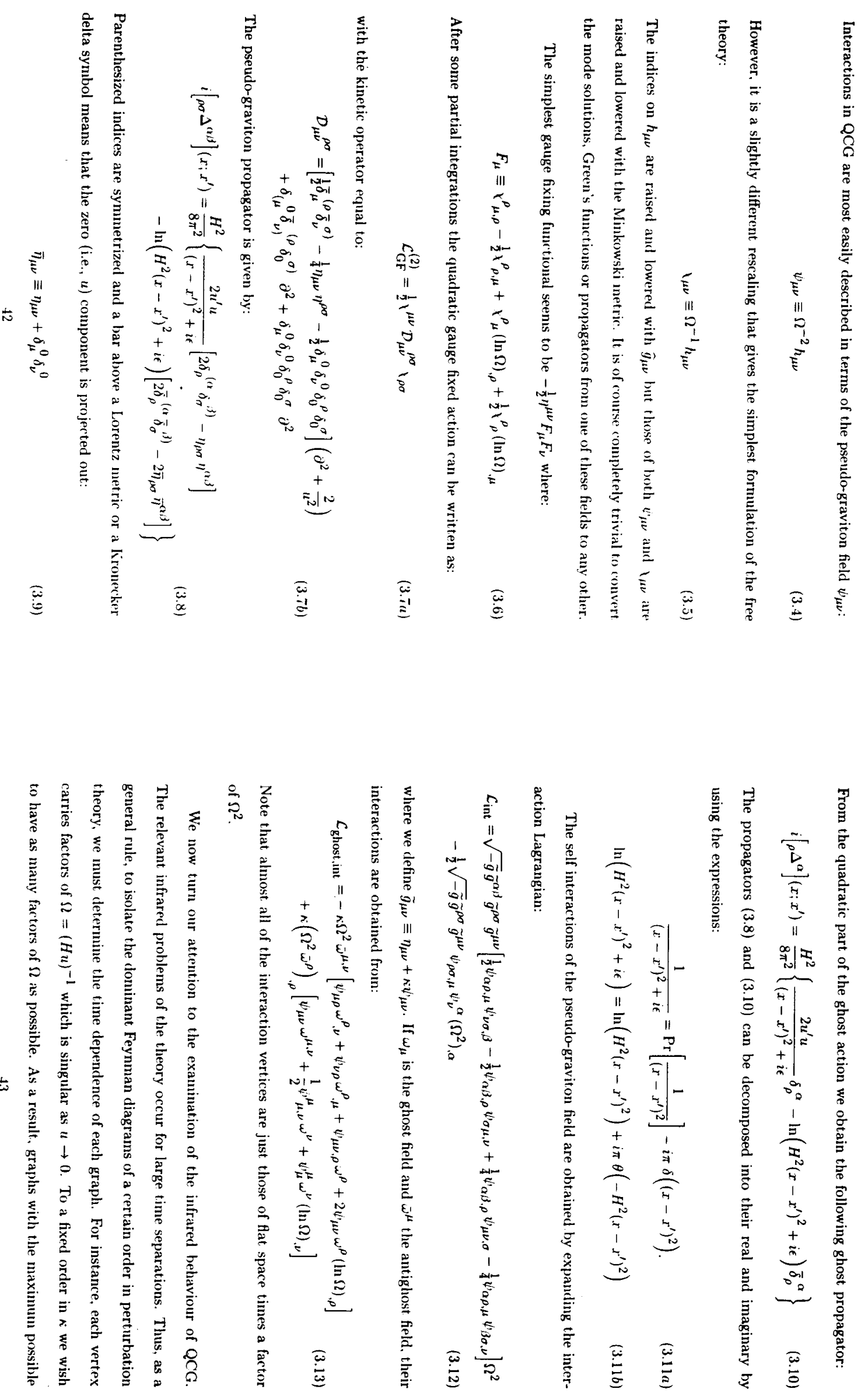


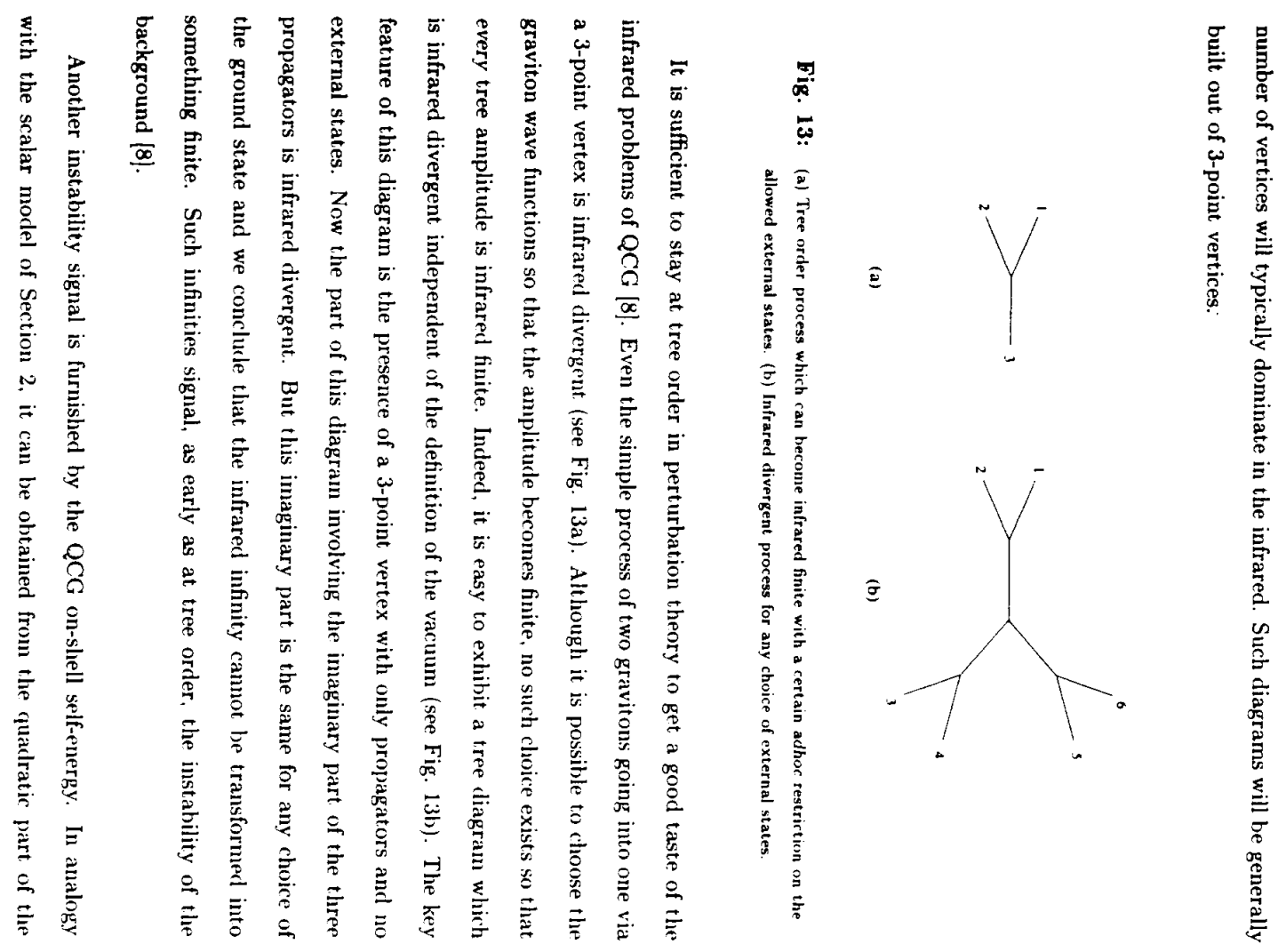

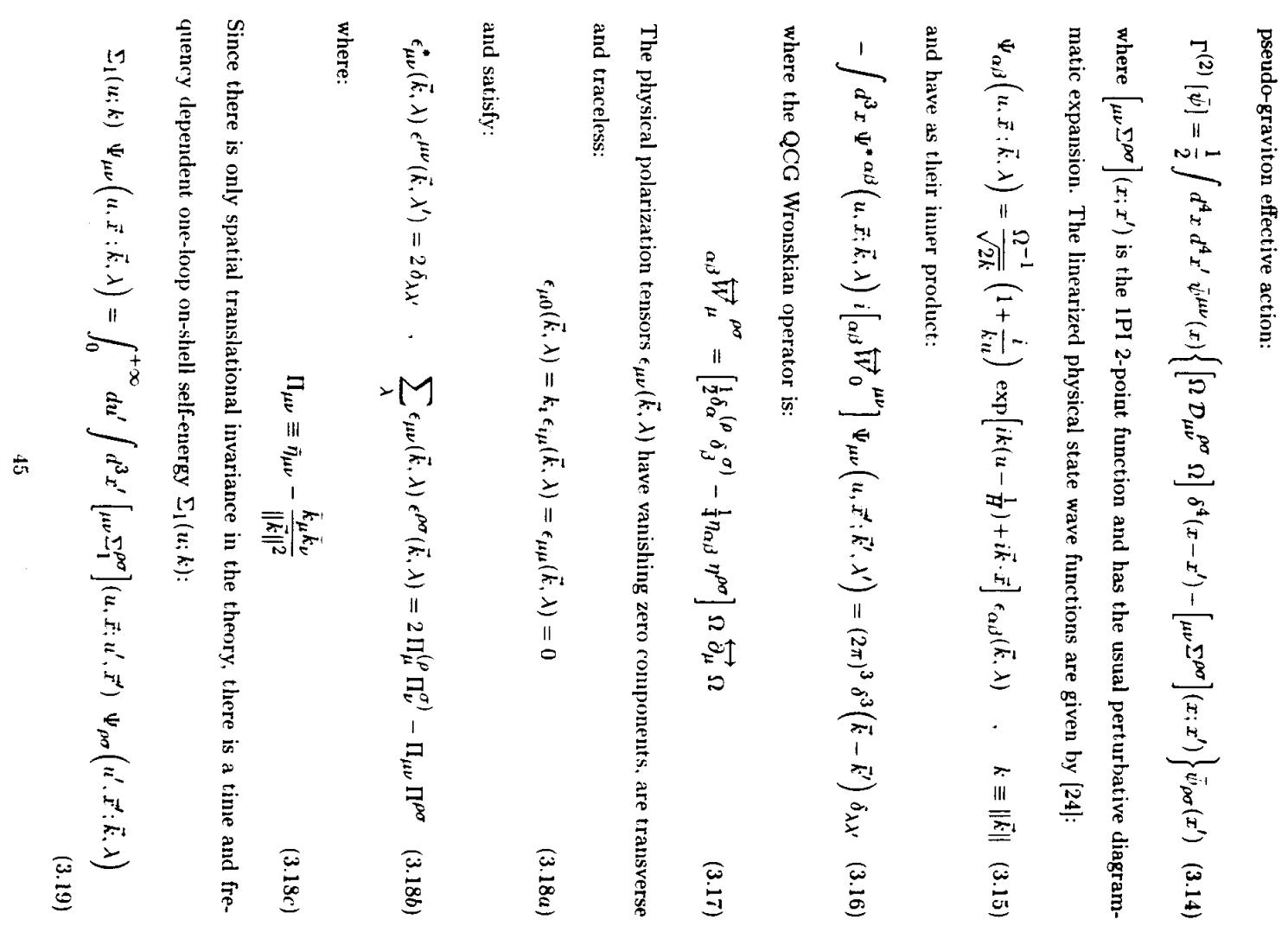



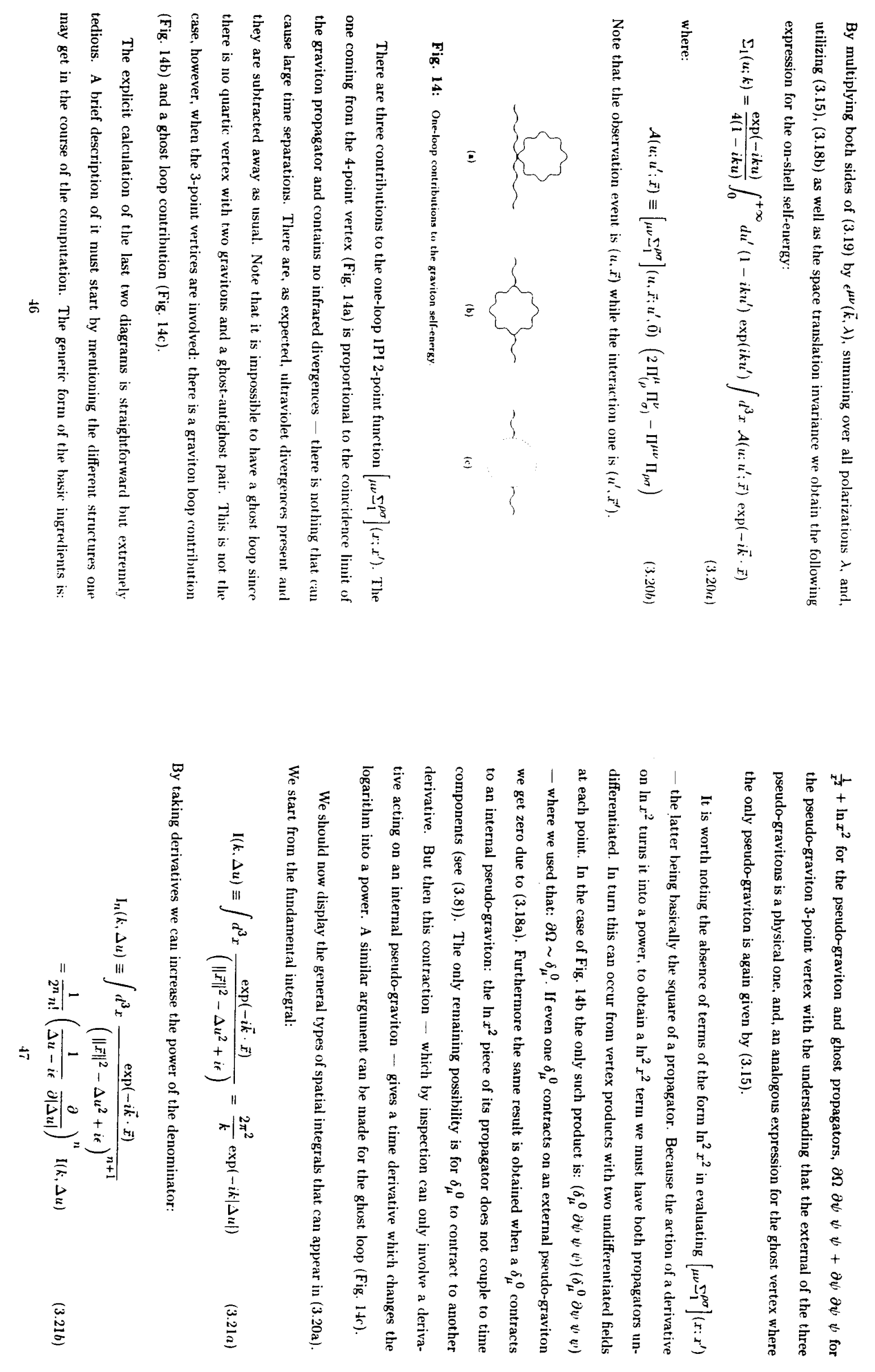

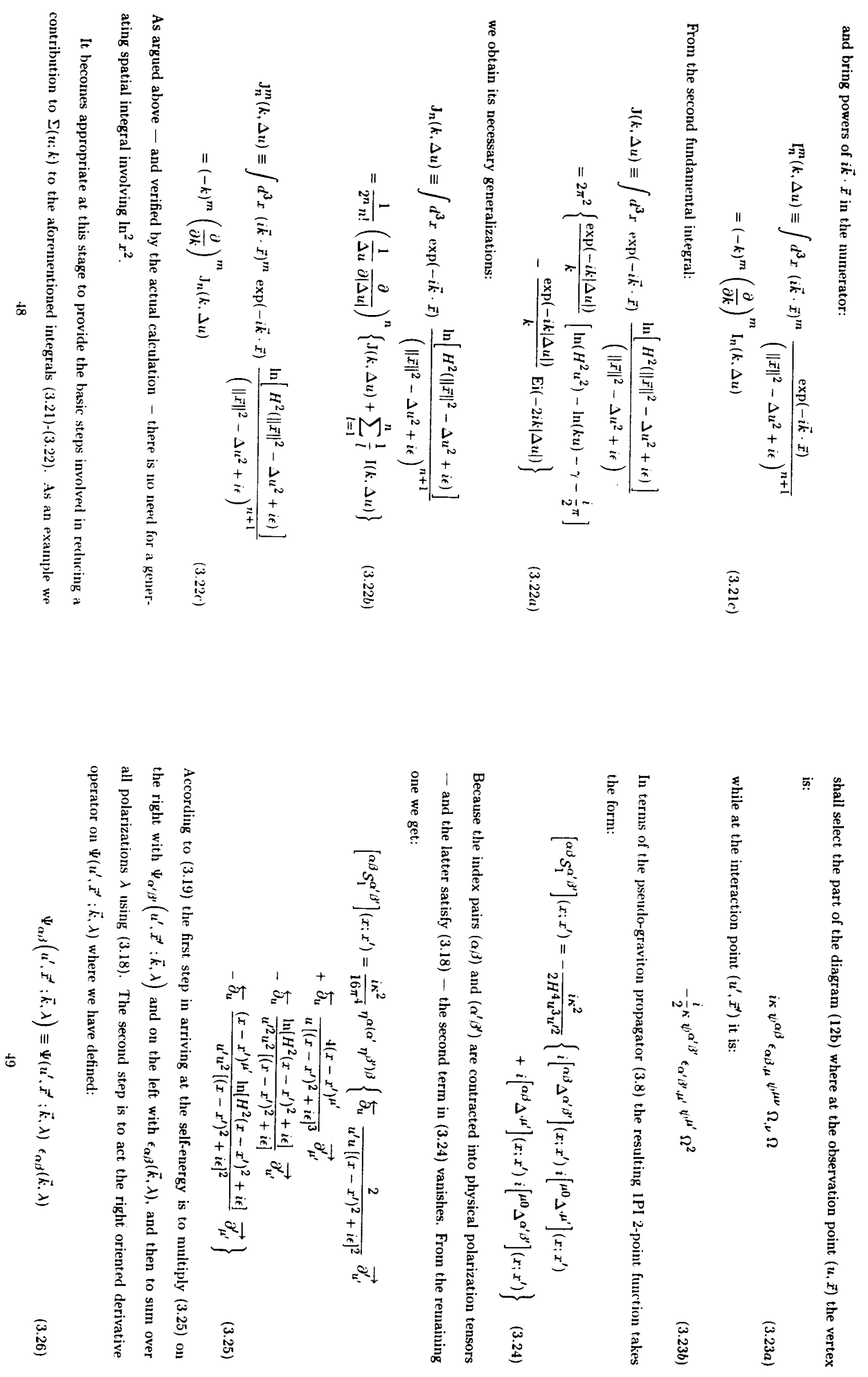

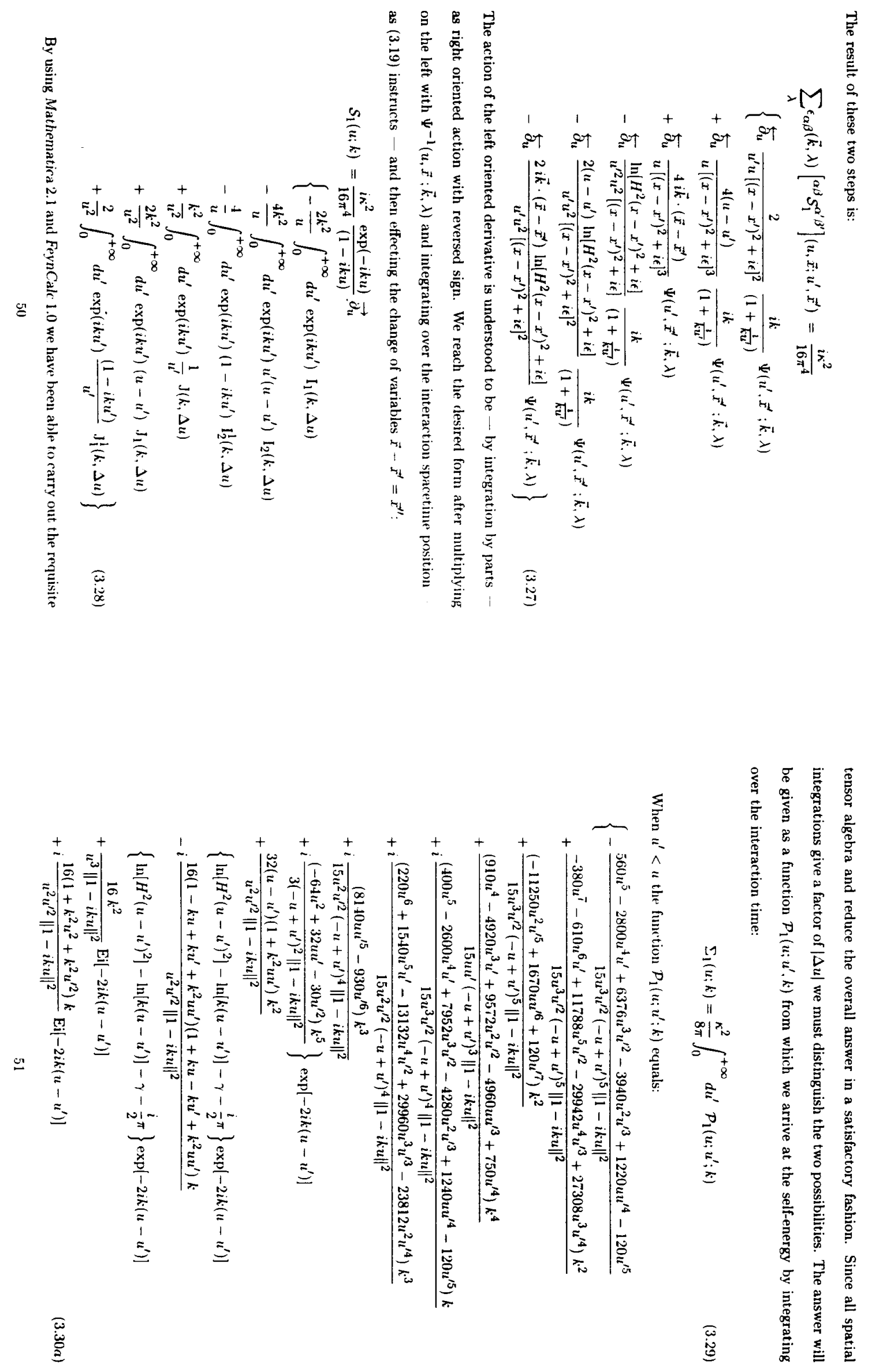


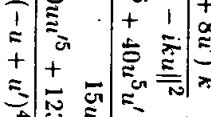

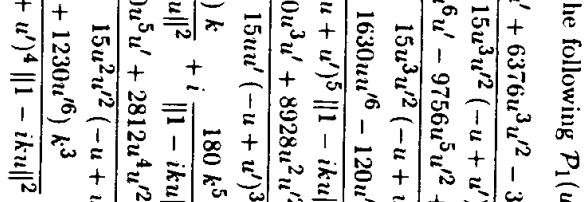

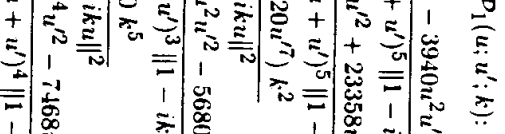

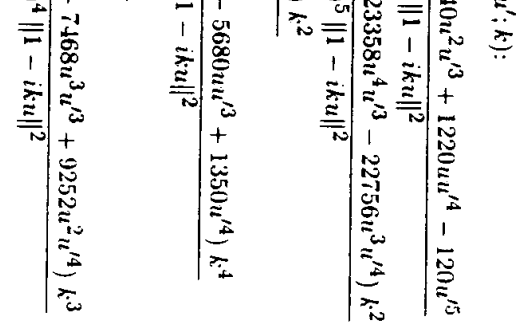

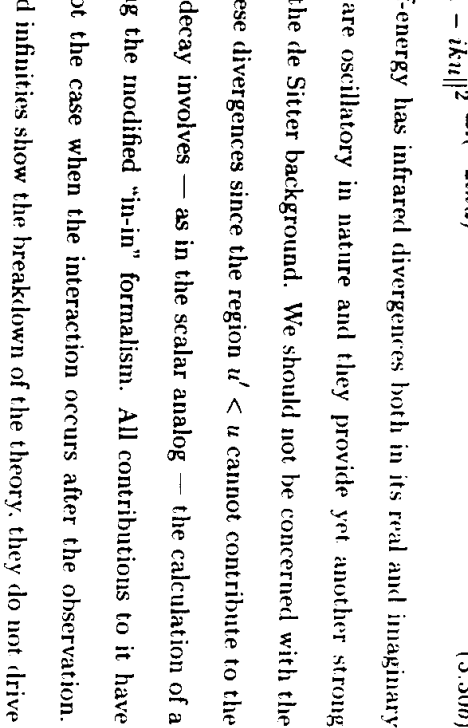

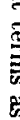
$\frac{2}{8}$

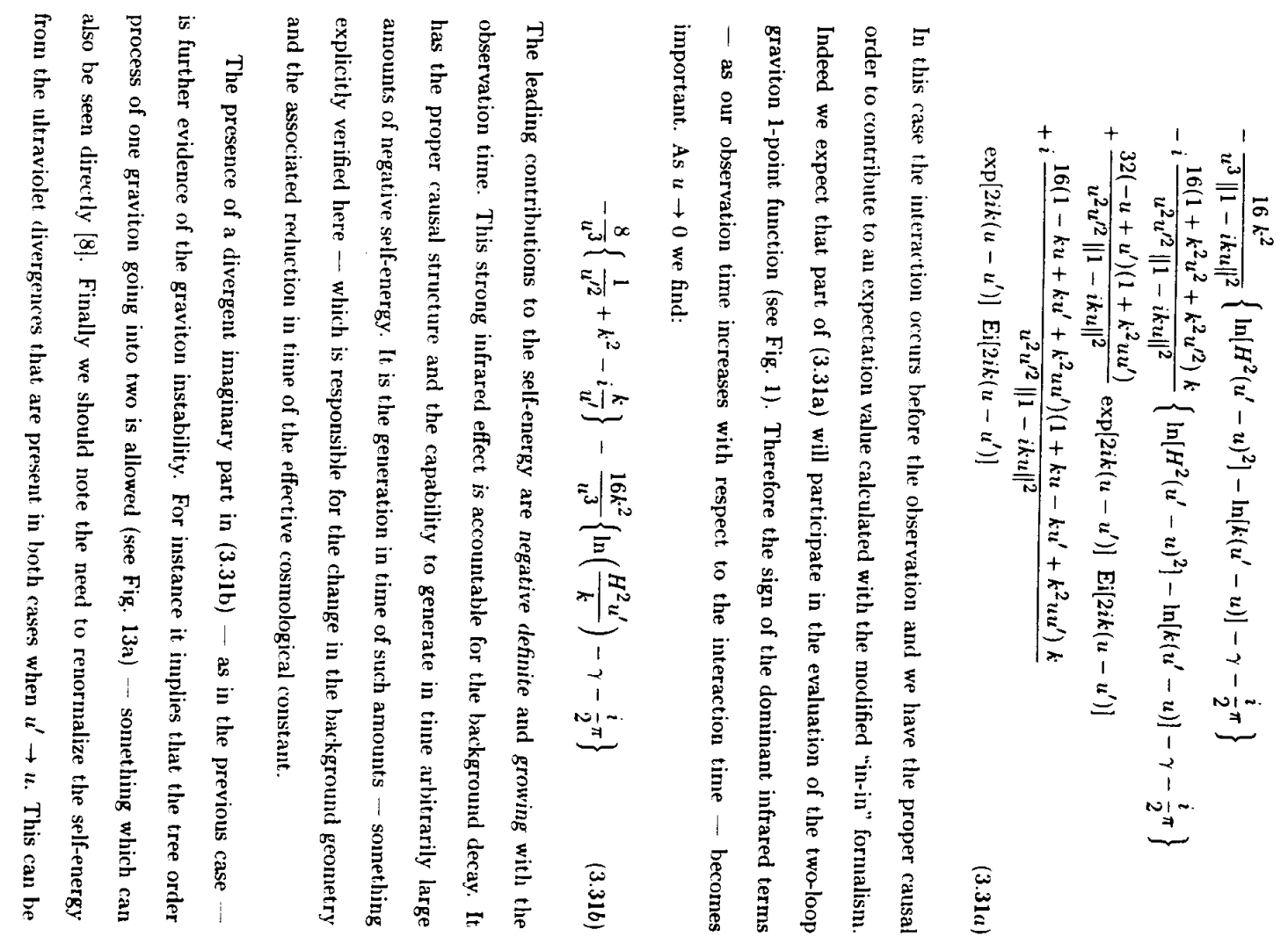




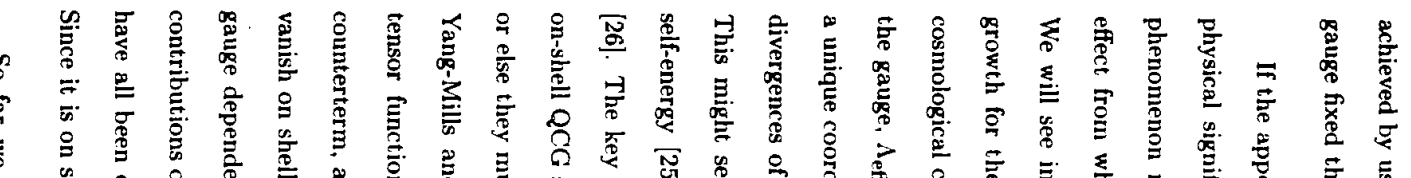

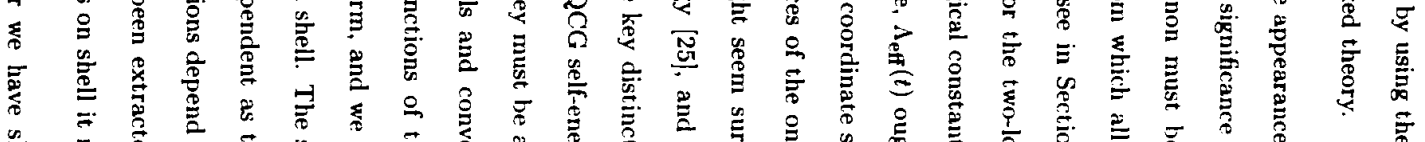

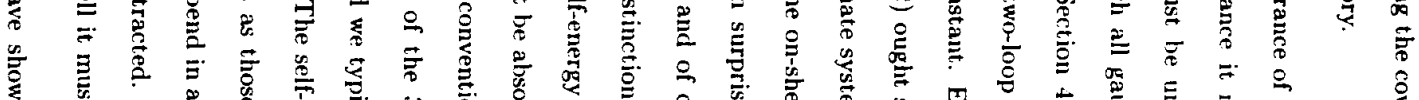

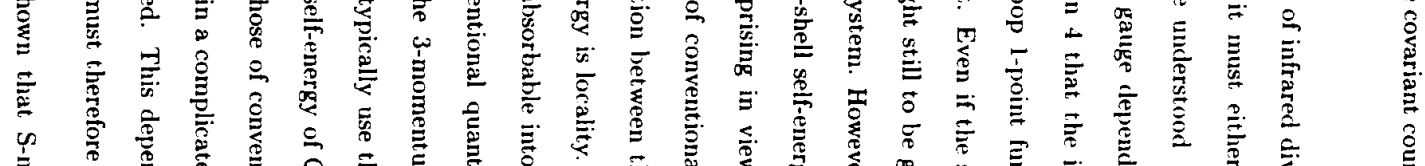

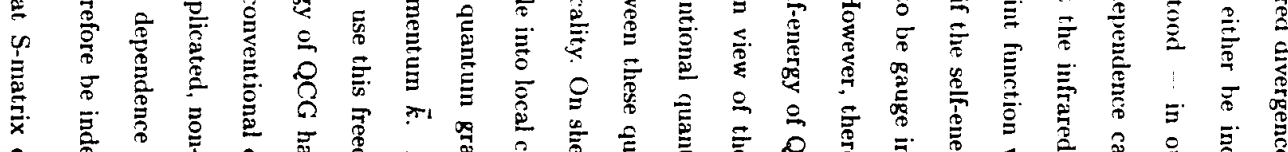

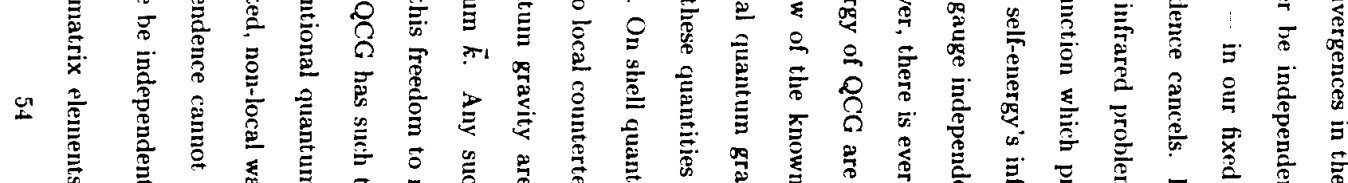

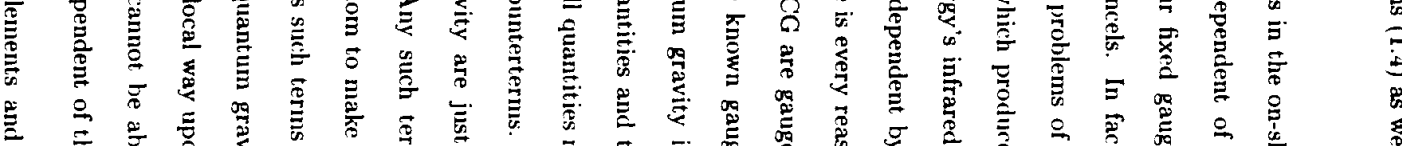

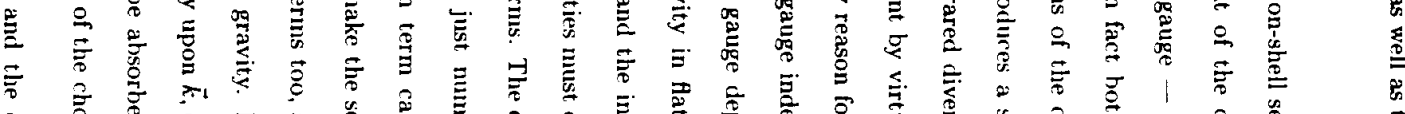

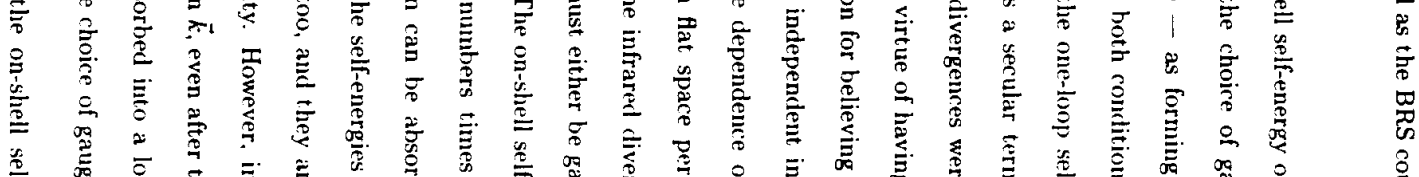

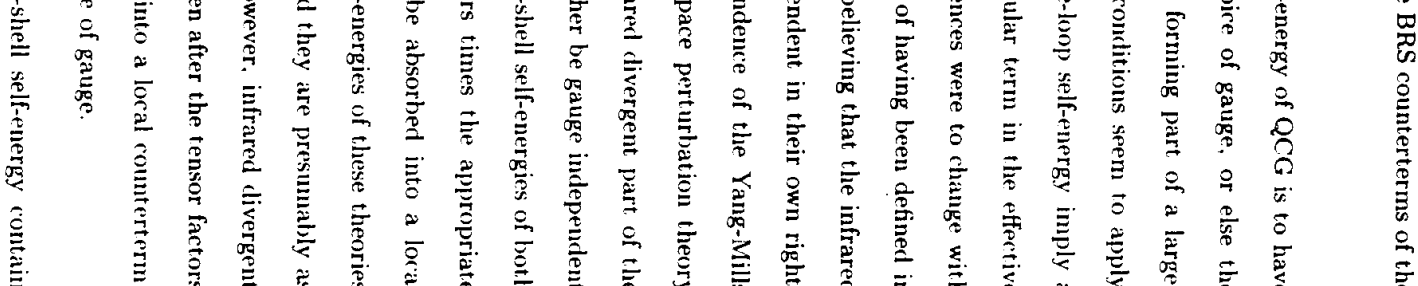

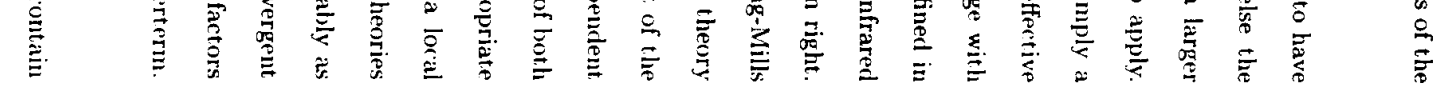

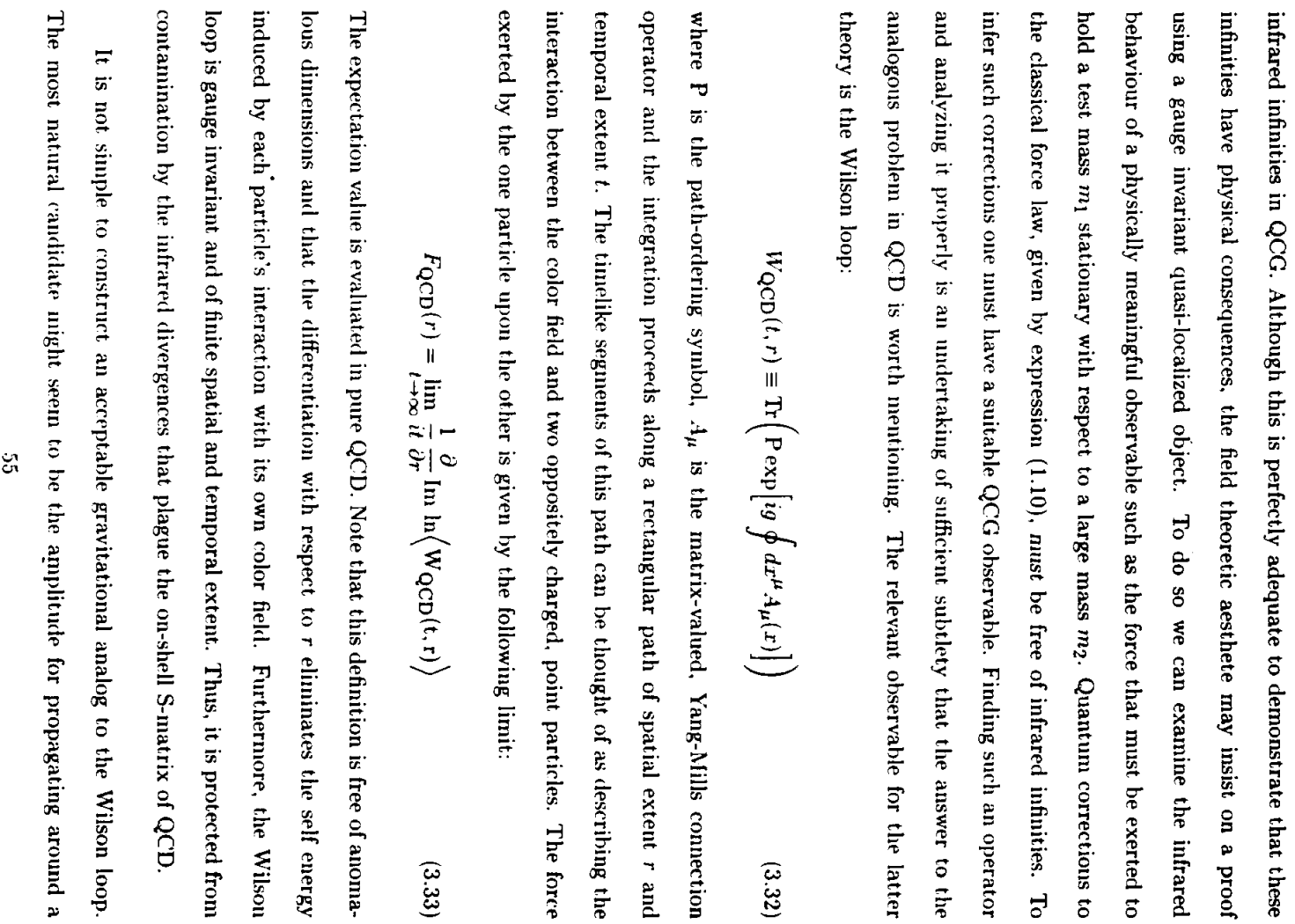



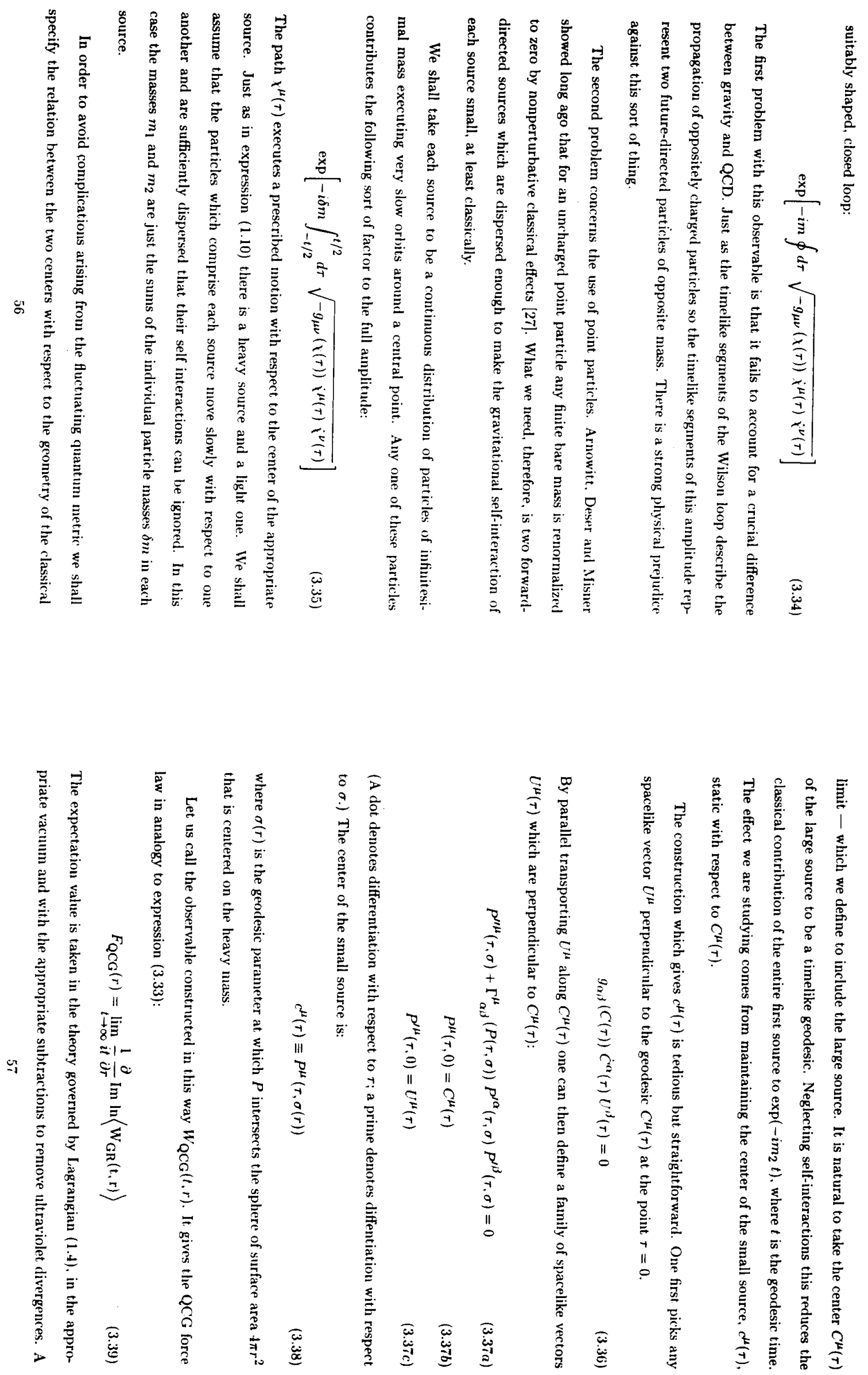

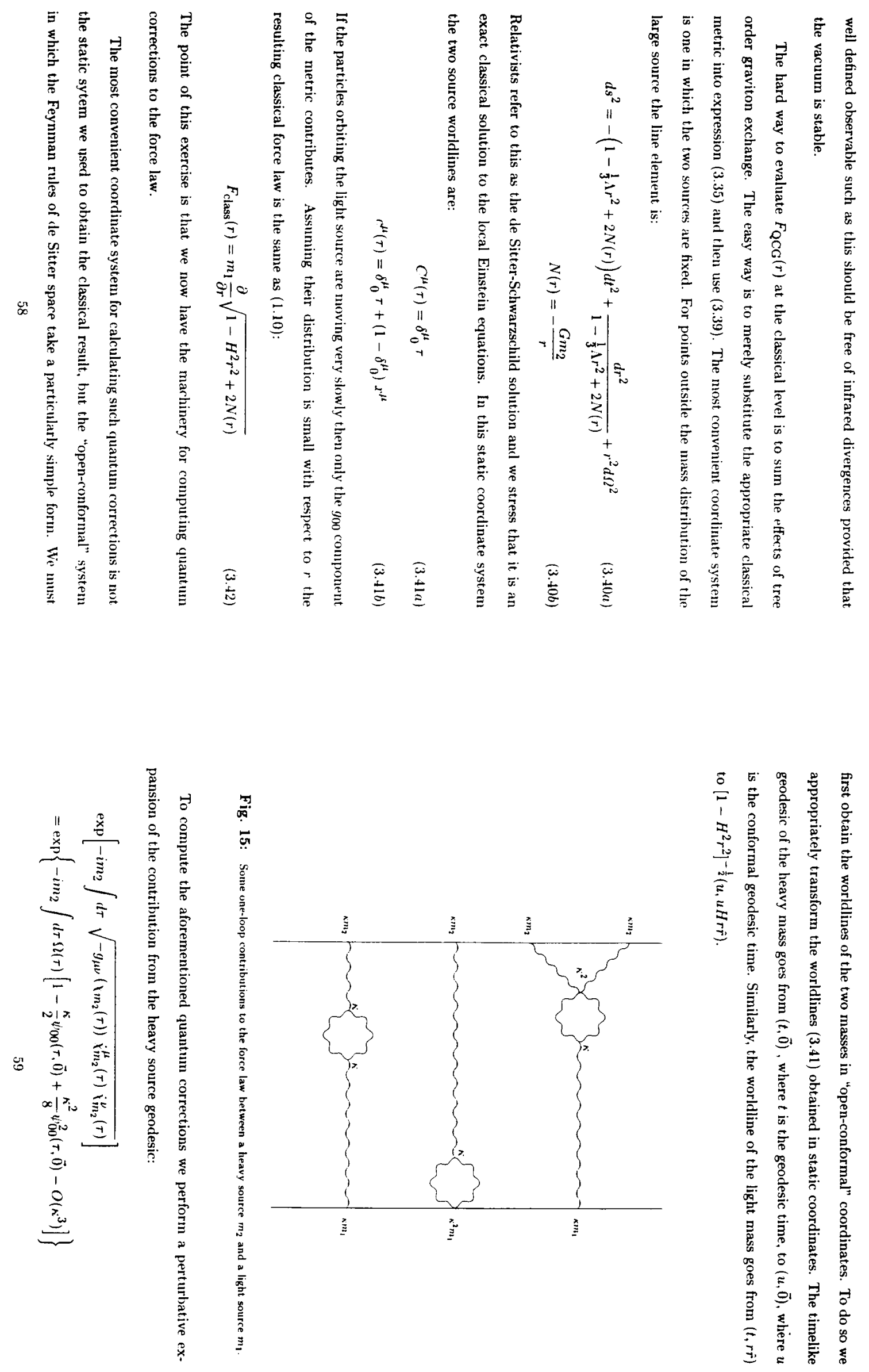


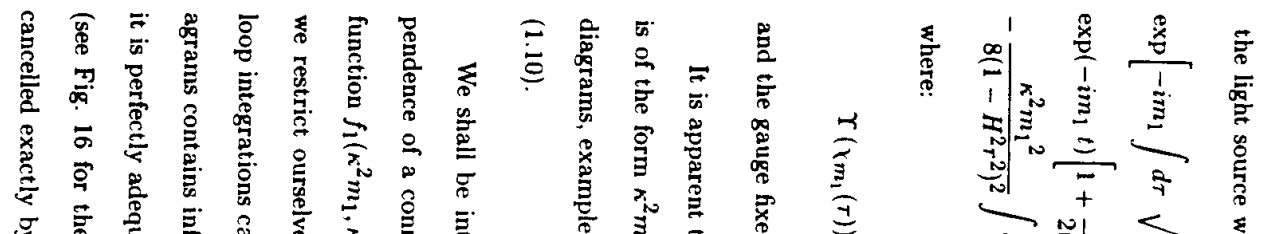

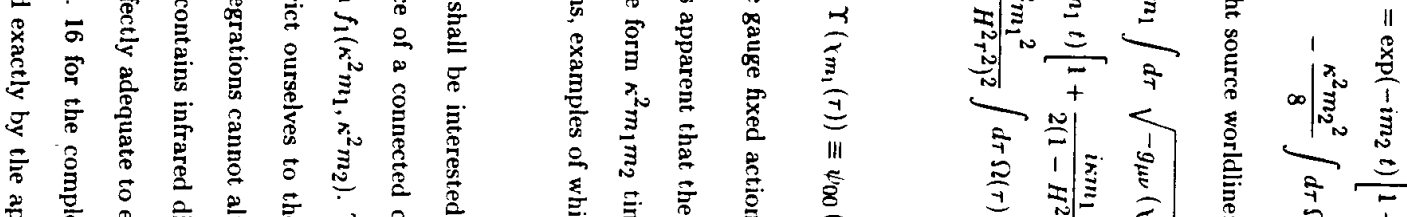

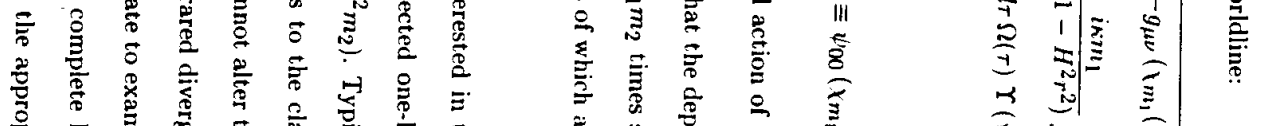

$\frac{\sqrt{3}}{\frac{5}{2}} \stackrel{\frac{2}{2}}{=}$

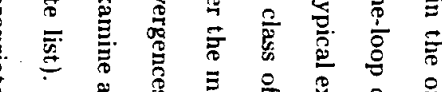

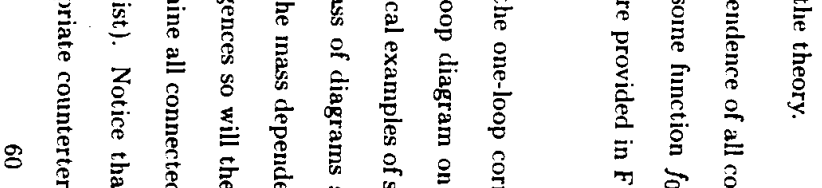

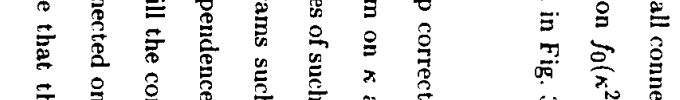

5 它

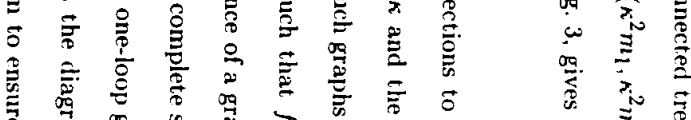

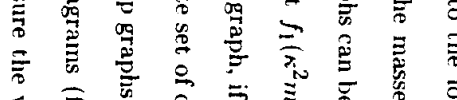

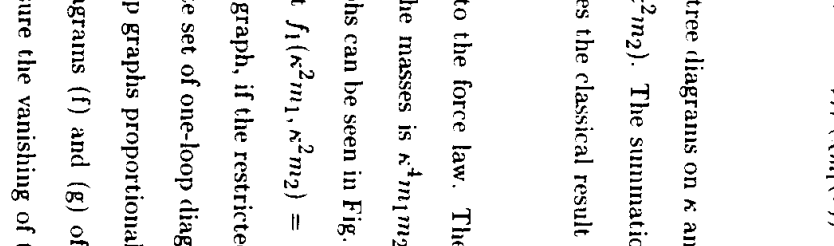

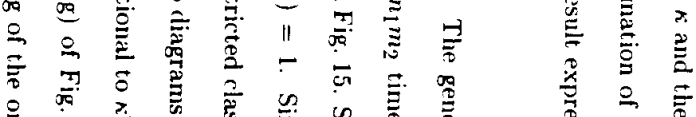

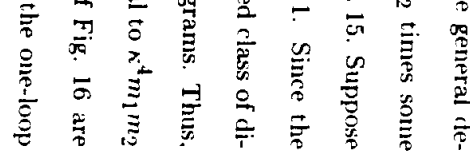

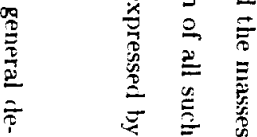

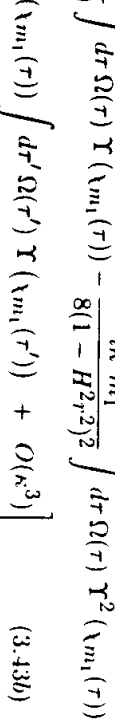

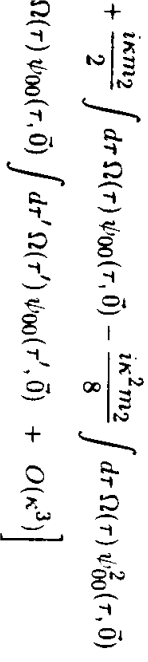

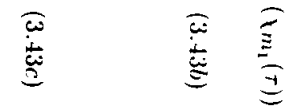

$\stackrel{\widehat{\omega}}{\stackrel{t}{\oplus}}$
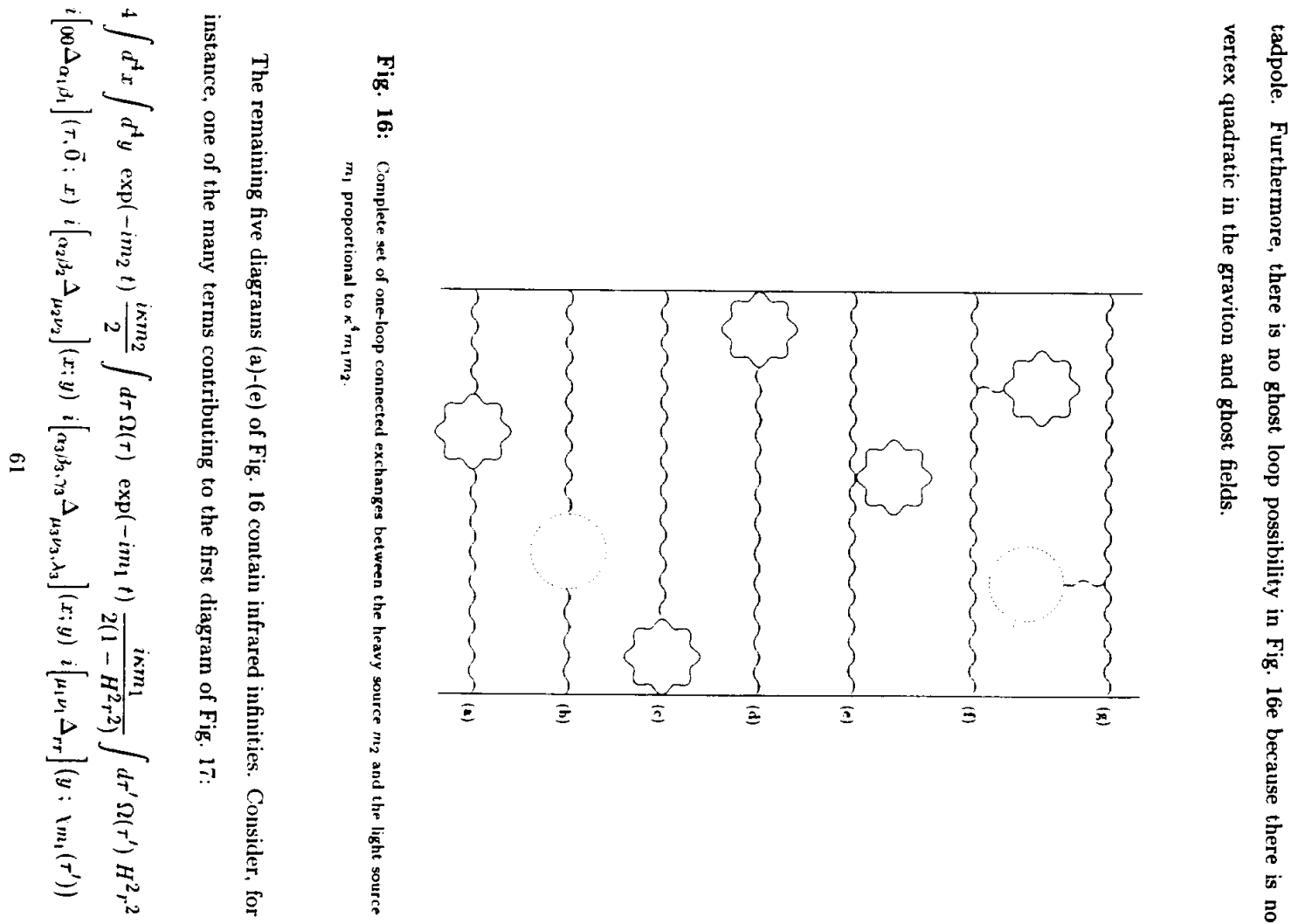


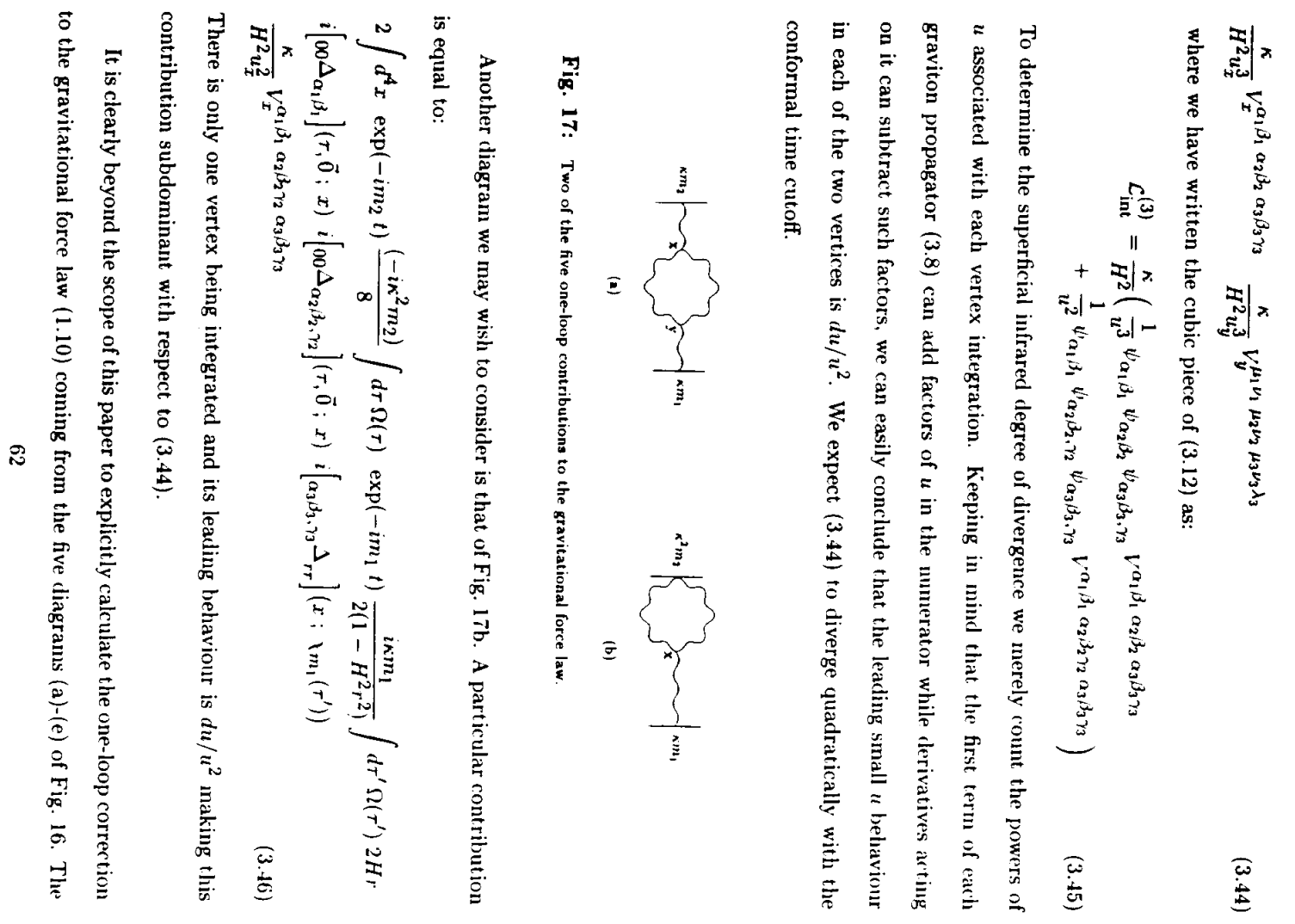

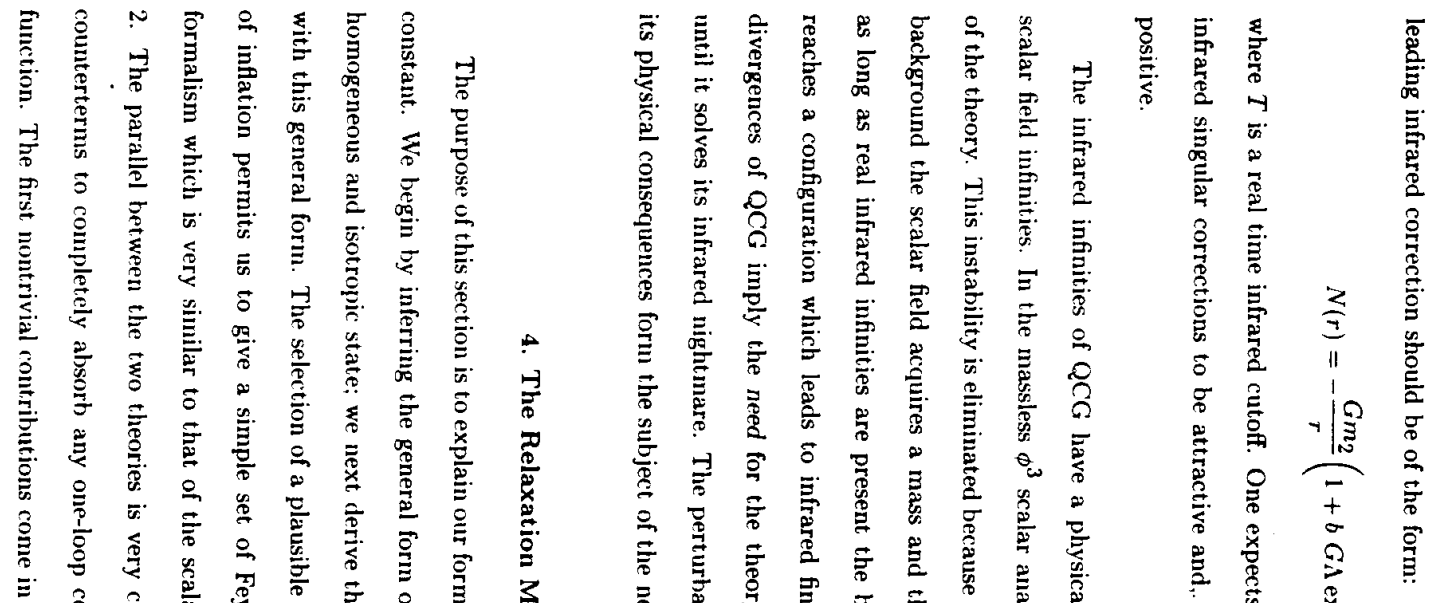

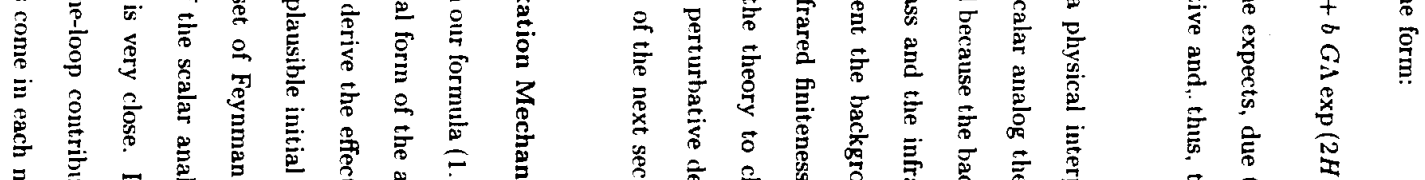

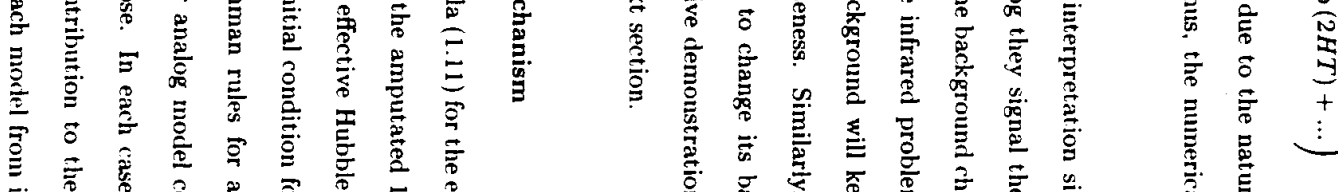

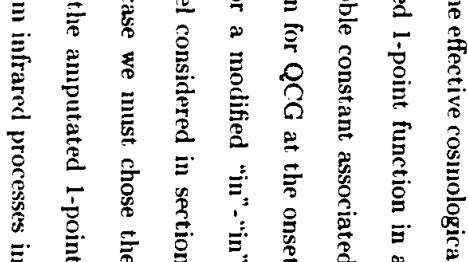
,

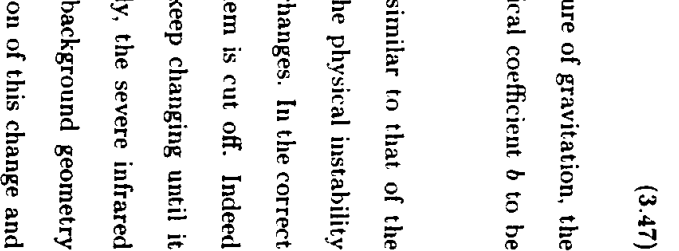



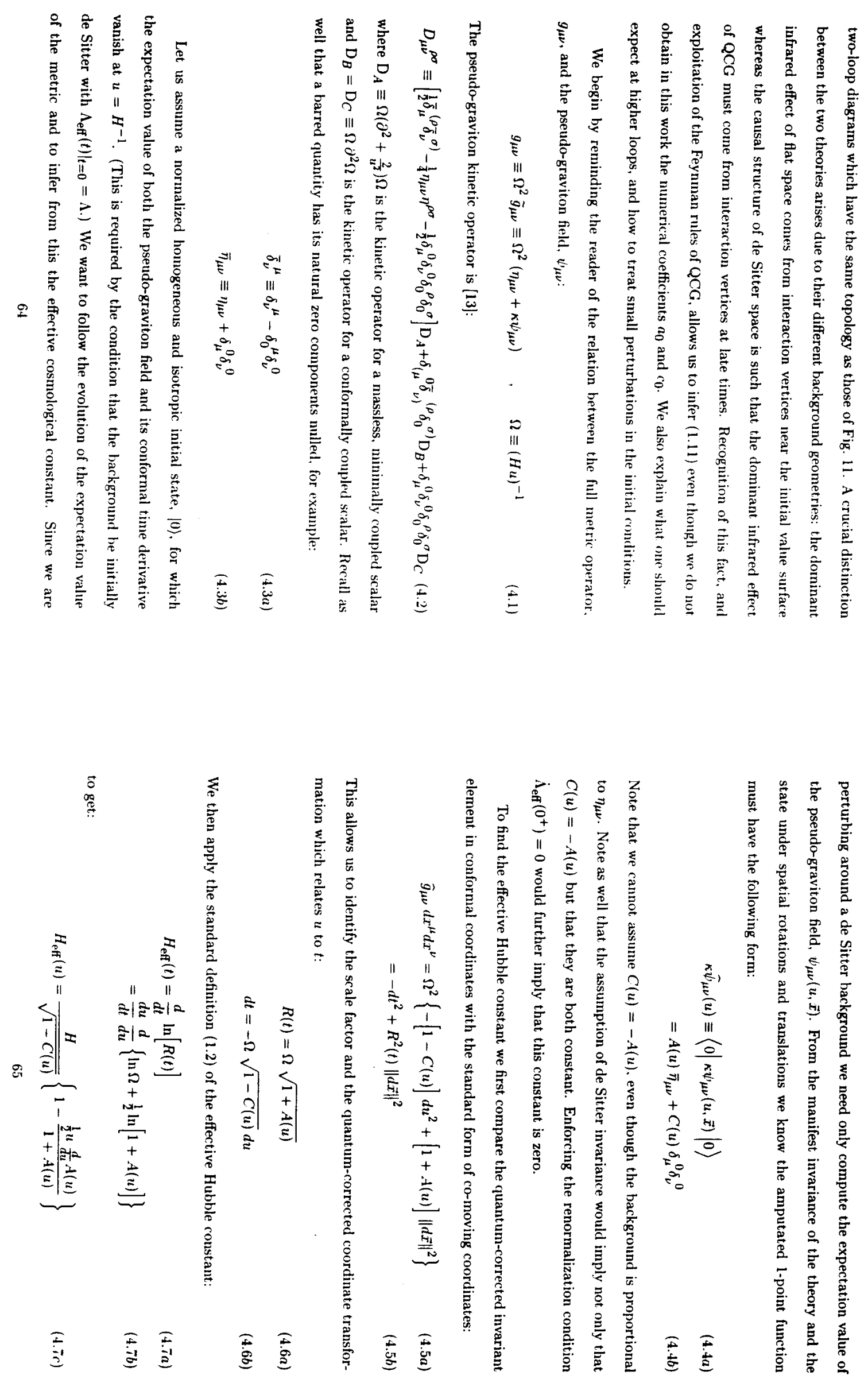

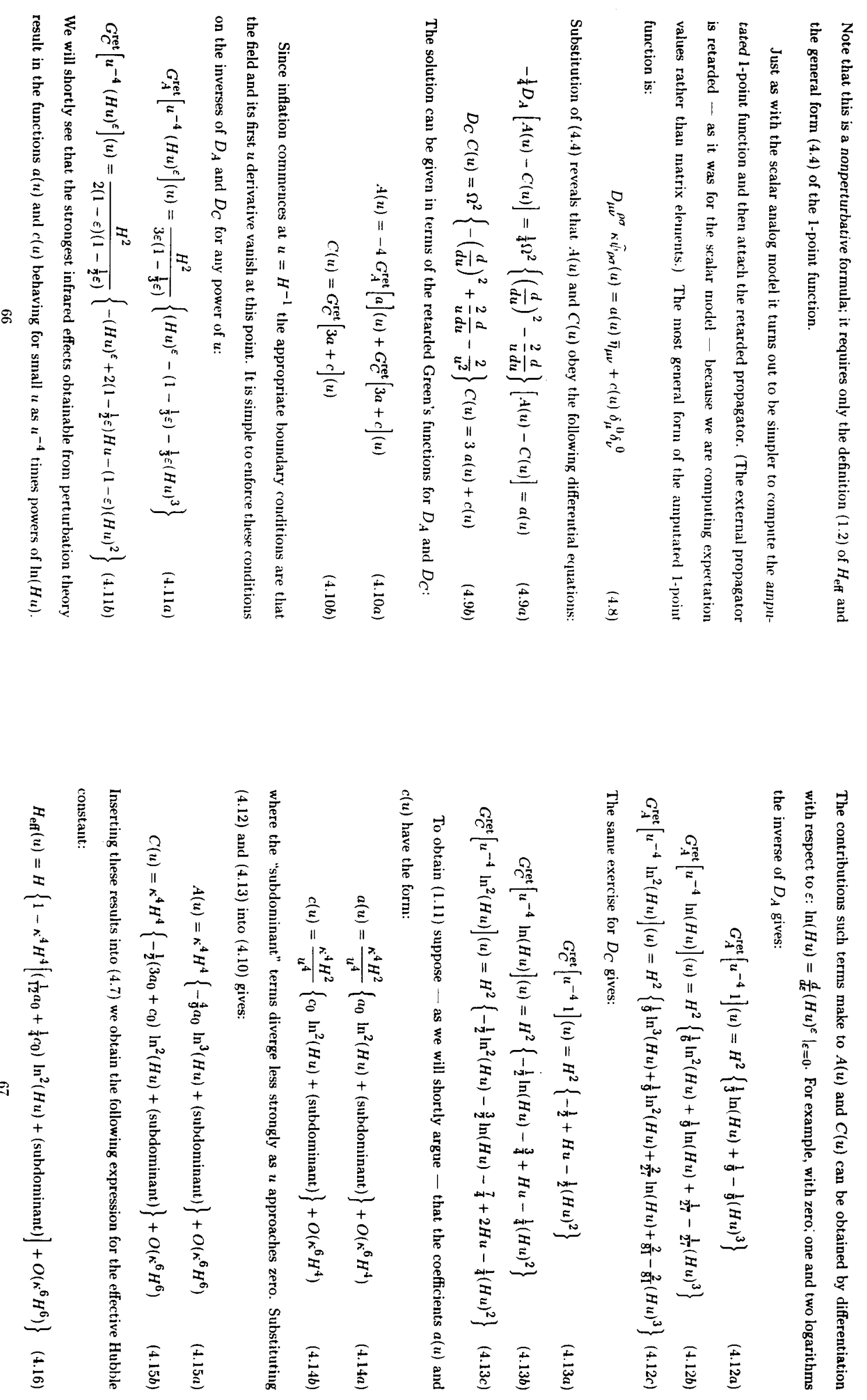


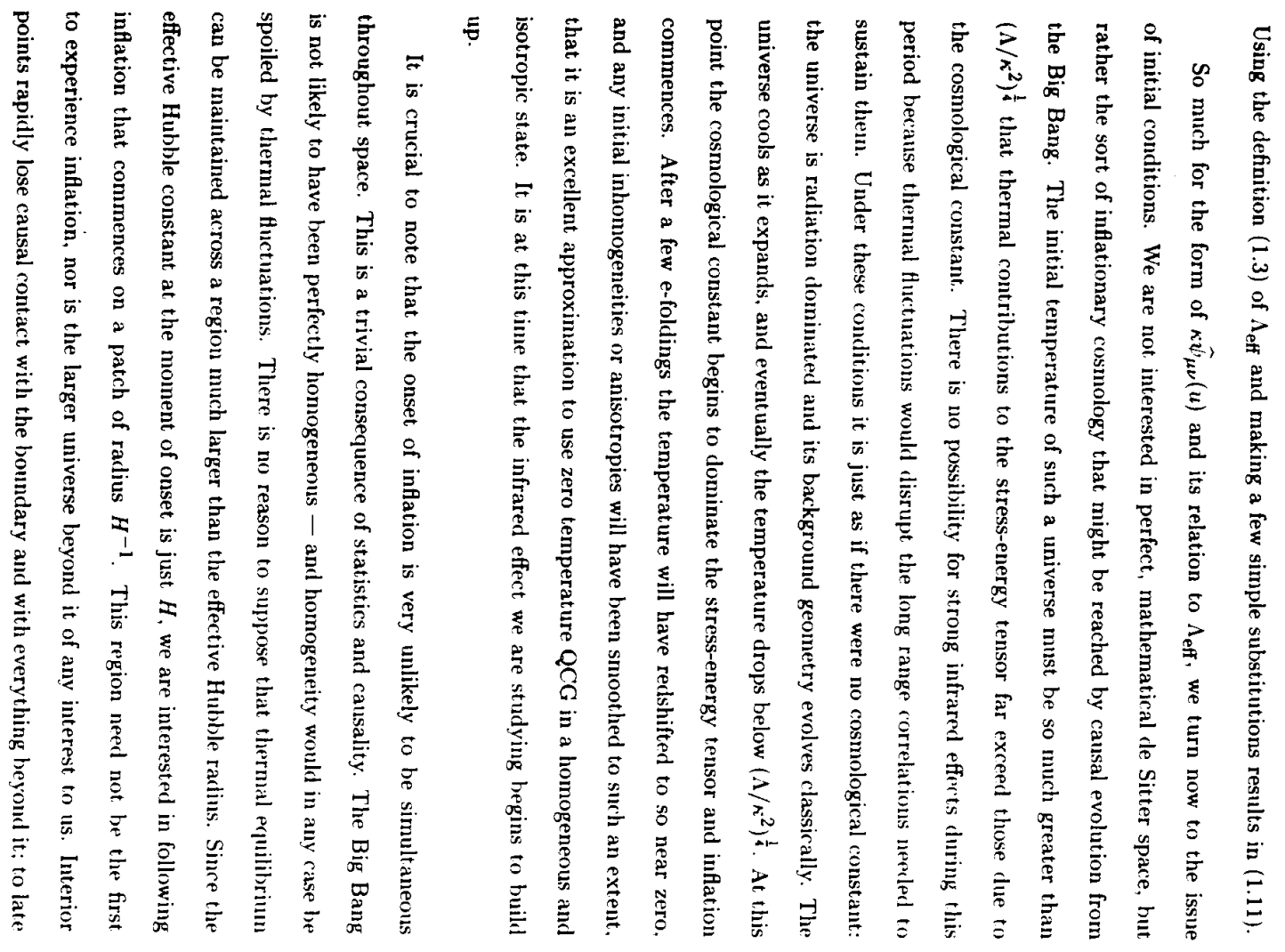

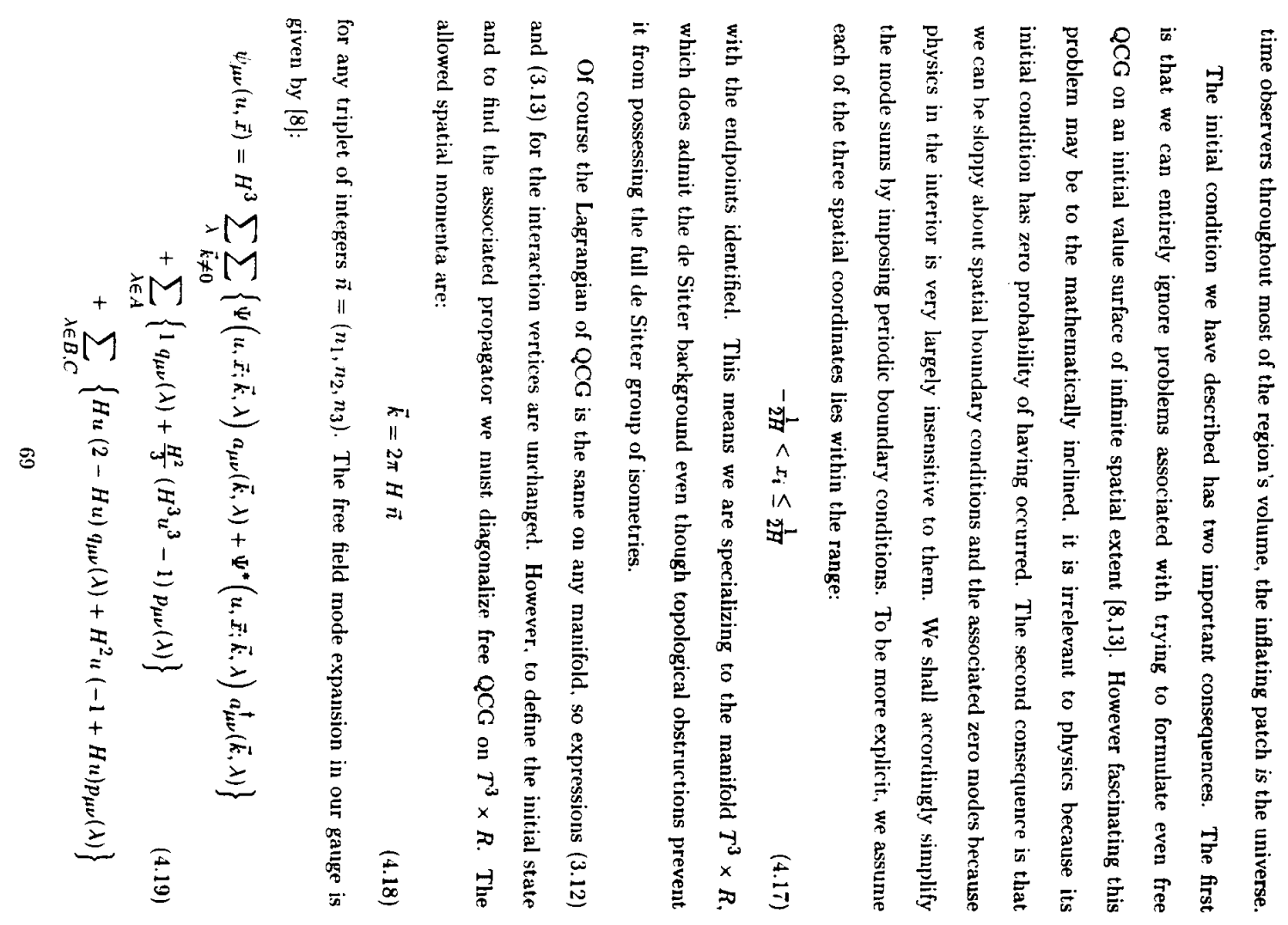




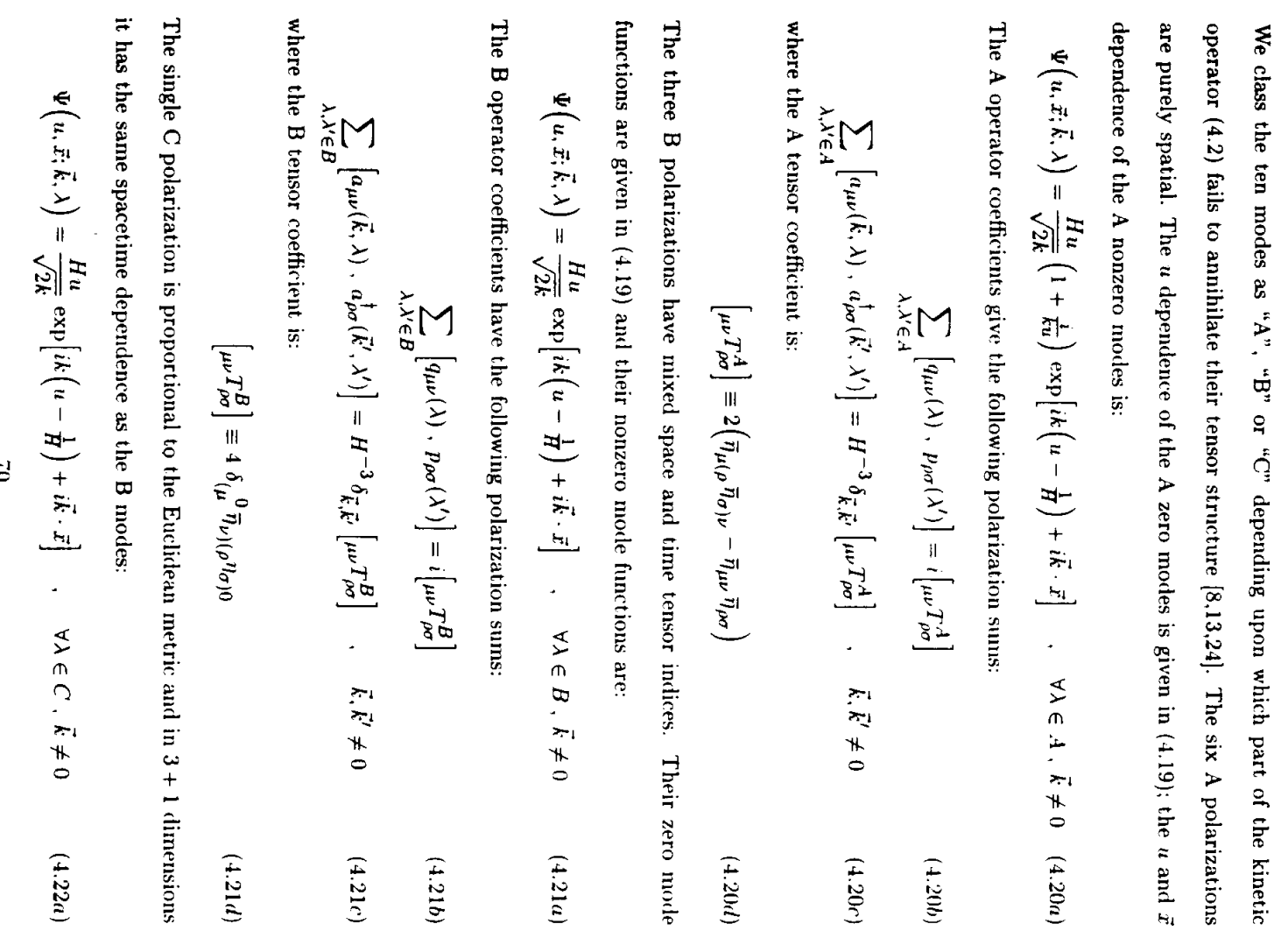

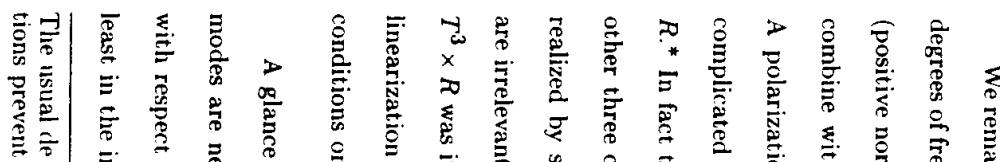

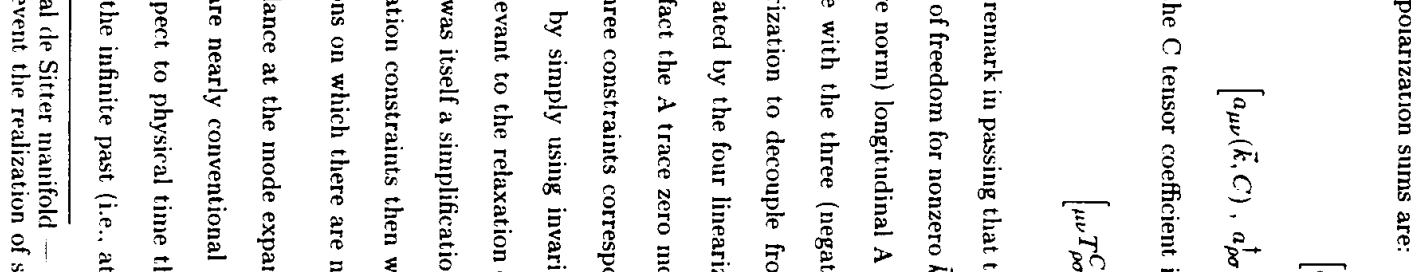

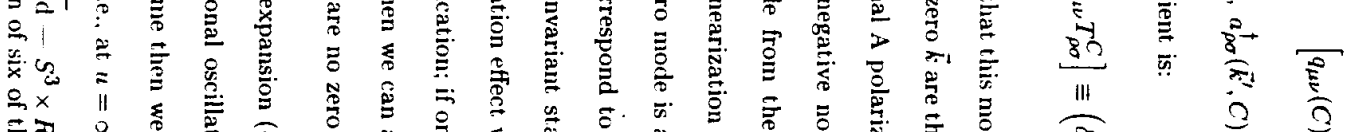

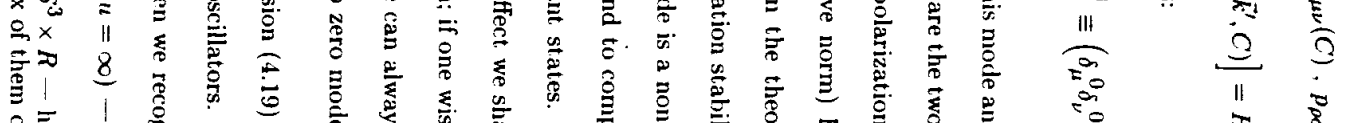

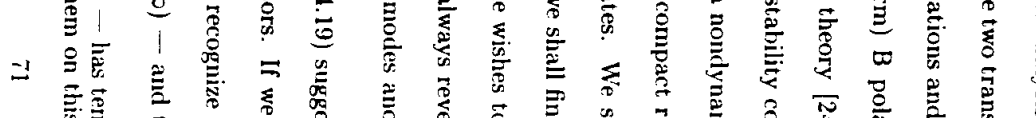

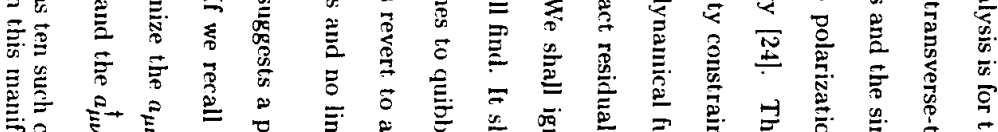

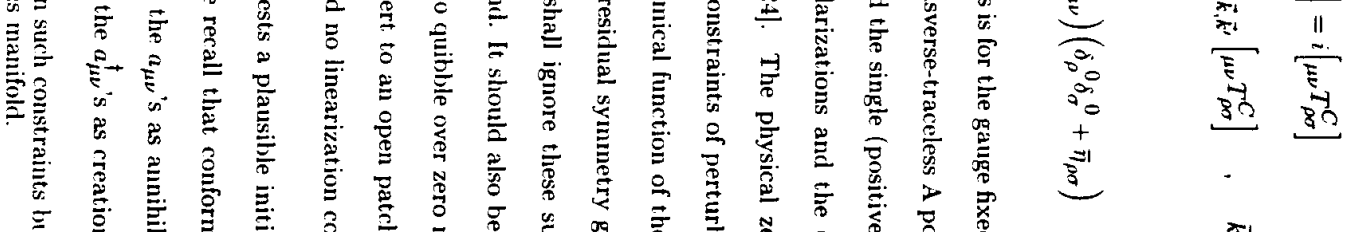

IIIII|||||

HIIIIIIIII

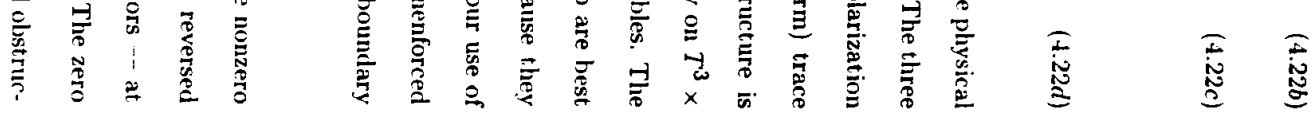




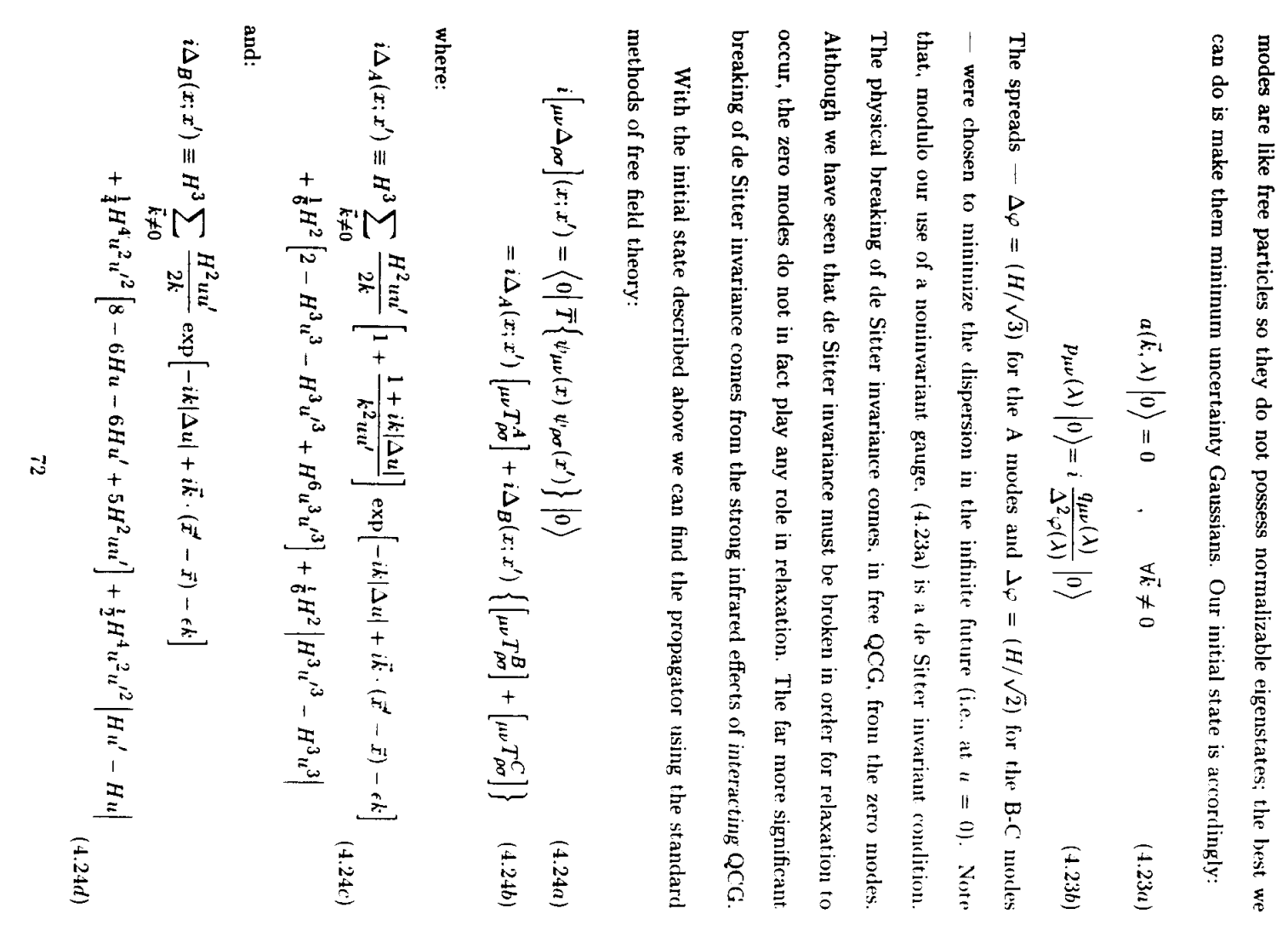

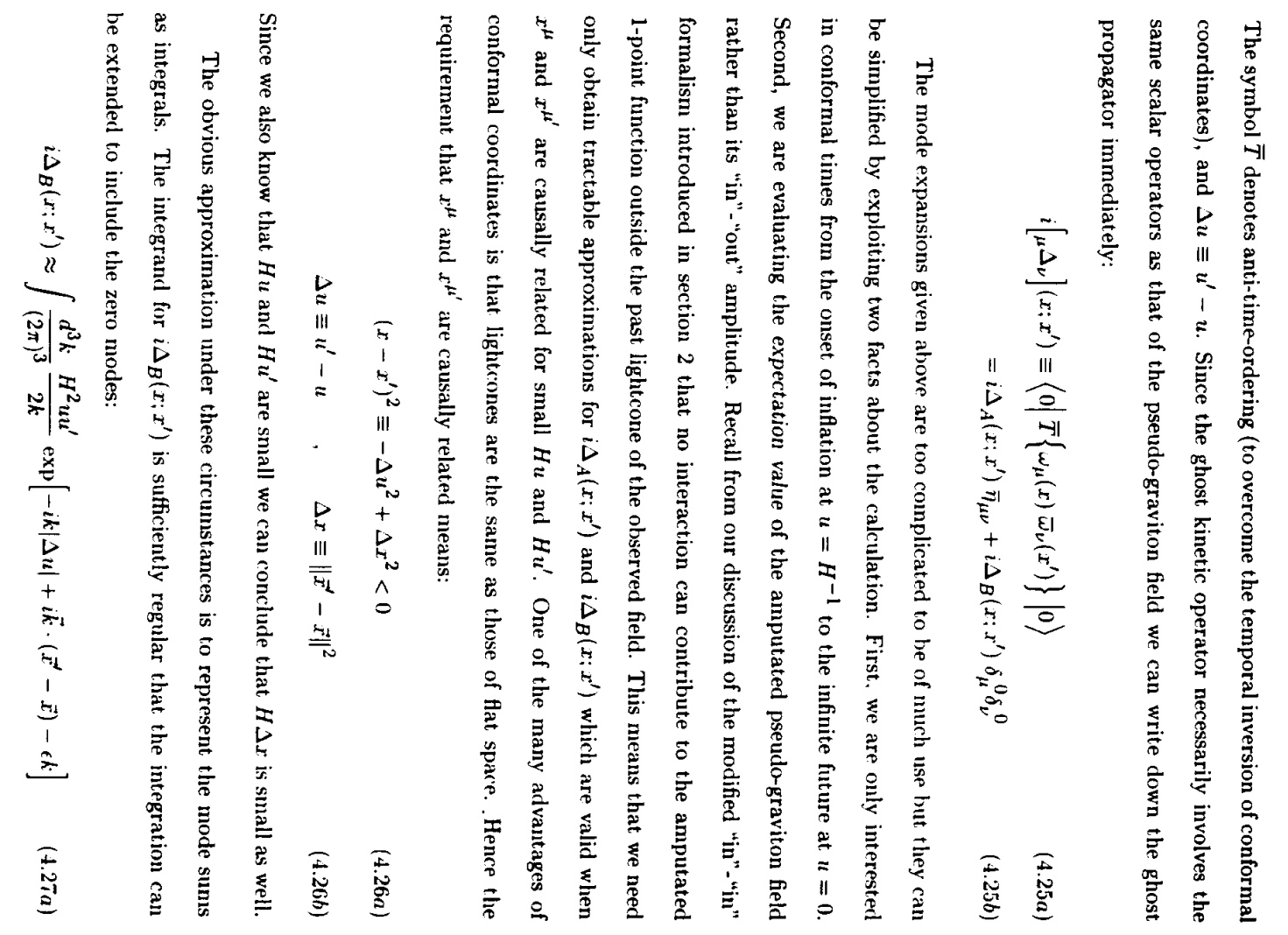



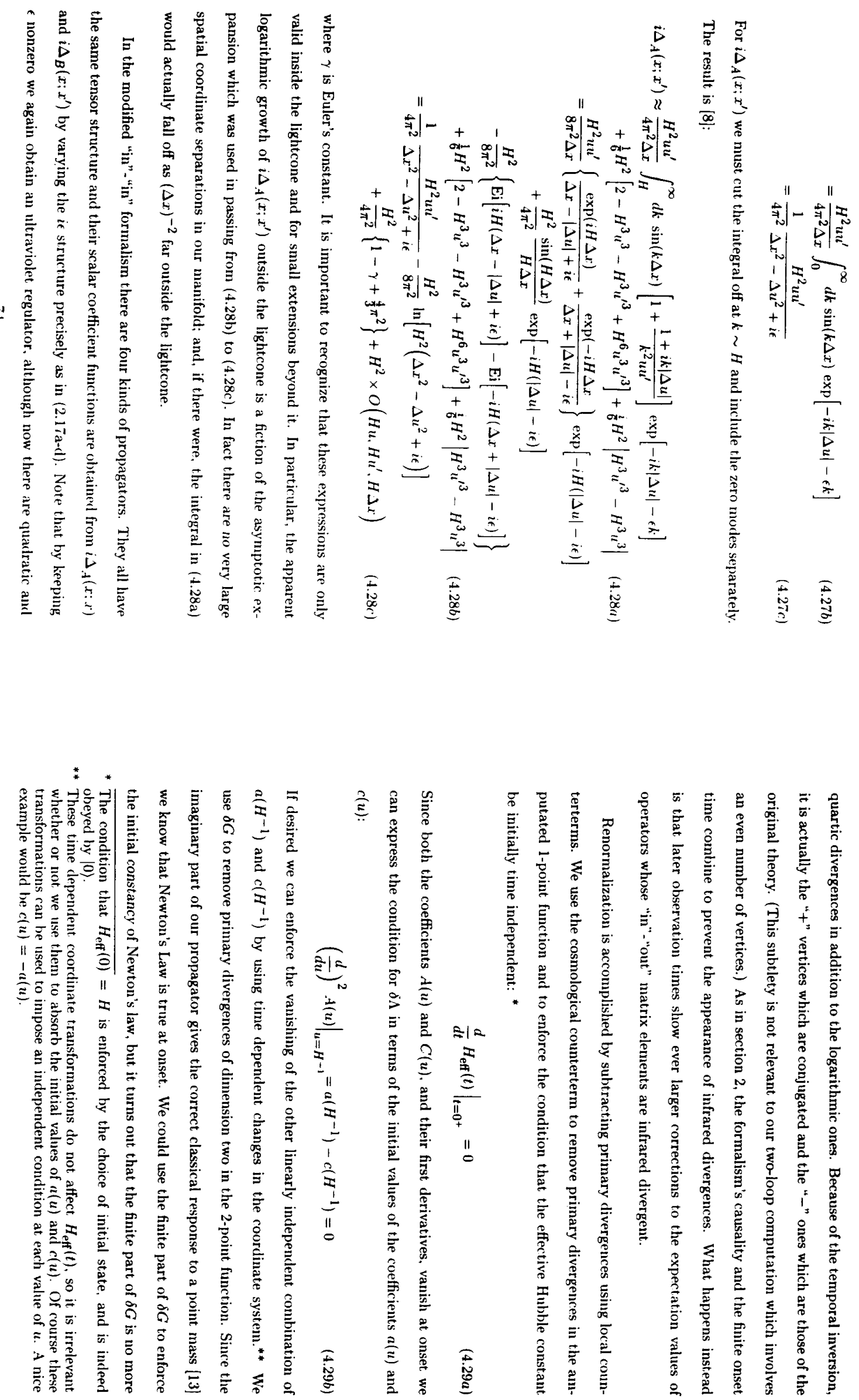

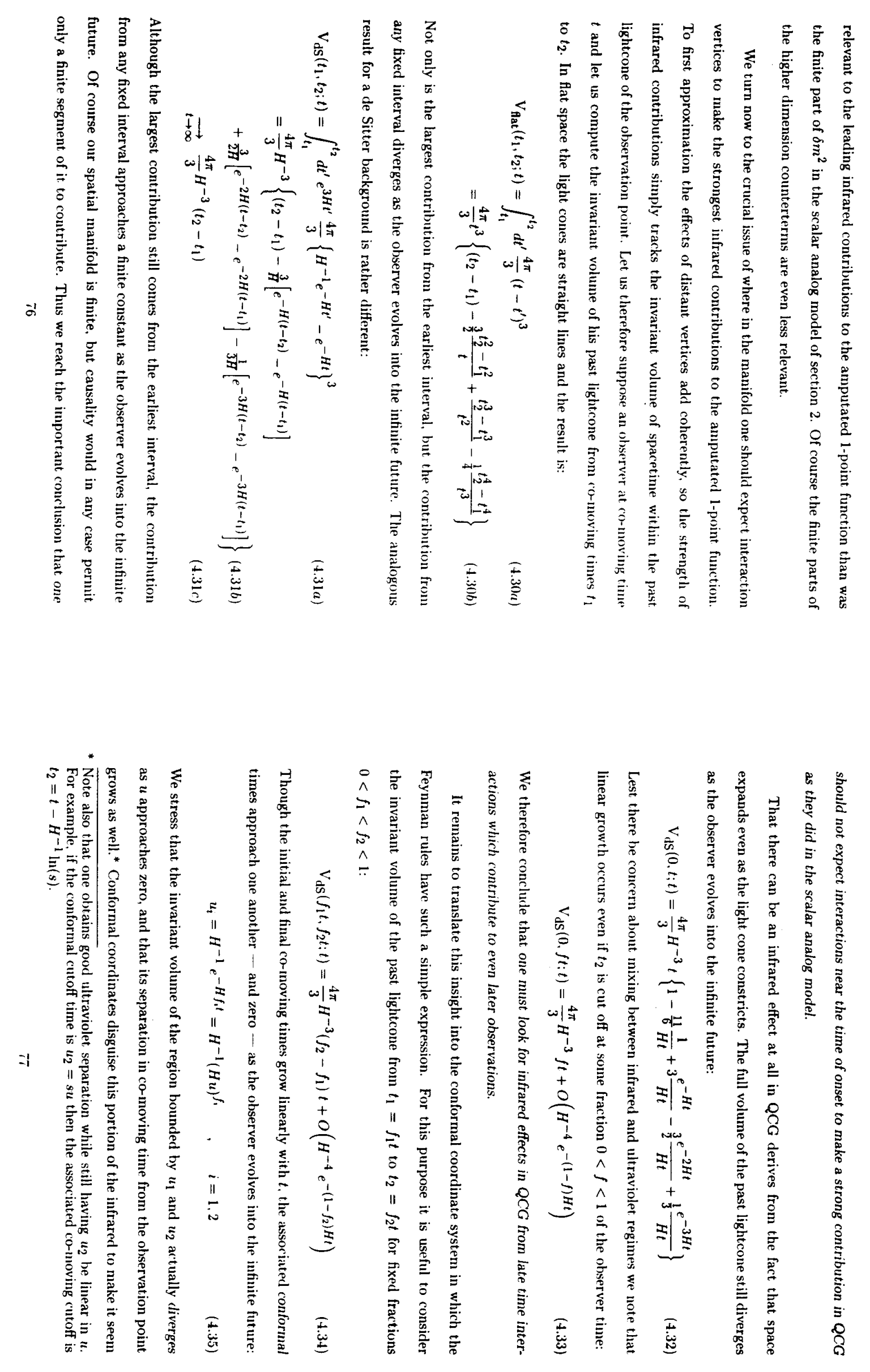


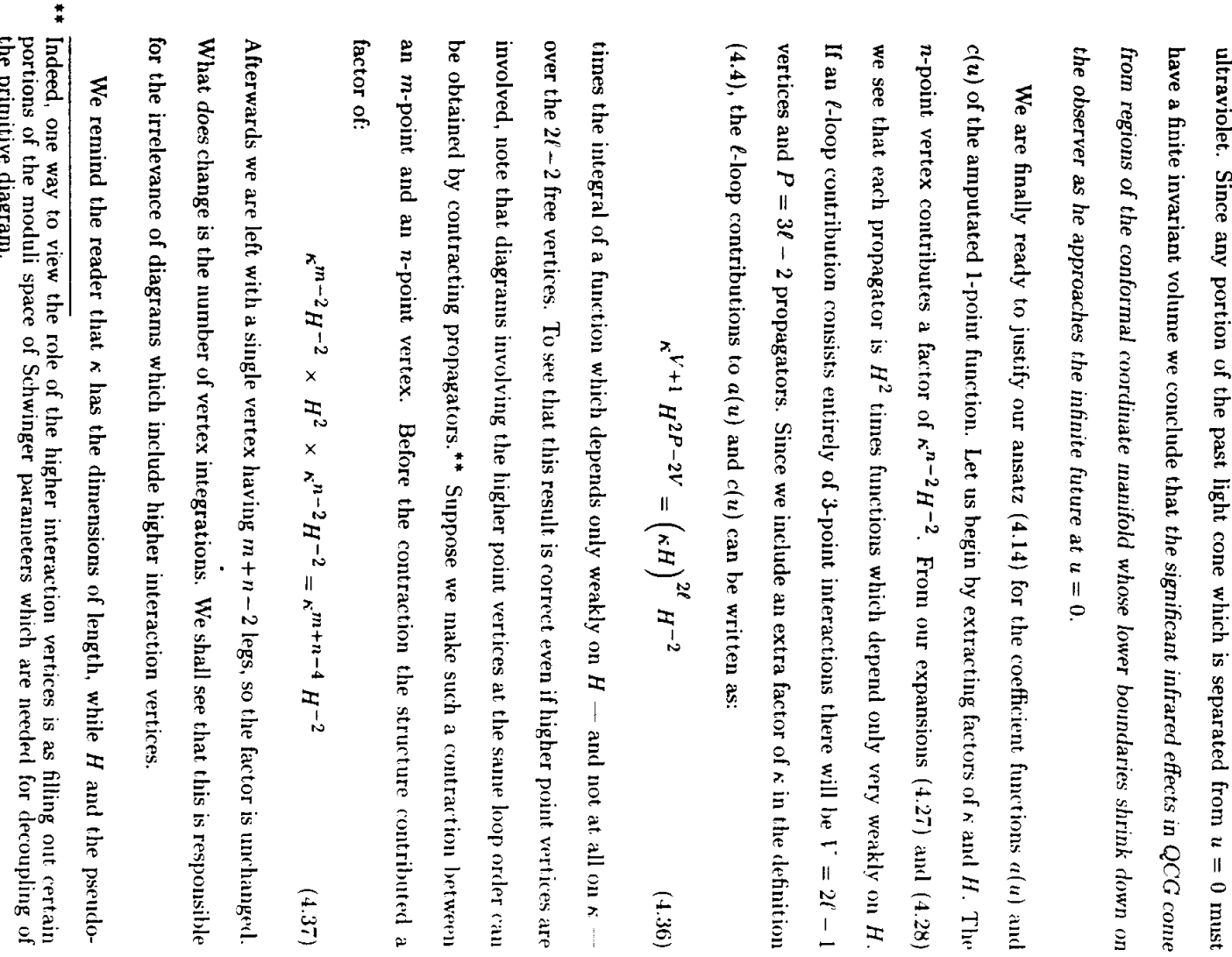

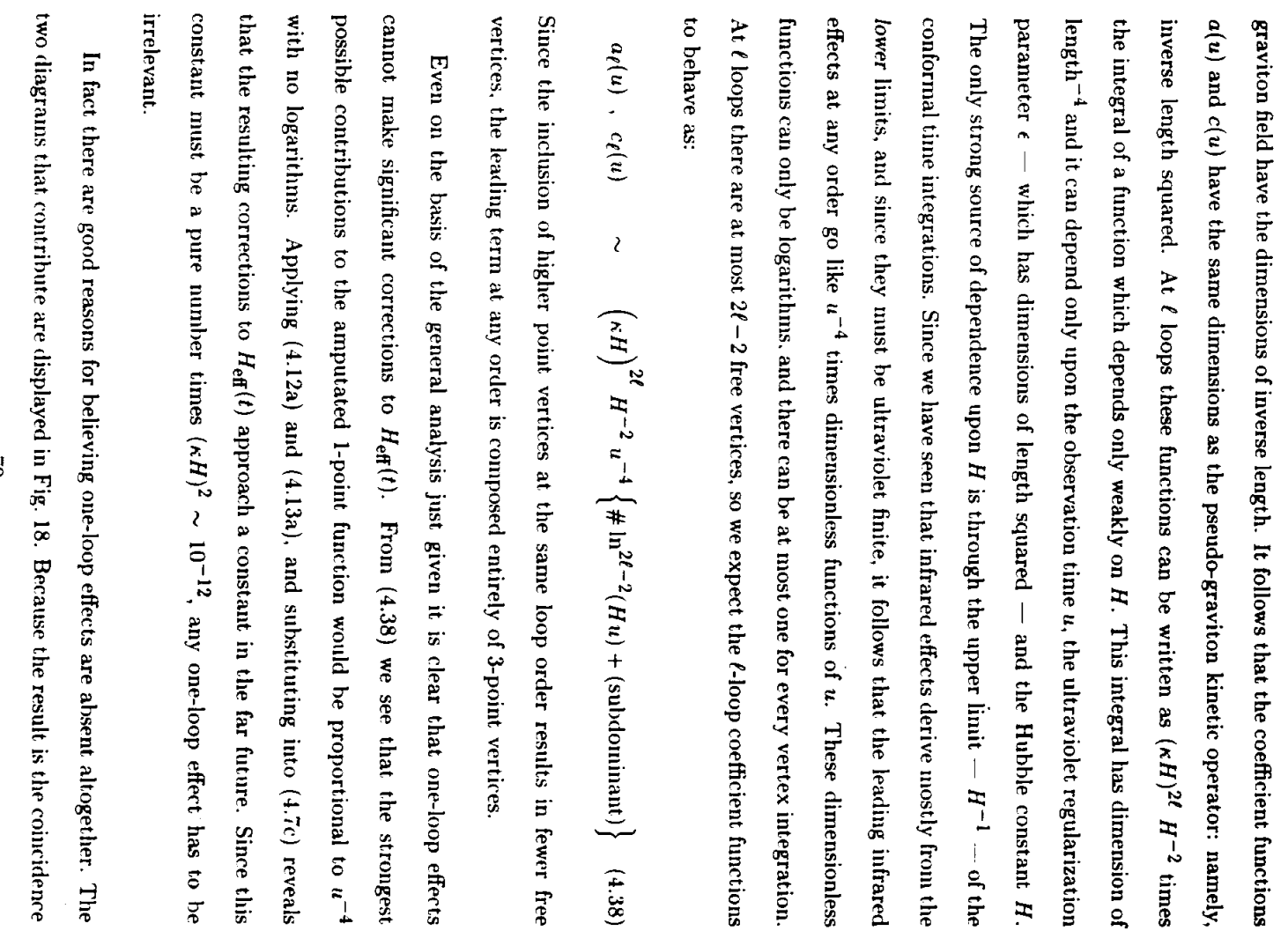



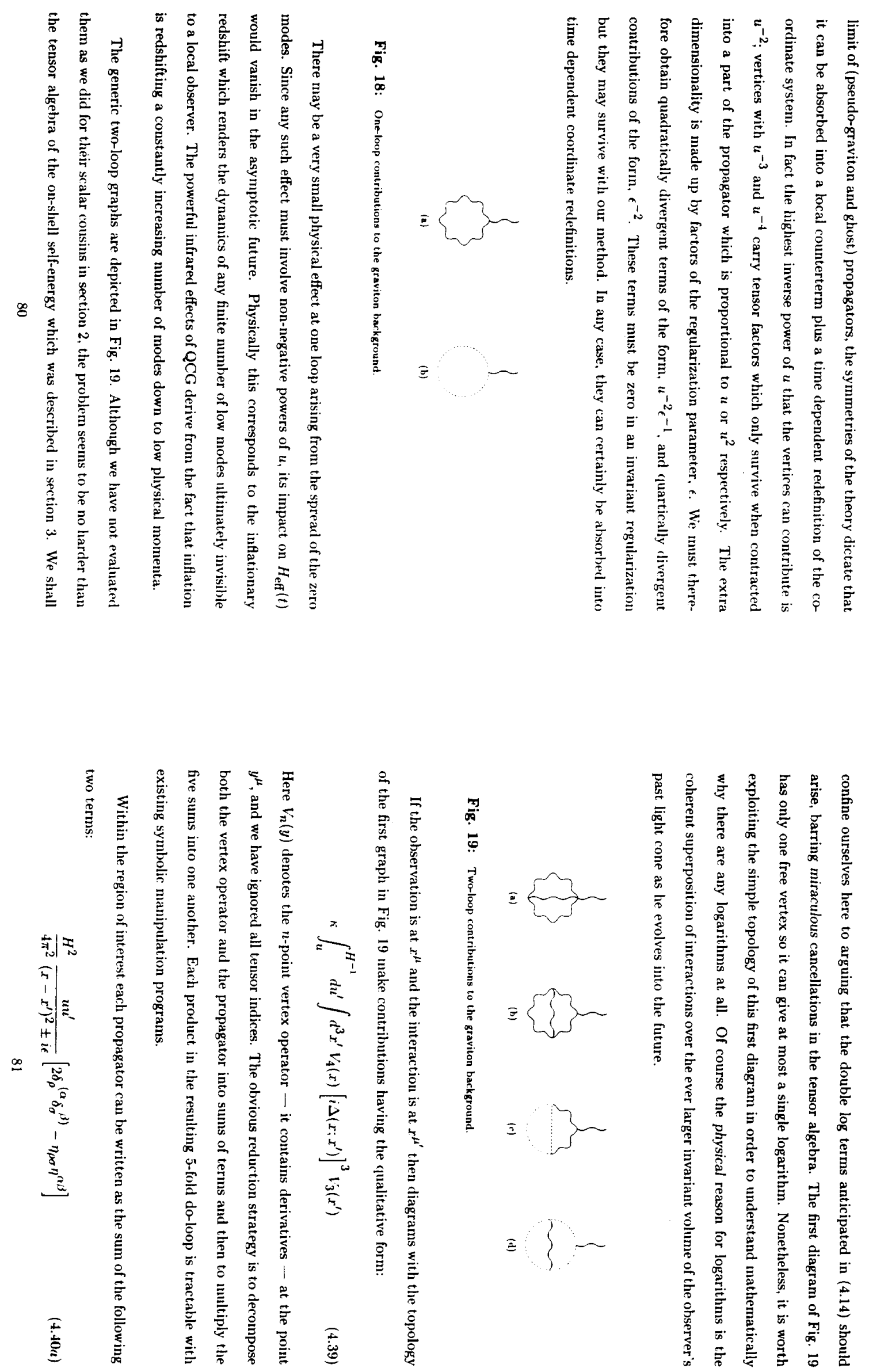

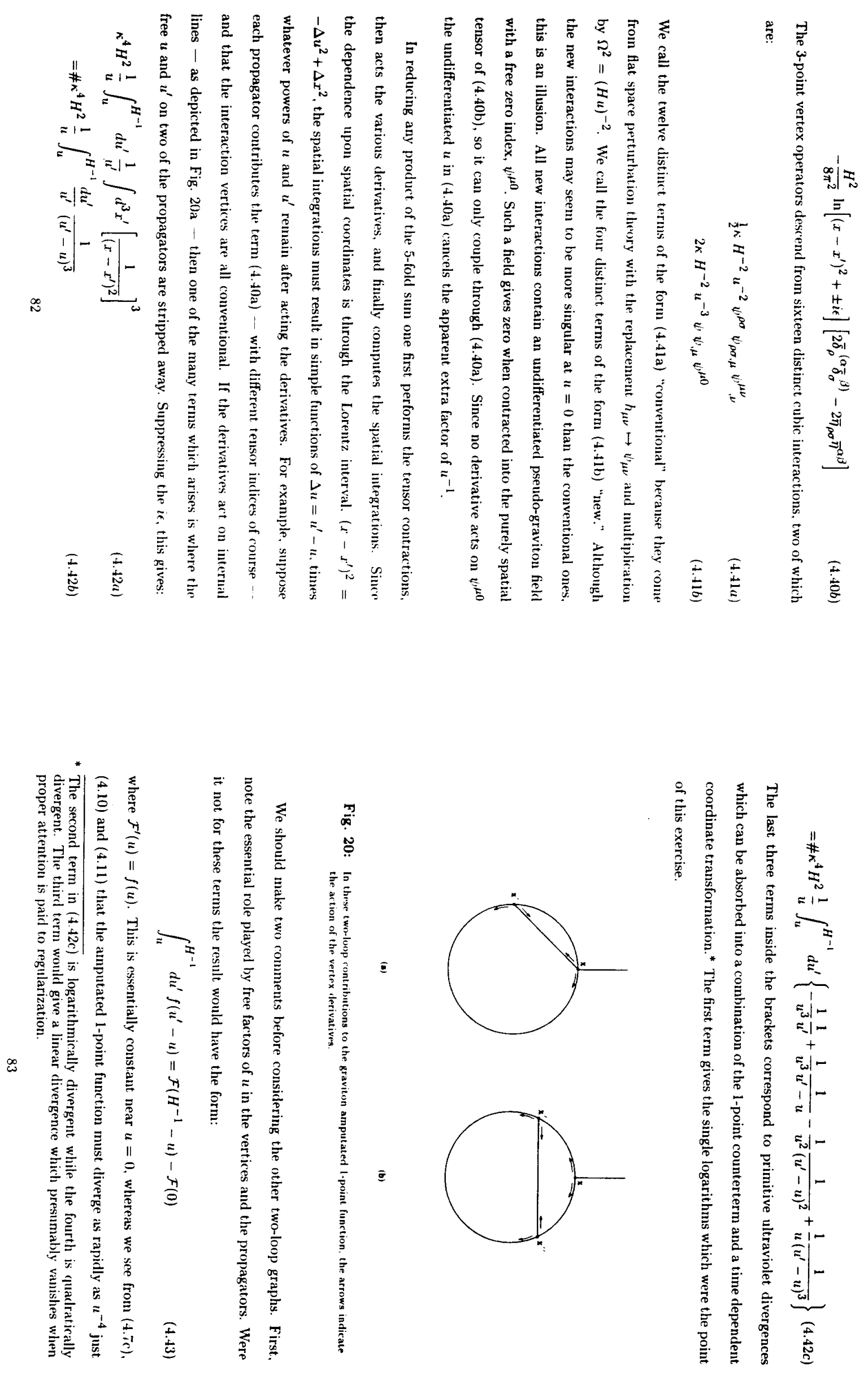

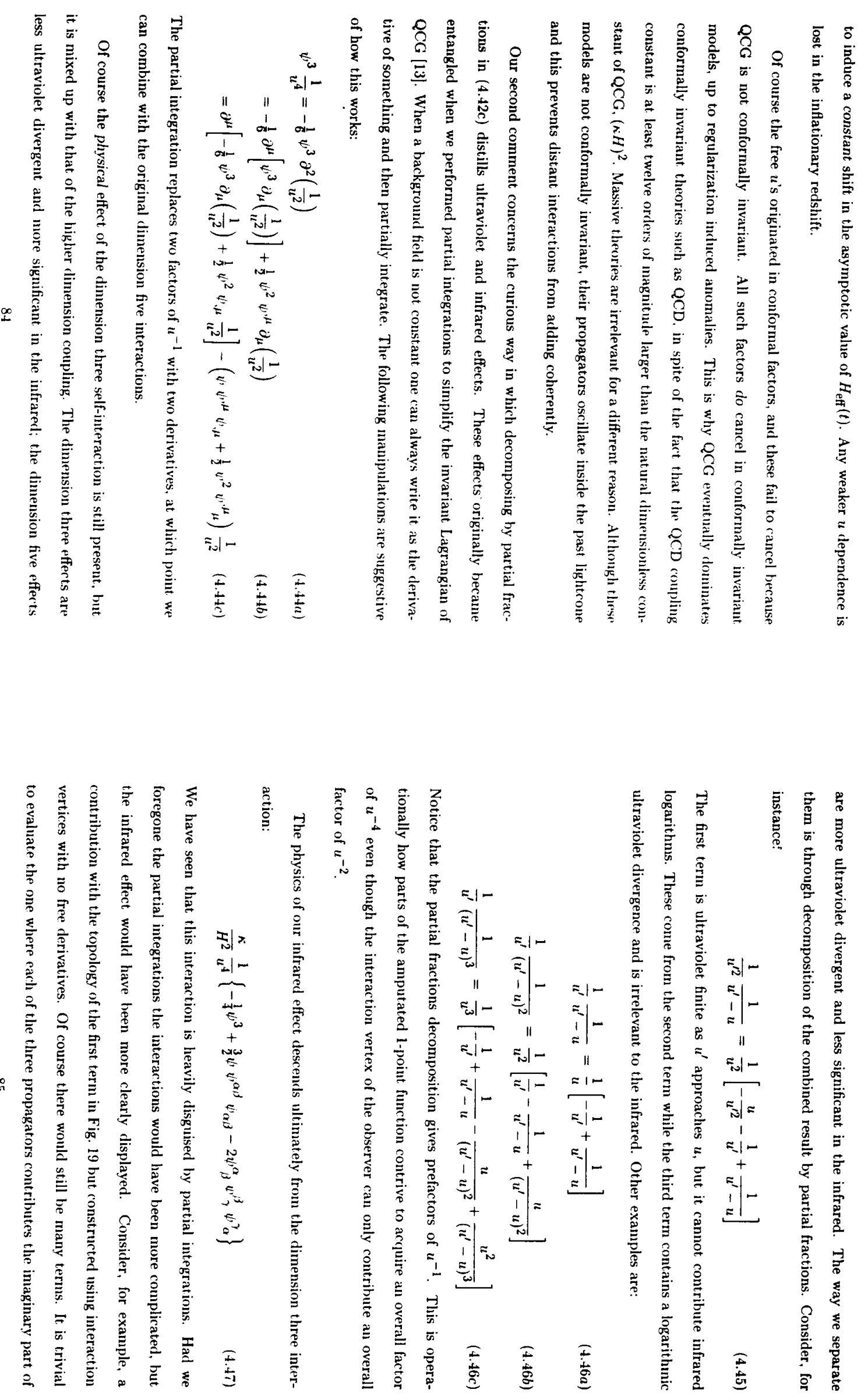

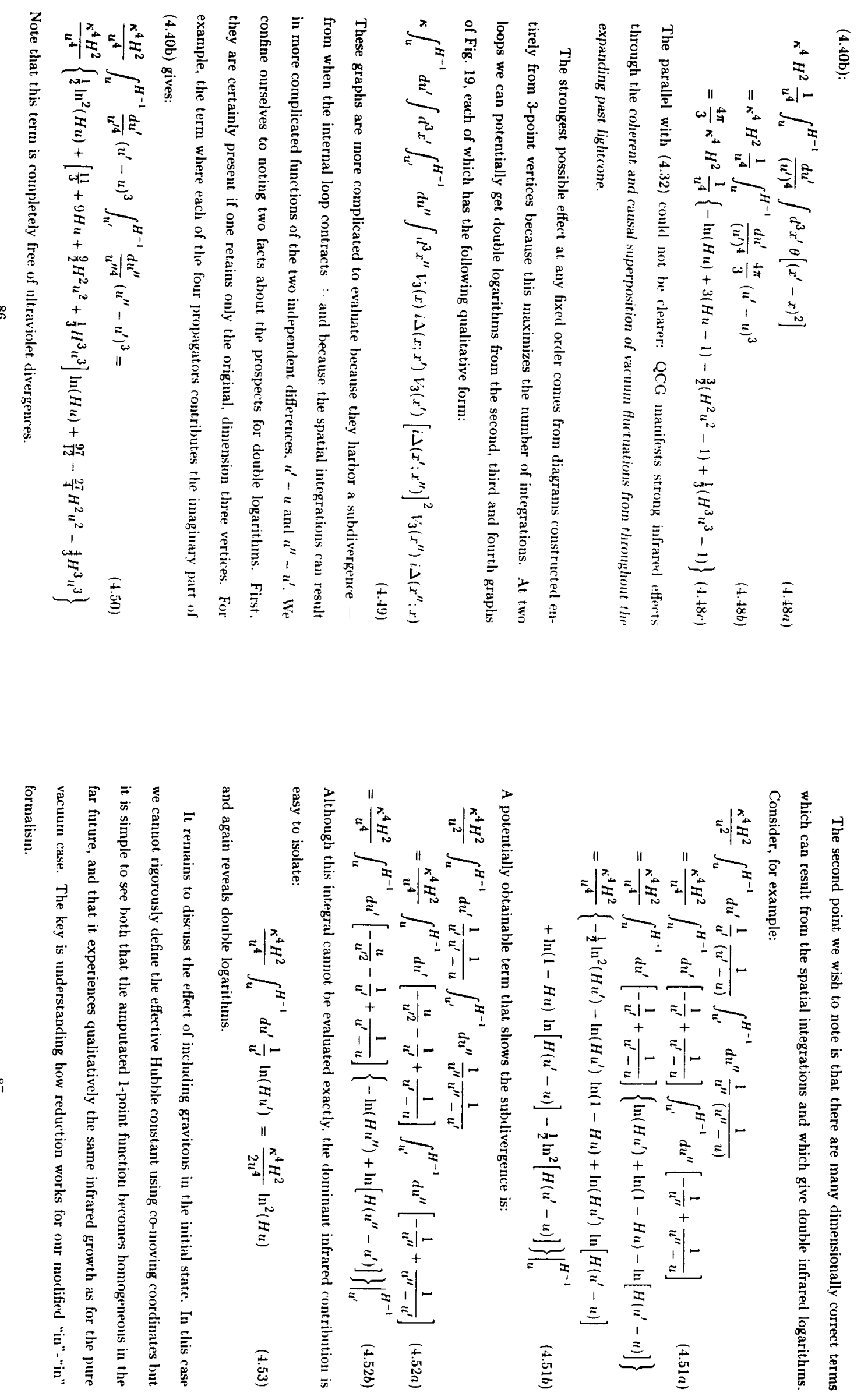

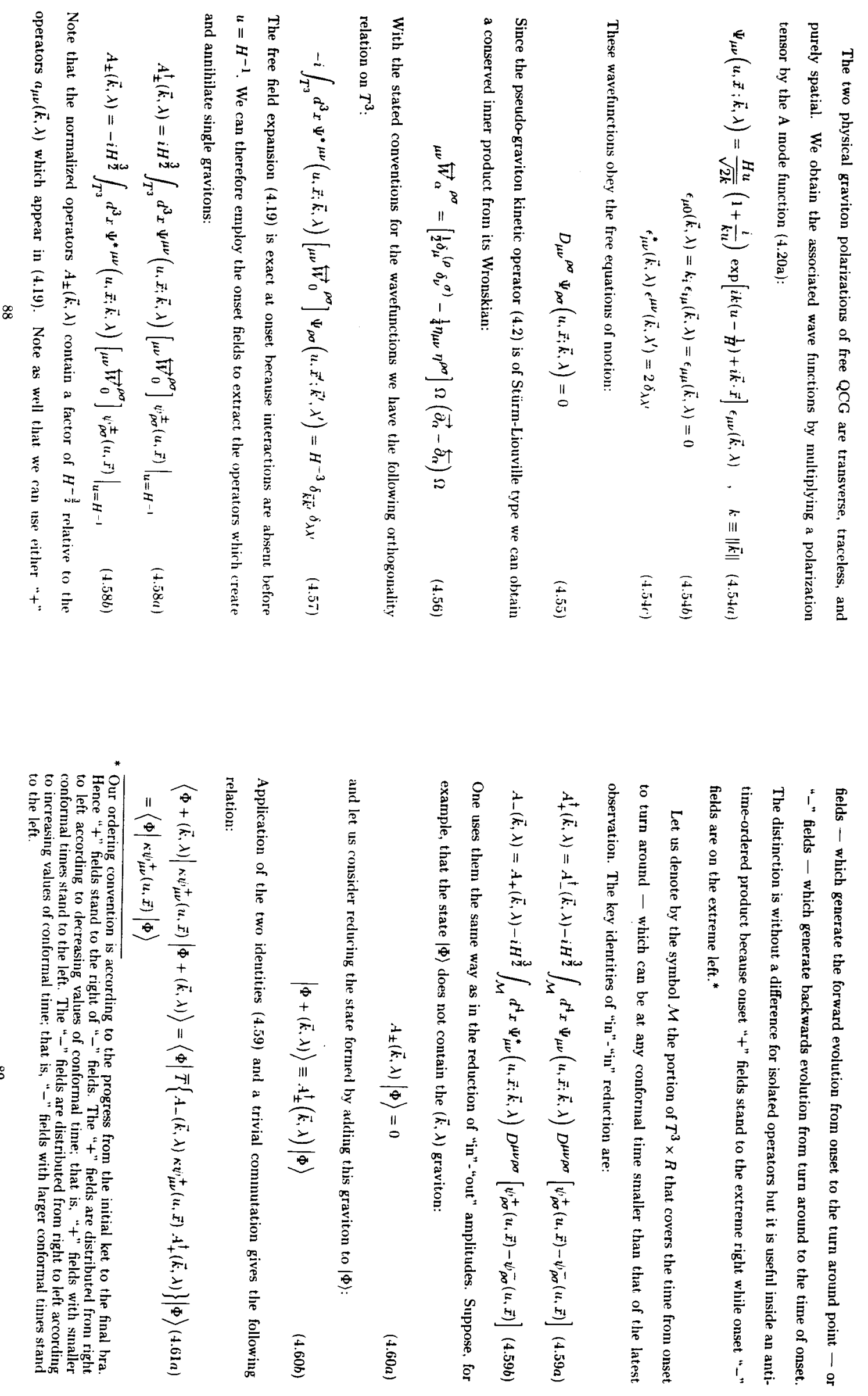

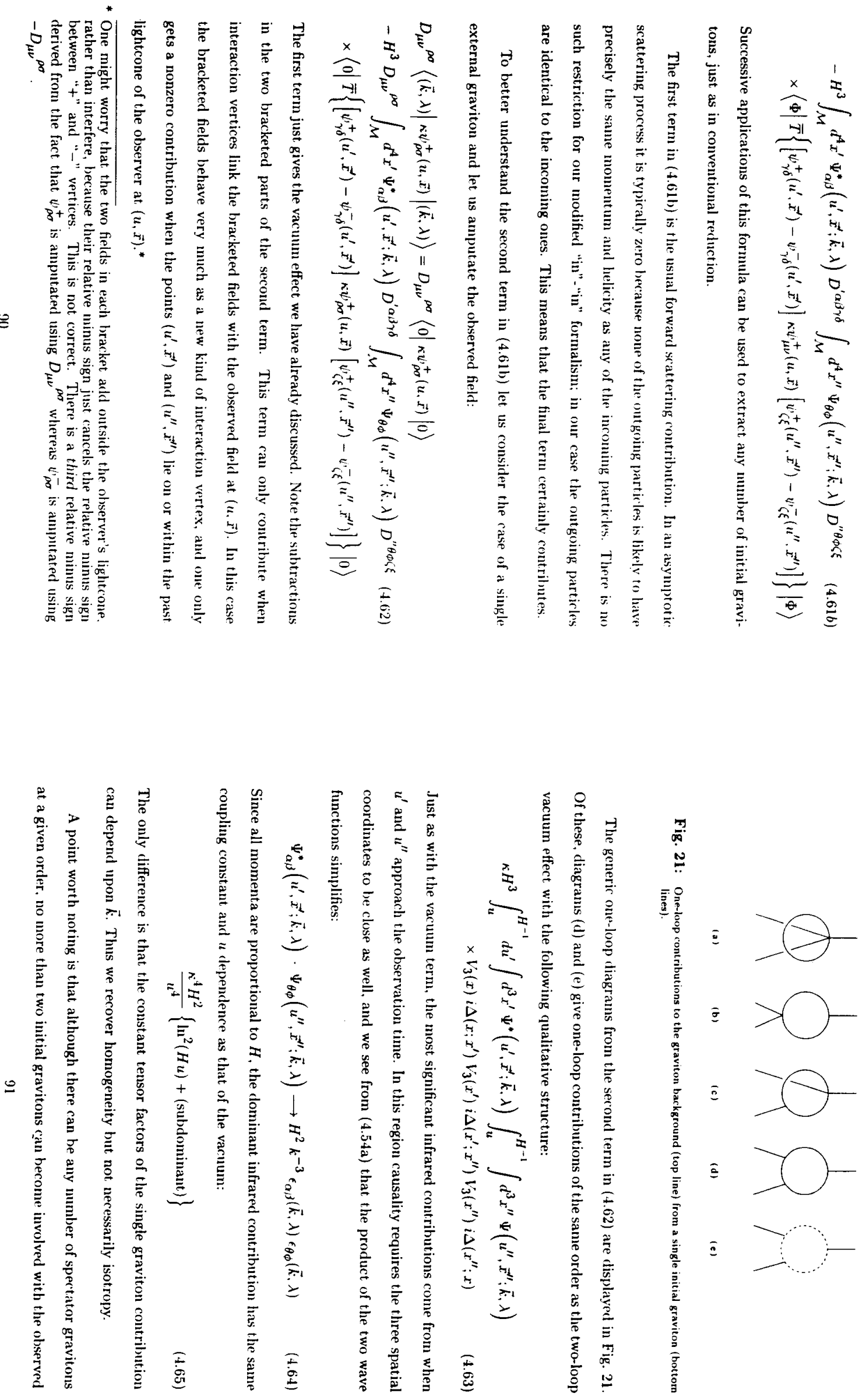

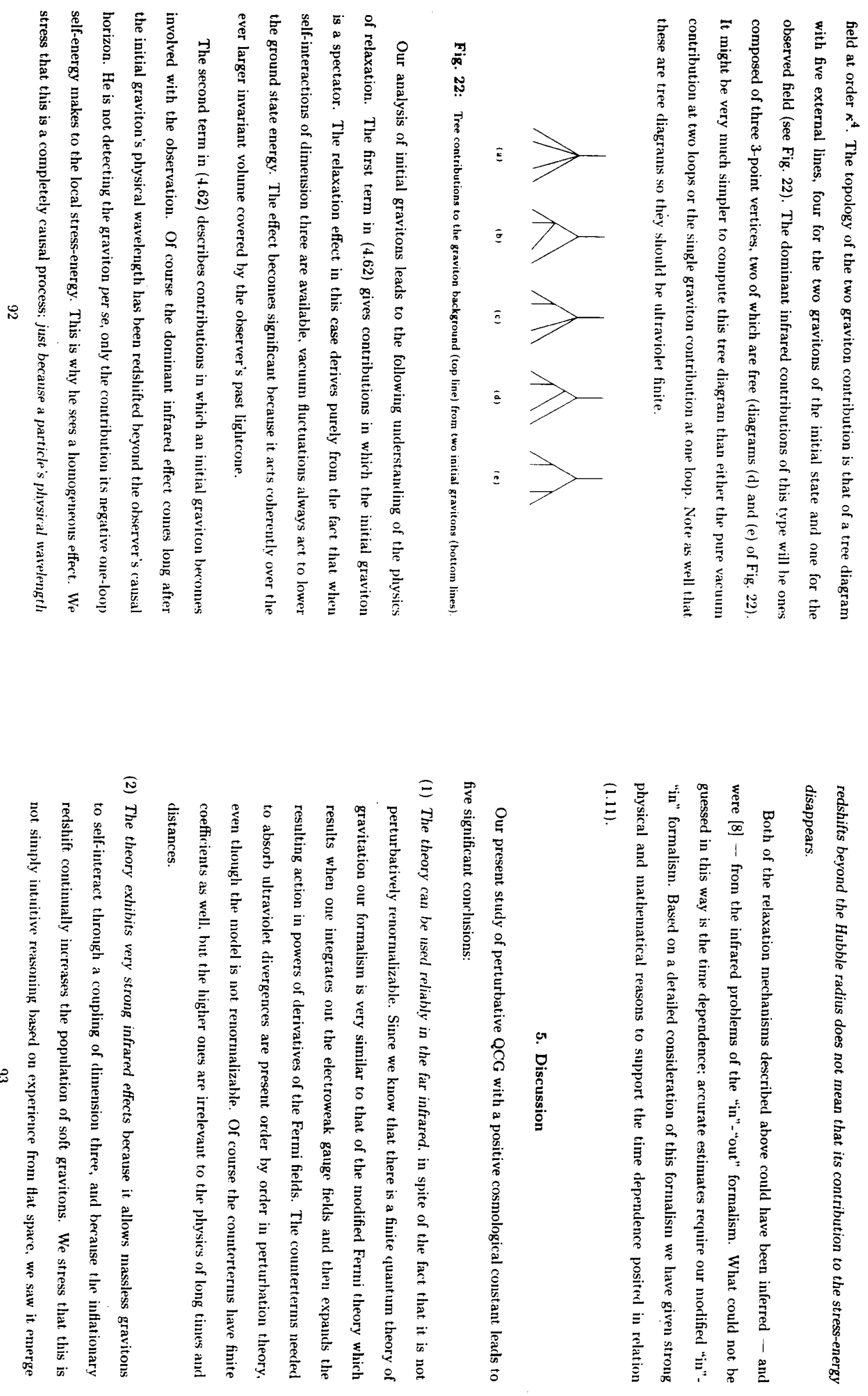

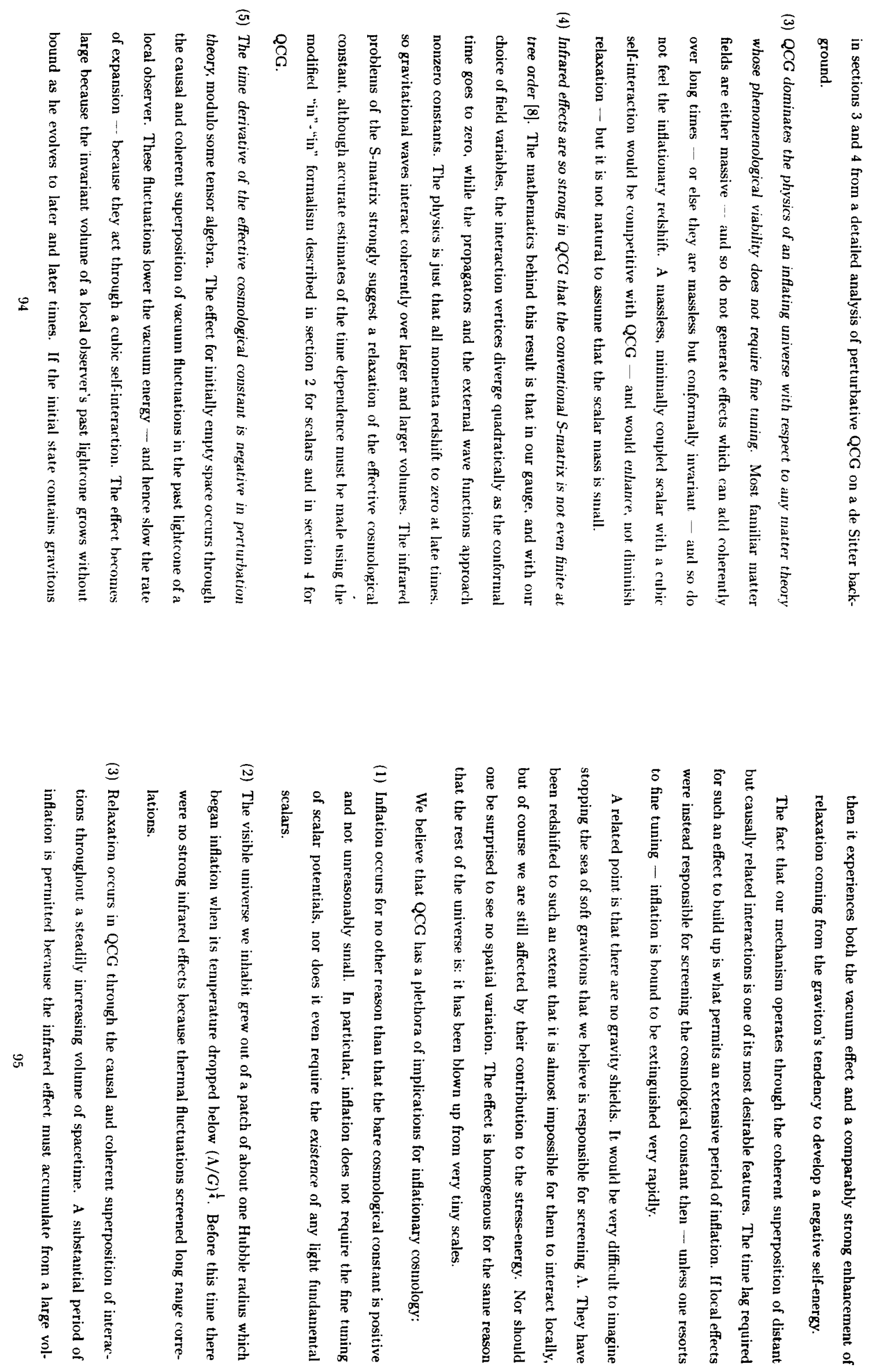

$$
\text { (n) }
$$



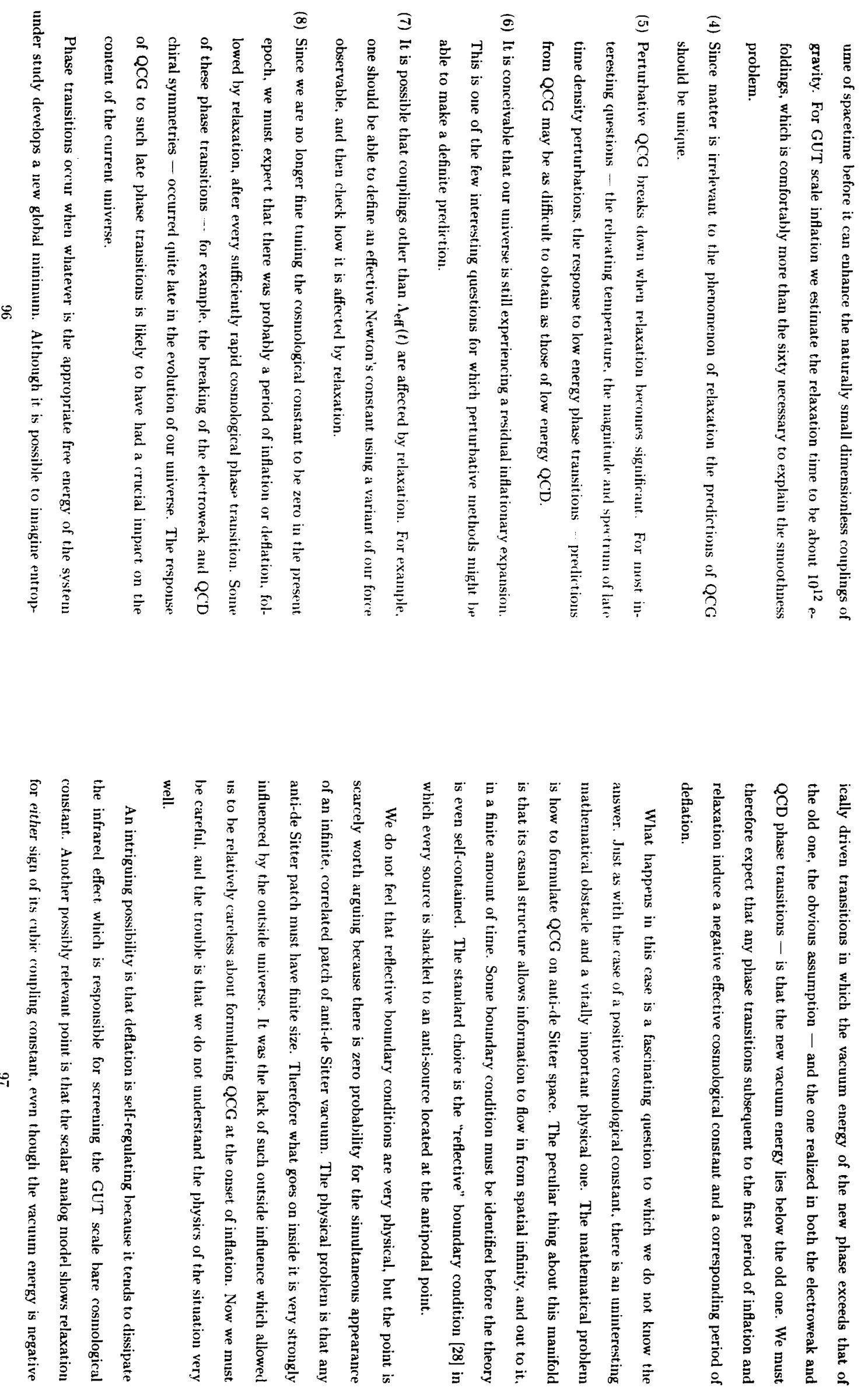

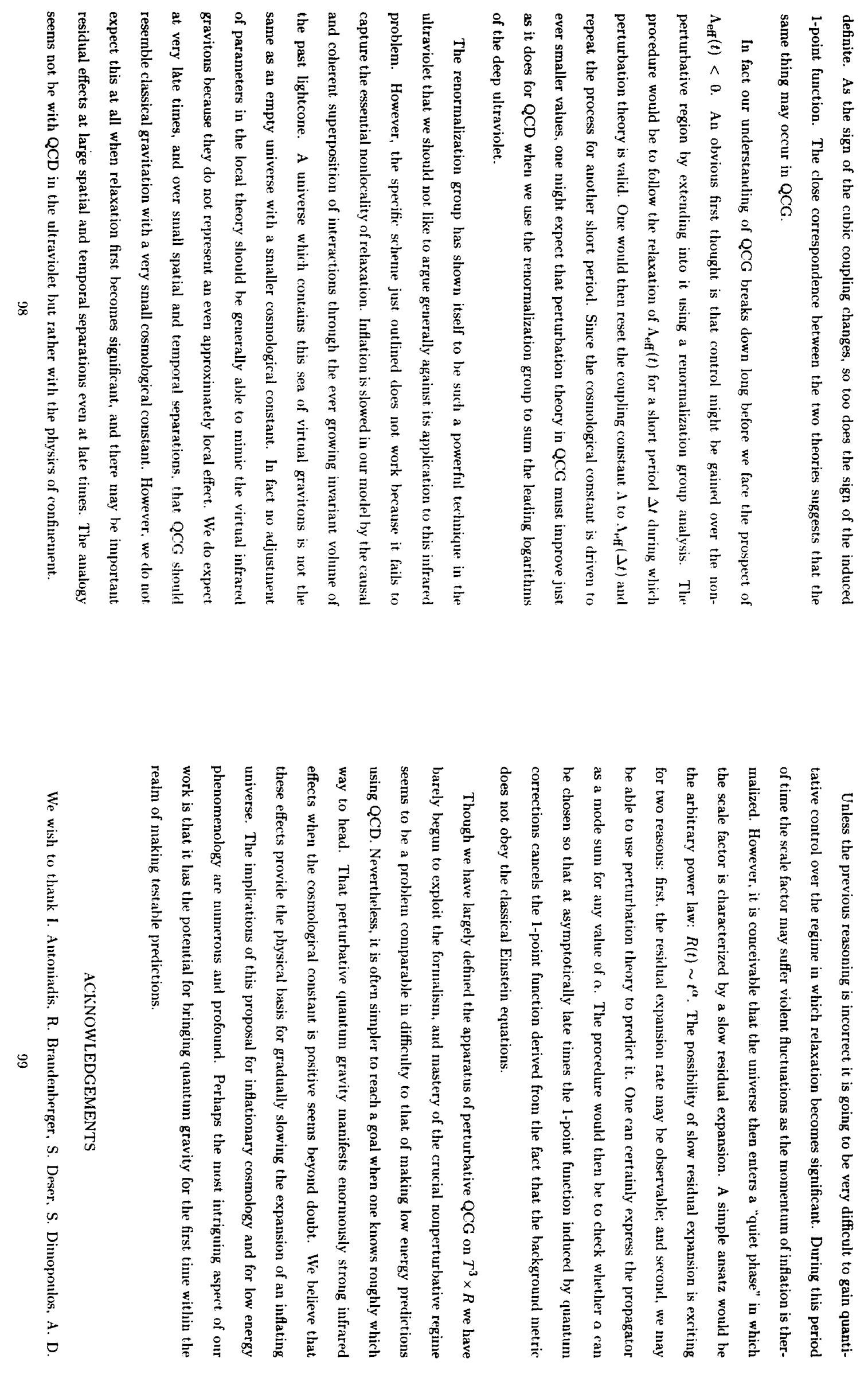

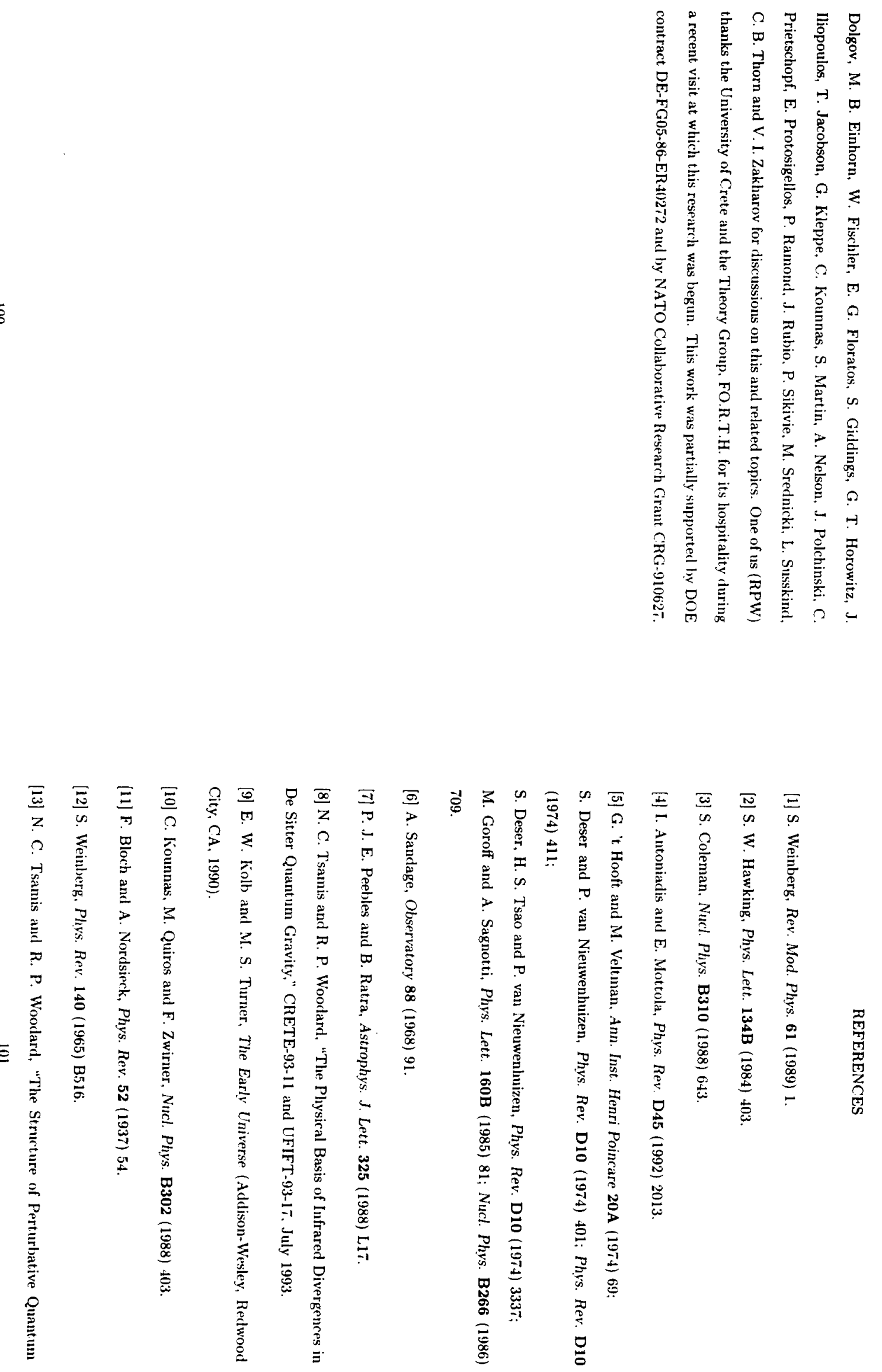


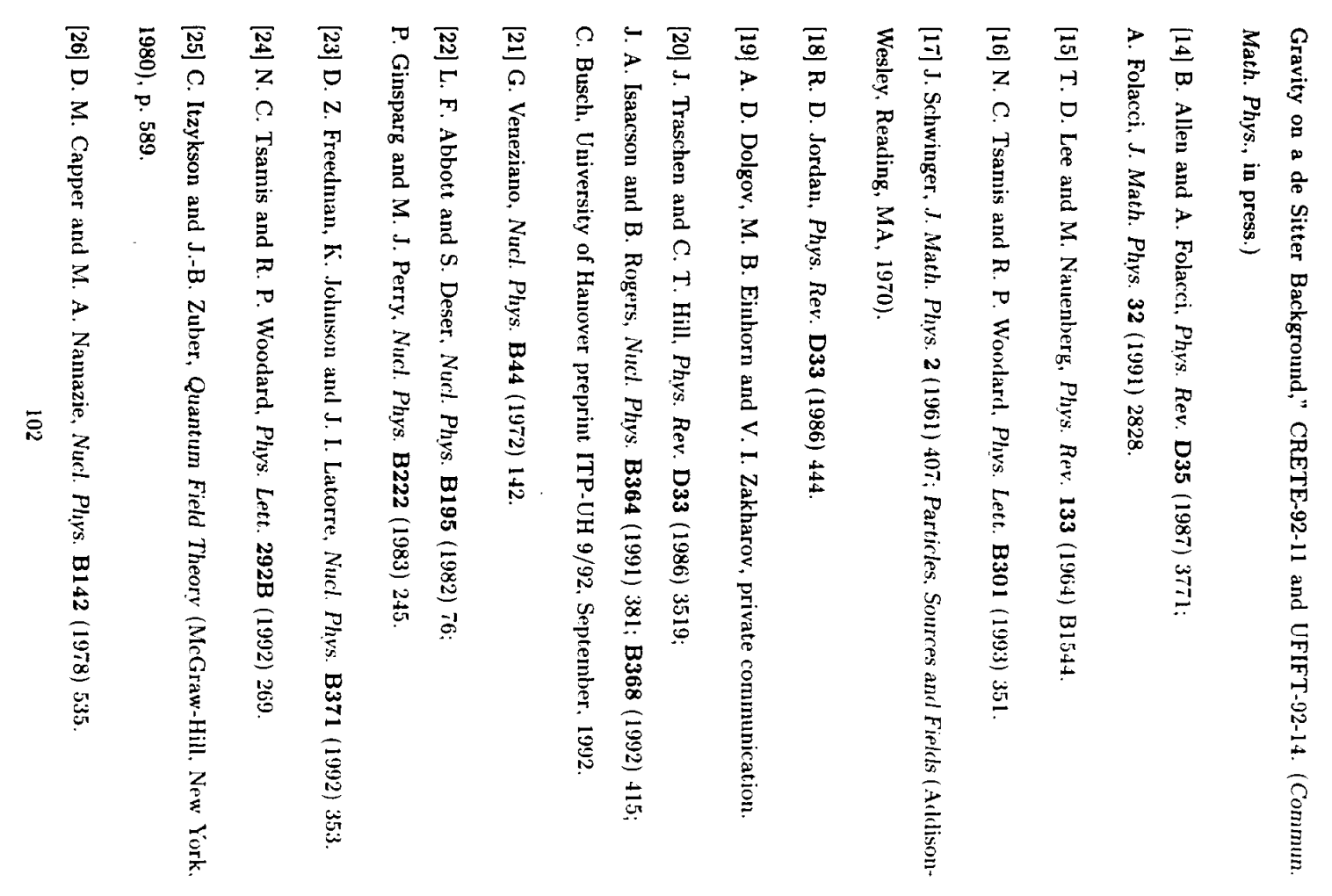

ప

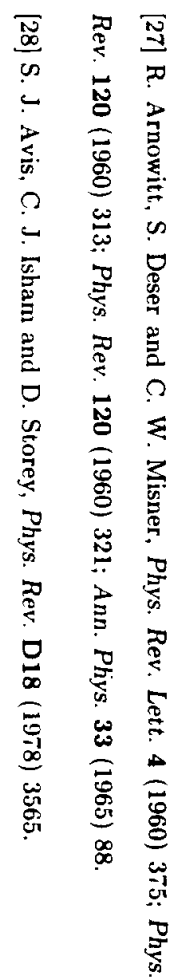


